In cooperation with the U.S. Air Force

\title{
Distribution and Sources of Polychlorinated Biphenyls in Woods Inlet, Lake Worth, Fort Worth, Texas, 2003
}

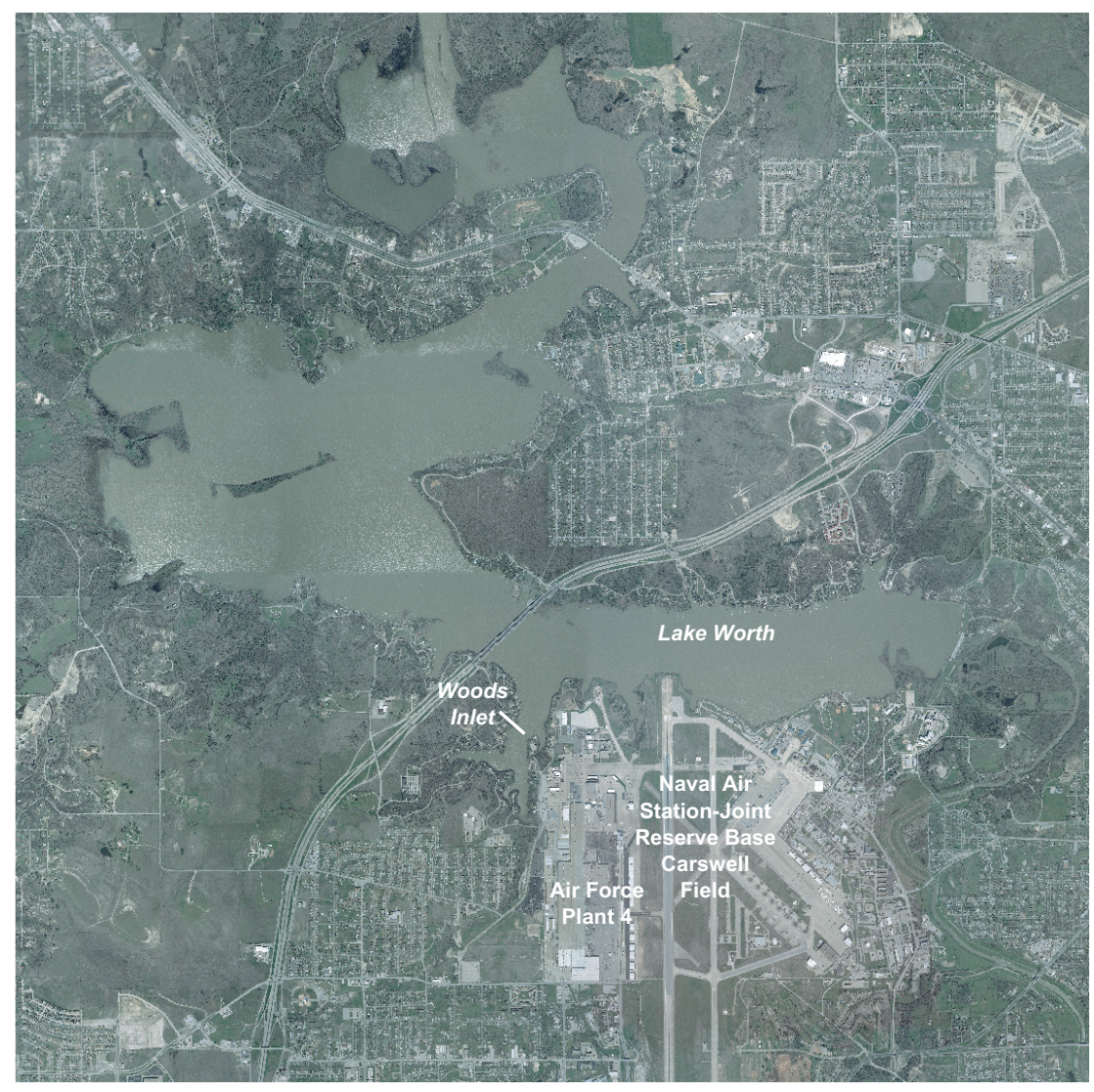

Scientific Investigations Report 2005-5064 


\section{Distribution and Sources of Polychlorinated Biphenyls in Woods Inlet, Lake Worth, Fort Worth, Texas, 2003}

By Richard E. Besse, Peter C. Van Metre, and Jennifer T. Wilson

In cooperation with the U.S. Air Force

Scientific Investigations Report 2005-5064 


\title{
U.S. Department of the Interior Gale A. Norton, Secretary
}

\author{
U.S. Geological Survey \\ Charles G. Groat, Director
}

\section{U.S. Geological Survey, Reston, Virginia: 2005}

For sale by U.S. Geological Survey, Information Services

Box 25286, Denver Federal Center

Denver, CO 80225

For more information about the USGS and its products:

Telephone: 1-888-ASK-USGS

World Wide Web: http://www.usgs.gov/

Any use of trade, product, or firm names in this publication is for descriptive purposes only and does not imply endorsement by the U.S. Government.

Although this report is in the public domain, permission must be secured from the individual copyright owners to reproduce any copyrighted materials contained within this report.

Suggested citation:

Besse, R.E., Van Metre, P.C., and Wilson, J.T., 2005, Distribution and sources of polychlorinated biphenyls in Woods Inlet, Lake Worth, Fort Worth, Texas, 2003: U.S. Geological Survey Scientific Investigations Report 2005-5064, 40 p. 


\section{Contents}

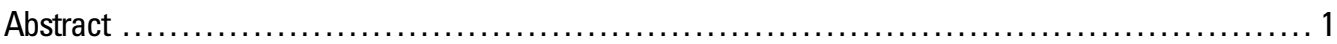

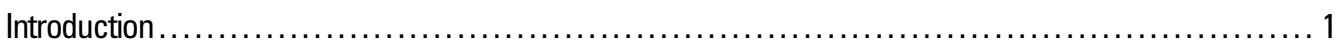

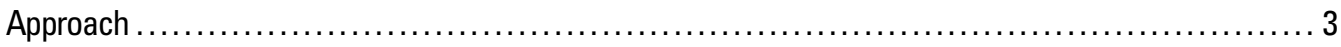

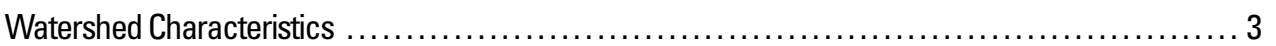

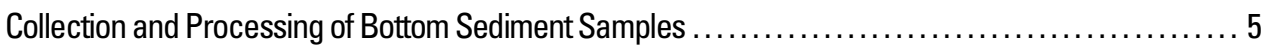

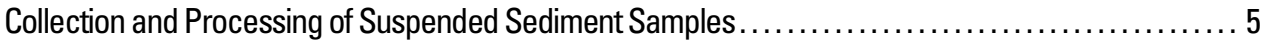

Collection and Processing of Streambed Sediment Samples ............................. 7

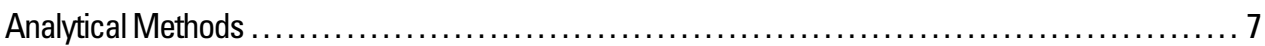

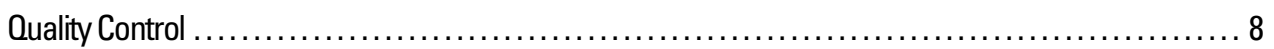

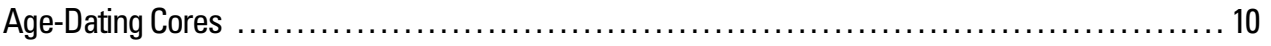

Distribution and Sources of Polychlorinated Biphenyls in Woods Inlet ........................... 10

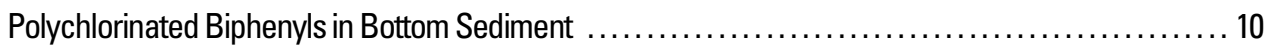

Polychlorinated Biphenyls in Suspended and Streambed Sediment ......................... 13

Source Identification Using Polychlorinated Biphenyl Congener Assemblages . . . . . . . . . . . . . . . 14

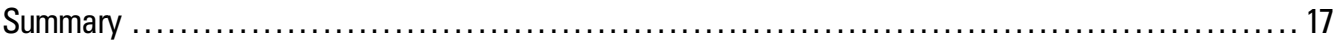

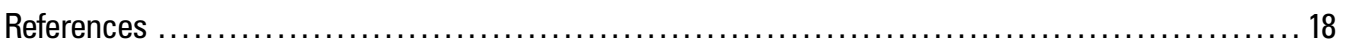

Appendixes

1. Core-specific and analytical polychlorinated biphenyl data from core, surficial bottom, suspended, and streambed sediment samples, Woods Inlet and tributaries, Lake Worth,

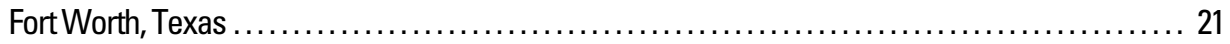

1.1 Porosity, cesium-137 $\left({ }^{137} \mathrm{Cs}\right.$ ) activity, mass accumulation rate (MAR), and deposition dates for gravity core samples, Woods Inlet, Lake Worth, Fort Worth, Texas, 2003 ..........23

1.2 Selected polychlorinated biphenyl (PCB) Aroclor and PCB congener concentrations in core, surficial bottom, suspended, and streambed sediment samples, Woods Inlet and tributaries, Lake Worth, Fort Worth, Texas, 2003

2. Analytical data for major and trace elements, selected polycyclic aromatic hydrocarbons, and selected organochlorine pesticides from core, surficial bottom, suspended, and streambed sediment samples, Woods Inlet and tributaries, Lake Worth, Fort Worth, Texas ....... 33

2.1 Selected major and trace element concentrations in surficial bottom, suspended, and streambed sediment samples, Woods Inlet and tributaries, Lake Worth, Fort Worth, Texas, 2003

2.2 Selected polycyclic aromatic hydrocarbon concentrations in surficial bottom, suspended, and streambed sediment samples, Woods Inlet and tributaries, Lake Worth, Fort Worth, Texas, 2003

2.3 Selected organochlorine pesticide concentrations in surficial bottom, suspended, and streambed sediment samples, Woods Inlet and tributaries, Lake Worth, Fort Worth, Texas, 2003 


\section{Figures}

1-3. Maps showing:

1. Location of study area and polychlorinated biphenyl (PCB) concentrations in surficial bottom sediment, Lake Worth, Fort Worth, Texas, 2000-2001

2. Sediment sampling sites for this study in Woods Inlet and tributaries, Lake Worth,

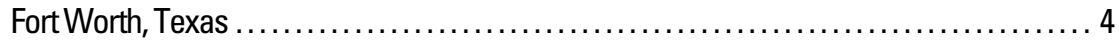

3. Watersheds of tributary streams to Woods Inlet, Lake Worth, Fort Worth, Texas ........ 6

4. Photograph showing passive suspended sediment sampler, Gruggs Park Creek (a tributary

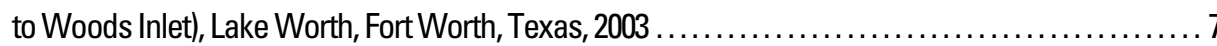

5. Graphs showing cesium-137 profiles in gravity cores used for age-dating, Woods Inlet, Lake

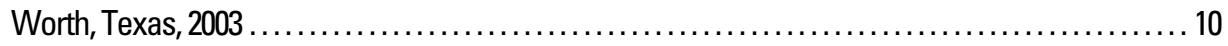

6. Graphs showing detection frequency by polychlorinated biphenyl (PCB) congener and sample type, Woods Inlet, Lake Worth, Fort Worth, Texas, 2003 11

7. Map showing total polychlorinated biphenyl (PCB) concentrations (sum of PCB congeners) in surficial bottom sediment, Woods Inlet, Fort Worth, Texas, 2003.

8. Graphs showing trends in total polychlorinated biphenyl (PCB) concentrations (sum of PCB congeners) in sediment cores relative to (a) sediment depth and (b) date of sediment deposition, Woods Inlet, Lake Worth, Fort Worth, Texas, 2003

9. Map showing total polychlorinated biphenyl (PCB) concentrations (sum of PCB congeners) in suspended and streambed sediment from tributary streams to Woods Inlet, Lake Worth, Fort Worth, Texas, 2003

10. Graphs showing selected polychlorinated biphenyl (PCB) congener assemblages normalized (divided) by total PCB (sum of PCB congeners) for surficial bottom sediment in areas of Woods inlet and suspended and streambed sediment in tributary streams to Woods Inlet, Lake Worth, Texas, 2003

11. Map showing results of cluster analysis using selected polychlorinated biphenyl (PCB) congeners, Woods Inlet and tributaries, Lake Worth, Fort Worth, Texas, 2003 17

\section{Tables}

1. Sampling site descriptive information, Woods Inlet and tributaries, Lake Worth, Fort Worth,

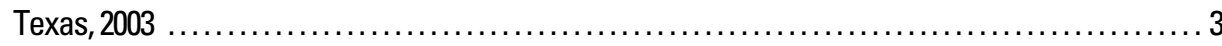

2. Polychlorinated biphenyl congeners analyzed for this report $\ldots \ldots \ldots \ldots \ldots \ldots \ldots \ldots \ldots \ldots \ldots$

3. Summary of median relative percent differences (RPDs) of duplicate samples from this study and other coring and suspended sediment studies done by the U.S. Geological Survey (USGS) in Texas.

4. Root mean squared difference (RMSD), from smallest to largest, between normalized concentrations of 17 polychlorinated biphenyl congeners in suspended and streambed sediment samples in tributaries and mean of all surficial bottom sediment sample concentrations of those congeners in Woods Inlet, Lake Worth, Fort Worth, Texas, 2003 


\title{
Distribution and Sources of Polychlorinated Biphenyls in Woods Inlet, Lake Worth, Fort Worth, Texas, 2003
}

\author{
By Richard E. Besse, Peter C. Van Metre, and Jennifer T. Wilson
}

\section{Abstract}

Woods Inlet is a flooded stream channel on the southern shore of Lake Worth along the western boundary of Air Force Plant 4 in Fort Worth, Texas, where elevated polychlorinated biphenyl (PCB) concentrations in sediment were detected in a previous study. In response, the U.S. Geological Survey, in cooperation with the U.S. Air Force, conducted a study in 2003 to map the extent of elevated PCB concentrations in Woods Inlet and to identify possible sources (or more specifically, source areas) of PCBs in the watershed of Woods Inlet. Three gravity cores (penetration to pre-reservoir sediment at three sites) and 17 box cores (surficial bottom sediment samples) were collected in Woods Inlet. Suspended sediment in stormwater runoff and streambed sediment were sampled in tributaries to Woods Inlet following storms. Assemblages of PCB congeners in surficial inlet sediments and suspended and streambed sediments were analyzed to indicate sources of PCBs in the inlet sediments on the basis of chemical signatures of PCBs. Woods Inlet receives runoff primarily from three tributaries: (1) Gruggs Park Creek, (2) the small unnamed creek that drains a Texas National Guard maintenance facility, called TNG Creek for this report, and (3) Meandering Road Creek. Twenty-seven of 209 possible PCB congeners were analyzed. The sum of the congeners was used as a measure of total PCB. The spatial distribution of total PCB concentrations in the inlet indicates that most PCBs are originating in the Meandering Road Creek watershed. Peak total PCB concentrations in the three gravity cores occurred at depths corresponding to sediment deposition dates of about 1960 for two of the cores and about 1980 for the third core. The magnitudes of peak total PCB concentrations in the gravity cores followed a spatial distribution generally similar to that of surficial bottom sediment concentrations. Total PCB concentrations in suspended and streambed sediment varied greatly between sites and indicated a likely source of PCBs associated with a sampling site that receives runoff from Air Force Plant 4. Three approaches to the analyses of congener assemblages indicate that PCBs in surficial bottom sediment of Woods Inlet primarily enter Lake Worth from Meandering Road Creek and that runoff from Air Force Plant 4 is a source of the PCBs in Meandering Road Creek. Although current (2003) transport of PCBs from Air Force Plant 4 to the creek is occurring, large decreases in PCB concentrations with decreasing age in two cores indicate that PCB loading to the inlet has decreased greatly since the 1960s. Because runoff entering Meandering Road Creek from some parts of Air Force Plant 4 was not measured or sampled in this study, it cannot be said with certainty that the Air Force Plant 4 site sampled is the only source of PCBs to Meandering Road Creek.

\section{Introduction}

Lake Worth is a reservoir on the West Fork Trinity River on the western edge of Fort Worth, Tex. (fig. 1). Air Force Plant 4 (AFP4) and Naval Air Station-Joint Reserve Base Carswell Field (NAS-JRB) are on the southern shore of Lake Worth. In spring 2000, following fish sampling by the U.S. Geological Survey (USGS) (Moring, 2002), the Texas Department of Health (TDH) issued a fish-consumption advisory because high levels of polychlorinated biphenyls (PCBs) detected in fish samples posed a "significant health risk" (Texas Department of Health, 2004). The occurrence of PCBs in fish prompted an investigation by the USGS, in cooperation with the U.S. Air Force (USAF), to sample and analyze Lake Worth bottom sediment for sediment-bound contaminants, including PCBs. The findings of that study (Harwell and others, 2003) reported elevated PCB concentrations in surficial sediment in Woods Inlet relative to those in surficial sediment in other parts of the lake (fig. 1). This finding indicated that a source of PCBs likely was in the watershed of Woods Inlet. Woods Inlet is on the southern shore of Lake Worth along the western boundary of AFP4 and downstream from urban development in the cities of Fort Worth 

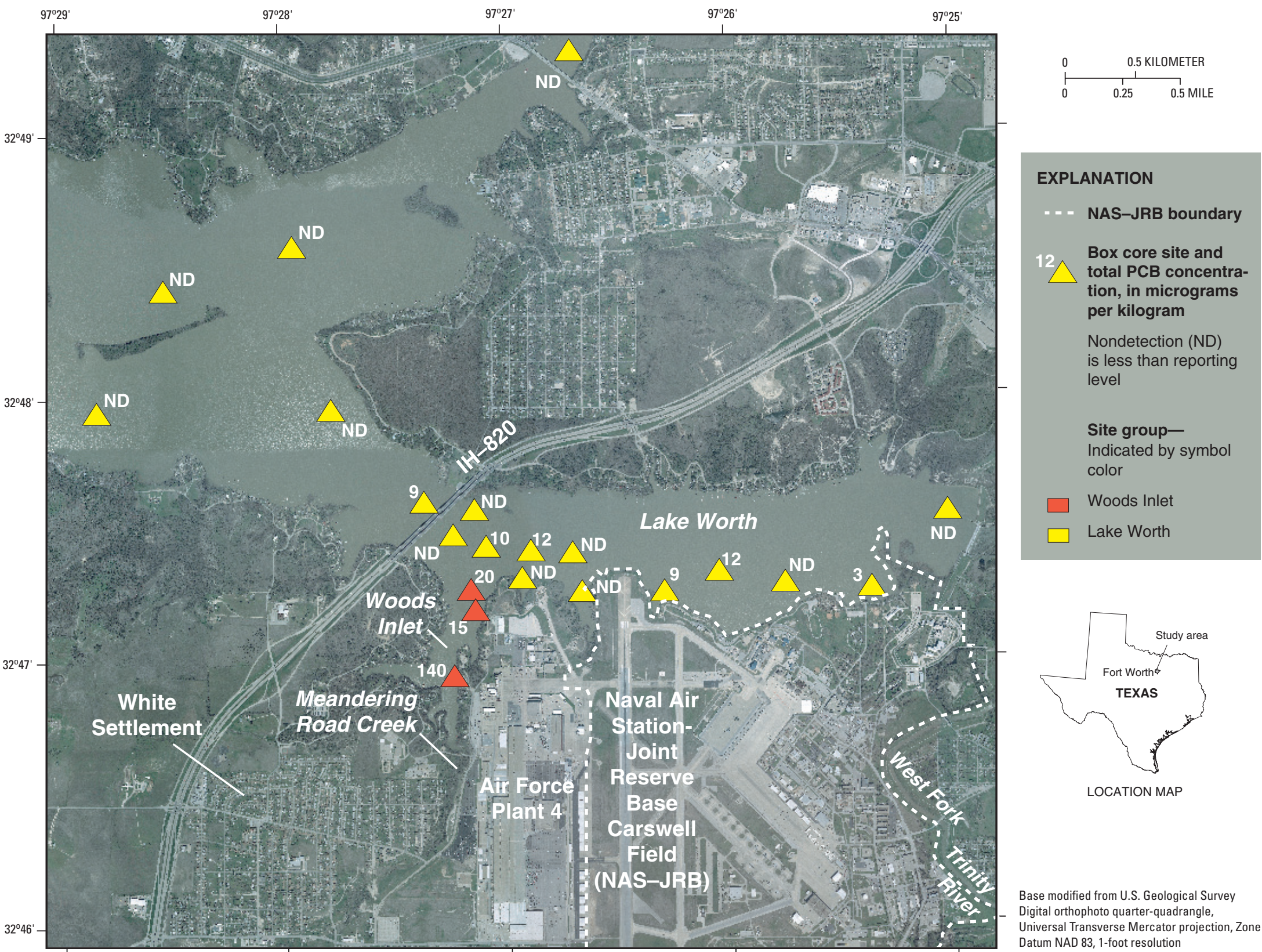

Base modified from U.S. Geological Survey

Digital orthophoto quarter-quadrangle,

Universal Transverse Mercator projection, Zone 14, Datum NAD 83, 1-foot resolution

Figure 1. Location of study area and polychlorinated biphenyl (PCB) concentrations in surficial bottom sediment, Lake Worth, Fort Worth, Texas, $2000-2001$ (modified from Harwell and others, 2003, fig. 10). 
and White Settlement. Harwell and others (2003) also detected higher concentrations of selected trace elements (metals) and polycyclic aromatic hydrocarbons (PAHs) in Woods Inlet than in other parts of the lake.

In response to the elevated PCB concentrations in sediment in Woods Inlet, the USGS, again in cooperation with the USAF, conducted a study in 2003 to map the distribution of elevated PCB concentrations in Woods Inlet and to identify possible sources (or more specifically, source areas) of PCBs in the watershed of Woods Inlet. This report describes the methods and findings of that study. Gravity cores and surficial inlet bottom sediment samples were collected and analyzed to map the distribution of PCB concentrations in Woods Inlet. Suspended sediment in stormwater runoff and streambed sediment in tributaries to Woods Inlet were sampled following storms to identify current (2003) sources of PCBs. Assemblages of PCB congeners (groups of individual PCB compounds) in bottom sediments and suspended and streambed sediments were analyzed to indicate sources of PCBs in the bottom sediments in the inlet on the basis of chemical signatures of PCBs. Sediment samples also were analyzed for major and trace elements, selected PAHs, and selected organochlorine pesticides. Although those results are insufficient to describe distribution in Woods Inlet or to identify potential sources of trace elements, PAHs, and pesticides, those data are included in an appendix of this report.

The authors thank NAS-JRB and Lockheed Martin Corporation for access to the inlet and tributary sampling sites and for providing maps of watersheds on AFP4. Also, the authors thank the cities of Fort Worth and White Settlement for allowing the USGS to install suspended sediment samplers on streams.

\section{Approach}

The distribution of PCBs in Woods Inlet was determined using a combination of surficial bottom sediment samples (top 5 centimeters $[\mathrm{cm}]$ at 20 sites) and bottom sediments from gravity cores that penetrated the lacustrine sediment sequence that was deposited since 1914, when Lake Worth was constructed (three sites) (fig. 2; table 1). Sources of PCBs in current (2003) storm runoff were investigated by sampling suspended sediment at five sites on tributary streams (fig. 2) during three storms and by sampling streambed sediment at four of those five sites after each of the three storms. Historical and presentday sources of PCBs also were investigated by evaluating the relative distributions of $\mathrm{PCB}$ congeners in the stream and inlet sediment samples. Congener assemblages can be indicative of different PCB sources (Cacela and others, 2002; Colman, 2000; Johnson and others, 2000).

\section{Watershed Characteristics}

Woods Inlet receives runoff primarily from three tributaries: (1) Gruggs Park Creek, (2) the small unnamed creek that
Table 1. Sampling site descriptive information, Woods Inlet and tributaries, Lake Worth, Fort Worth, Texas, 2003.

$[--$, not recorded $]$

\begin{tabular}{|c|c|c|c|c|}
\hline $\begin{array}{c}\text { Site } \\
\text { identifier } \\
\text { (fig. 2) }\end{array}$ & $\begin{array}{l}\text { Latitude } \\
\text { (degrees, } \\
\text { minutes) }\end{array}$ & $\begin{array}{c}\text { Longitude } \\
\text { (degrees, } \\
\text { minutes) }\end{array}$ & $\begin{array}{l}\text { Sample } \\
\text { date }\end{array}$ & $\begin{array}{c}\text { Water } \\
\text { depth } \\
\text { (meters) }\end{array}$ \\
\hline \multicolumn{5}{|c|}{ Surficial bottom sediment } \\
\hline B1 & $97^{\circ} 27.551^{\prime}$ & $32^{\circ} 46.968^{\prime}$ & $04 / 22 / 03$ & 1.5 \\
\hline B2 & $97^{\circ} 27.498^{\prime}$ & $32^{\circ} 46.962^{\prime}$ & $04 / 22 / 03$ & 2.5 \\
\hline B3 & $97^{\circ} 27.377^{\prime}$ & $32^{\circ} 46.941^{\prime}$ & $04 / 22 / 03$ & 3.6 \\
\hline B4 & $97^{\circ} 27.354^{\prime}$ & $32^{\circ} 46.783^{\prime}$ & $04 / 22 / 03$ & 1.2 \\
\hline B5 & $97^{\circ} 27.319^{\prime}$ & $32^{\circ} 46.822^{\prime}$ & $04 / 22 / 03$ & 2.7 \\
\hline B6 & $97^{\circ} 27.255^{\prime}$ & $32^{\circ} 46.721^{\prime}$ & $04 / 22 / 03$ & .9 \\
\hline B7 & $97^{\circ} 27.268^{\prime}$ & $32^{\circ} 46.772^{\prime}$ & $04 / 22 / 03$ & 1.5 \\
\hline B8 & $97^{\circ} 27.271^{\prime}$ & $32^{\circ} 46.859^{\prime}$ & $04 / 22 / 03$ & 3.3 \\
\hline B9 & $97^{\circ} 27.273^{\prime}$ & $32^{\circ} 46.895^{\prime}$ & $04 / 22 / 03$ & 3.4 \\
\hline B10 & $97^{\circ} 27.266^{\prime}$ & $32^{\circ} 46.980^{\prime}$ & $04 / 22 / 03$ & 3.8 \\
\hline B11 & $97^{\circ} 27.288^{\prime}$ & $32^{\circ} 46.999^{\prime}$ & $04 / 22 / 03$ & 4.2 \\
\hline B12 & $97^{\circ} 27.322^{\prime}$ & $32^{\circ} 47.006^{\prime}$ & $04 / 22 / 03$ & 4.3 \\
\hline B13 & $97^{\circ} 27.240^{\prime}$ & $32^{\circ} 47.058^{\prime}$ & $04 / 22 / 03$ & 4.6 \\
\hline B14 & $97^{\circ} 27.273^{\prime}$ & $32^{\circ} 47.074^{\prime}$ & $04 / 22 / 03$ & 4.4 \\
\hline B15 & $97^{\circ} 27.282^{\prime}$ & $32^{\circ} 47.088^{\prime}$ & $04 / 22 / 03$ & 4.0 \\
\hline B16 & $97^{\circ} 27.156^{\prime}$ & $32^{\circ} 47.055^{\prime}$ & $04 / 22 / 03$ & 4.0 \\
\hline B17 & $97^{\circ} 27.201^{\prime}$ & $32^{\circ} 47.150^{\prime}$ & $04 / 22 / 03$ & 4.8 \\
\hline \multicolumn{5}{|c|}{ Core sediment } \\
\hline WWD1 & $97^{\circ} 27.309^{\prime}$ & $32^{\circ} 46.950^{\prime}$ & $04 / 21 / 03$ & 3.8 \\
\hline WWD2 & $97^{\circ} 27.422^{\prime}$ & $32^{\circ} 46.967^{\prime}$ & $04 / 21 / 03$ & 3.4 \\
\hline WWD3 & $97^{\circ} 27.267^{\prime}$ & $32^{\circ} 46.811^{\prime}$ & $04 / 21 / 03$ & 2.7 \\
\hline \multicolumn{5}{|c|}{ Suspended and streambed sediment } \\
\hline GRUGGS & $97^{\circ} 27.877^{\prime}$ & $32^{\circ} 46.732^{\prime}$ & Multiple & -- \\
\hline TNG & $97^{\circ} 27.424^{\prime}$ & $32^{\circ} 46.679^{\prime}$ & Multiple & -- \\
\hline LMRC & $97^{\circ} 27.212^{\prime}$ & $32^{\circ} 46.637^{\prime}$ & Multiple & -- \\
\hline OF4 & $97^{\circ} 27.215^{\prime}$ & $32^{\circ} 46.572^{\prime}$ & Multiple & -- \\
\hline UMRC & $97^{\circ} 27.809^{\prime}$ & $32^{\circ} 46.003^{\prime}$ & Multiple & -- \\
\hline
\end{tabular}

drains a Texas National Guard maintenance facility (hereinafter, TNG Creek), and (3) Meandering Road Creek (fig. 2). Suspended and streambed sampling sites were established on each of these three creeks. One site near the mouth of Gruggs Park Creek (GRUGGS) receives runoff from urban and agricultural areas and from an interstate highway, but it does not receive runoff from AFP4. A second site near the mouth of TNG Creek (TNG) receives runoff from the Texas National Guard maintenance facility and urban areas but not from AFP4. A third site near the mouth of Meandering Road Creek (LMRC) receives runoff from three stormwater outfalls that drain areas of AFP4, 


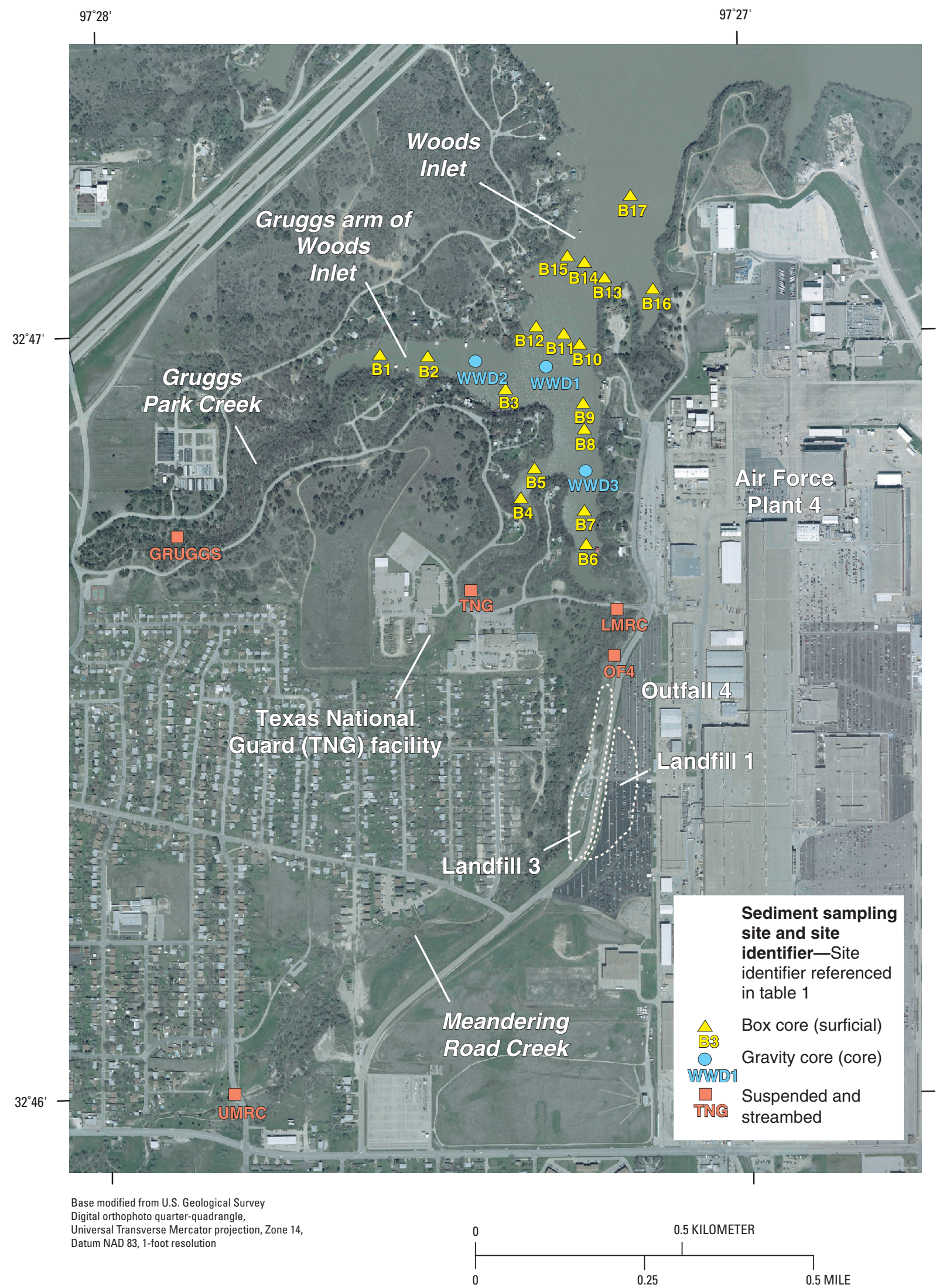

Figure 2. Sediment sampling sites for this study in Woods Inlet and tributaries, Lake Worth, Fort Worth, Texas. 
from two historical landfills (1 and 3) on AFP4, and from urban areas south and west of AFP4. A fourth site at outfall 4 about 200 meters (m) upstream from LMRC on Meandering Road Creek (OF4) receives runoff from buildings, parking areas, and one historical landfill on AFP4. A fifth site on Meandering Road Creek upstream from AFP4 (UMRC) receives runoff from urban areas but not from AFP4. GRUGGS and UMRC are considered urban reference sites because the sites receive runoff from urban areas but not from AFP4 or the Texas National Guard facility. The watershed areas (fig. 3) upstream from LMRC (4.1 square kilometers [ $\left.\left.\mathrm{km}^{2}\right]\right)$, GRUGGS $\left(2.0 \mathrm{~km}^{2}\right)$, and TNG $\left(0.4 \mathrm{~km}^{2}\right)$ are 46,55 and 71 percent urban (including industrial and transportation categories), respectively. The watershed area upstream from LMRC includes the watershed areas upstream from UMRC $\left(2.8 \mathrm{~km}^{2}\right)$ and OF4 $\left(0.2 \mathrm{~km}^{2}\right)$, which are 38 and 96 percent urban, respectively.

Suspended sediment samples were collected during three storms at each of the five sites. Streambed sediment samples were collected at all of the sites except OF4 following each of the three storms in which suspended sediment samples were collected.

\section{Collection and Processing of Bottom Sediment Samples}

Of the 20 sediment sampling sites in Woods Inlet, 17 were sampled for surficial bottom sediment only (fig. 2) using a 14by 14 - by $20-\mathrm{cm}$ Wildco box corer. The box-core samples (top $5 \mathrm{~cm}$ ) were removed from the box by vertical extrusion and sectioning following the methods of Van Metre and others (2004). Each sample was homogenized and split. A subsample for analysis of organic compounds was transferred to a baked-glass jar and chilled pending shipment to the USGS National Water Quality Laboratory (NWQL) in Denver, Colo. A subsample for analysis of major and trace elements (selected sites only), organic carbon, and grain size was transferred to a polypropylene jar, chilled, and returned to the USGS office in Austin, Tex. There, samples for analysis of major and trace elements and organic carbon were frozen, freeze-dried, and ground to a fine powder before shipment to the NWQL. Samples for analysis of grain size were stored in jars and shipped wet to the NWQL.

At three sampling sites, gravity cores were collected to investigate historical trends of sediment-associated contaminants in bottom sediment (fig. 2) following the sampling methods of Van Metre and others (2004). These sites were selected to represent historical trends in contaminants in the main body of Woods Inlet (WWD1) and in the two tributary arms, Gruggs Park Creek arm (WWD2) and Meandering Road Creek arm (WWD3). The cores were collected using a Benthos gravity corer with a diameter of $6.3 \mathrm{~cm}$, a barrel length of as much as $3.1 \mathrm{~m}$, and a polycarbonate core liner. Cores were subsampled on site by vertical extrusion of the sediment in measured increments using a piston fit into the bottom of the liner. All three gravity cores were subsampled at $5-\mathrm{cm}$ intervals from the top of the core to a depth of $10 \mathrm{~cm}$ (two samples) and thereafter in $10-\mathrm{cm}$ intervals to the bottom of the core. Each subsample was homogenized and split. Samples for analysis of organic compounds were transferred to a baked-glass jar, and samples for analysis of major and trace elements (one sample only), cesium$137\left({ }^{137} \mathrm{Cs}\right)$ for age-dating, and grain size were transferred to a polypropylene jar. Samples were chilled pending shipment to the NWQL or freeze-drying. Sampling tools were washed between each sample using phosphate-free detergent and native water.

\section{Collection and Processing of Suspended Sediment Samples}

Suspended sediment samples were collected at five sites during three storms using passive samplers (fig. 4). A passive sampler consists of a 36-cm diameter, capped steel pipe holding a 25-liter (L) Nalgene carboy with a water intake that is submerged during stormflow and an air exhaust tube. The sampler will obtain a 25-L sample of runoff from the "first flush" (initial rise in flow) during a storm. The streams are ephemeral and only flow in response to precipitation. During a storm, the water level rises above the level of the intake and fills the carboy. The air exhaust is constructed to block the flow of air or water once the carboy is filled, which prevents continual circulation through the sampler. Additional stormwater samples were collected during storms at some sites to provide a sufficient mass of suspended sediment for chemical analyses. The 25-L carboys were retrieved after the water level had fallen below the intakes of the samplers after a storm and transported to the USGS office in Fort Worth. The water was stored on ice until processing. Processing each sample took several hours, so processing all of the samples from a storm typically took from 1 to 2 days after the storm. In all, 15 environmental samples and one environmental duplicate sample were obtained for analysis.

Sediment was isolated from the water samples by in-line filtration following the methods of Mahler and Van Metre (2003). The 25-L carboy was agitated to suspend the sediment in the water column and immediately poured into a $25-\mathrm{L}$ churn. The churn has a paddle that, with steady motion, keeps the sediment suspended and the sample well mixed during processing. As the original $25 \mathrm{~L}$ was filtered, additional water was poured into the churn from other bottles if available. Sediment for the inorganic analyses (major and trace elements) was collected on a 142-millimeter $(\mathrm{mm})$ diameter, 0.45 -micron $(\mu \mathrm{m})$ pore size polytetrafluoroethylene (PTFE) filter in an acrylic filter holder. Sediment for the analysis of organic compounds was collected on a $293-\mathrm{mm}$ diameter, $0.45-\mu \mathrm{m}$ pore size PTFE filter in a stainless steel filter holder. Water was pumped from the churn with a peristaltic pump through the filter until the filter was clogged. The volume of water that was passed though the filter was noted. The filter was removed from the holder and placed in a locking plastic bag with 10 to 20 milliliters (mL) of deionized water. The filter was gently massaged in the bag to release the sediment from the filter. This process was repeated, usually three to six times, until enough sediment was collected for 


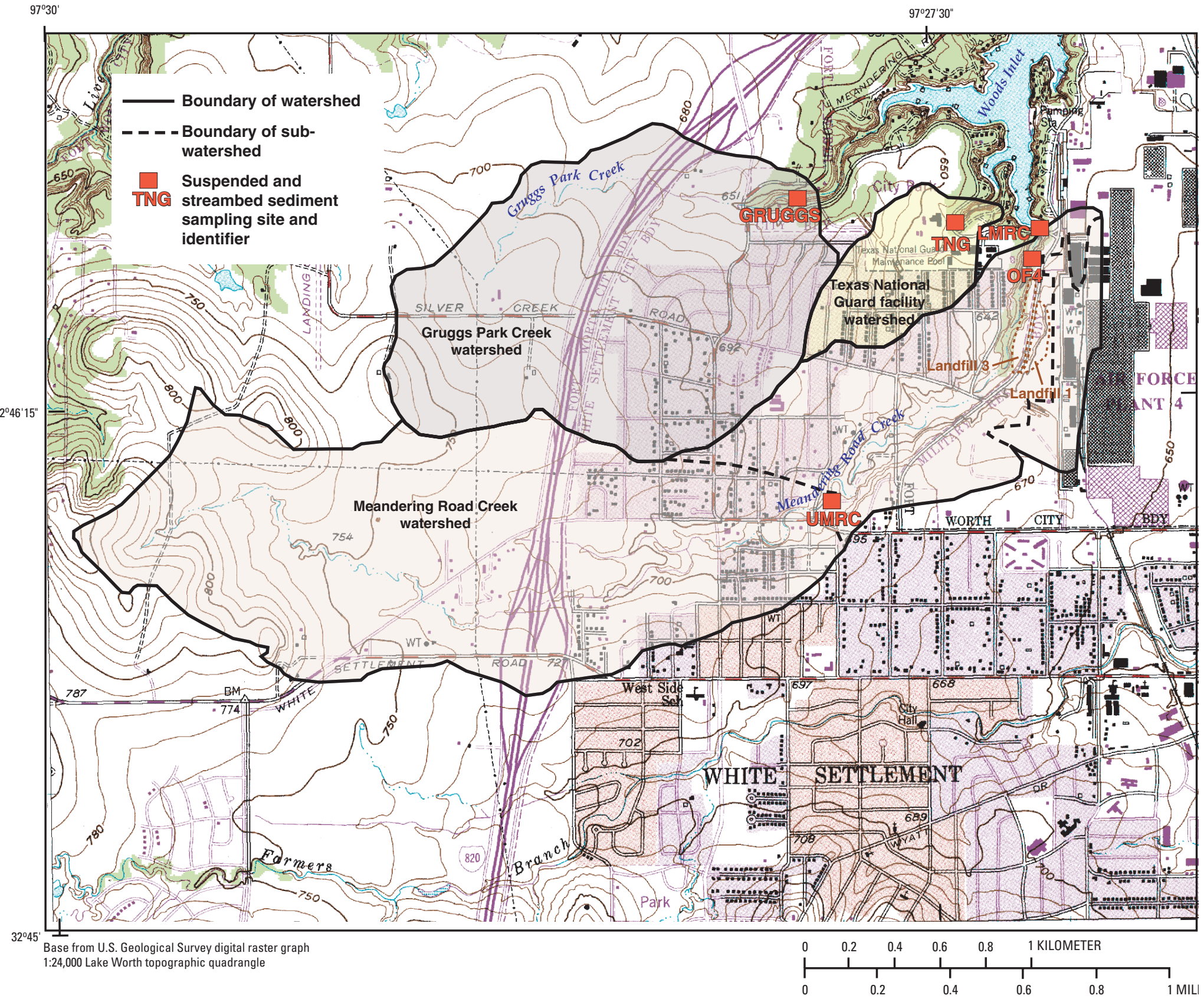

Figure 3. Watersheds of tributary streams to Woods Inlet, Lake Worth, Fort Worth, Texas. 


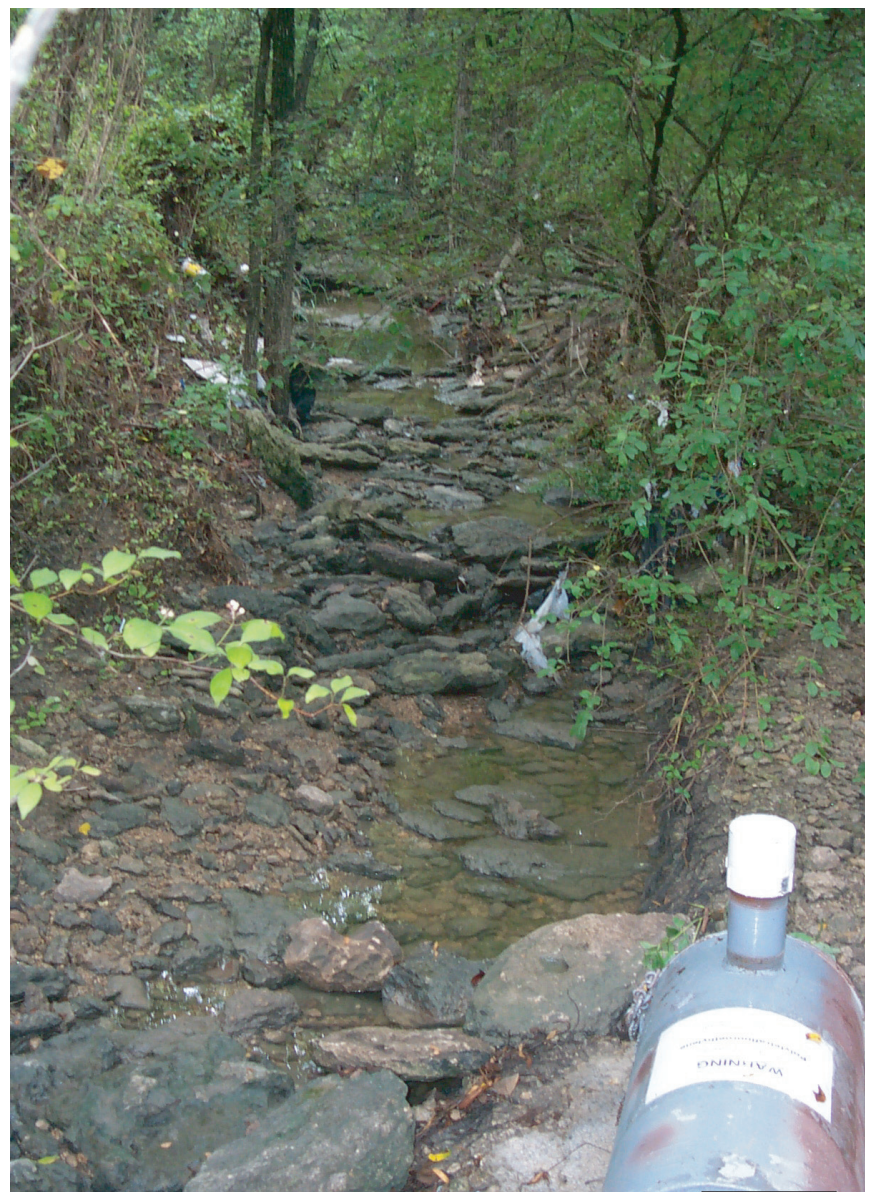

Figure 4. Passive suspended sediment sampler, Gruggs Park Creek (a tributary to Woods Inlet), Lake Worth, Fort Worth, Texas, 2003.

analysis. The sediment slurry was then poured into a $125-\mathrm{mL}$ glass or 125-mL Nalgene jar for organic and inorganic analysis, respectively. The samples for organic analysis were allowed to settle for approximately 4 days under refrigeration at which point the overlying water was decanted with a sterile glass pipette, and the samples were sent chilled to the NWQL. The samples for inorganic analysis were freeze-dried at the USGS office in Austin and then sent to the NWQL.

\section{Collection and Processing of Streambed Sediment Samples}

Streambed sediment samples were collected within 5 days of each storm runoff at four of the five sampling sites. No streambed sediment samples were collected at OF4 because the passive sampler is located at the end of a cement culvert, and therefore no streambed is upstream from the sampler. Twelve environmental samples and three environmental duplicate samples were collected. The environmental duplicates were collected independently by a second sampling team on the same day as the environmental samples were taken for each site. The objective in doing environmental duplicates this way was to test the repeatability of the streambed sediment sampling protocol, including environmental variability, sampling variability, and analytical uncertainty. Three laboratory duplicates (a single environmental sample split at the laboratory) of streambed sediment also were analyzed.

Streambed sediment samples were collected using a precleaned nylon spoon to scoop 10 subsamples from the streambed in depositional areas with relatively fine-grained sediment, upstream from each of the four passive samplers (Shelton and Capel, 1994). The 10 subsamples from each site were put into wide-mouth glass jars to make a composite sample and taken to the USGS laboratory in Fort Worth for processing. Two liters of native water was collected from each site for sieving the samples. In the laboratory, the sediment from each site was poured into a large pre-cleaned Pyrex mixing bowl and homogenized with a Teflon spatula. Approximately one-half of the material was passed through a 2-mm mesh stainless steel sieve and the fraction less than $2 \mathrm{~mm}$ was collected in a $250-\mathrm{mL}$ baked-glass jar for analysis of organic compounds. This sample was then put in a refrigerator and allowed to settle. The other half of the sample was processed for analysis of inorganic elements. Approximately $400 \mathrm{~mL}$ of native water was poured into a $1,000-\mathrm{mL}$ glass beaker. An aliquot (two to three tablespoons) of the composite sample was placed into the center of a $63-\mu$ m nylon sieve cloth. The corners of the cloth were then drawn up to form a bag. This bag was dipped repeatedly into the beaker containing the native water separating out the particles of less than $63-\mu \mathrm{m}$ diameter. This process was repeated until all of the composite sample was sieved, after which the slurry in the 1,000 - $\mathrm{mL}$ beaker was transferred to a 500-mL plastic bottle and stored in a refrigerator and allowed to settle. After settling, the overlying liquid was decanted with a sterile glass pipette. Samples for analysis of organic compounds were shipped chilled to the NWQL. Samples for elemental analysis were freeze-dried, ground to a fine powder, and shipped to the NWQL.

\section{Analytical Methods}

Samples for analysis of major and trace elements were completely digested using a mixture of hydrochloric-nitricperchloric-hydrofluoric acids and analyzed by inductively coupled plasma/mass spectrometry (ICP/MS) (Briggs and Meier, 2003). Mercury was analyzed by cold vapor atomic absorption spectrometry (Arbogast, 1996). ${ }^{137} \mathrm{Cs}$ activity was measured by counting freeze-dried sediments in fixed-geometry containers with a high-resolution, intrinsic germanium detector gammaspectrometer (Robbins and Edgington, 1976).

Organochlorine pesticides, PCBs, PAHs, and alkylsubstituted PAHs (alkyl-PAHs) were extracted, isolated, and analyzed using the procedures of Noriega and others (2003) and Olson and others (2004). Briefly, wet bottom sediment was extracted overnight with dichloromethane in a Soxhlet apparatus. The extract was reduced in volume and filtered. Two 


\section{Distribution and Sources of Polychlorinated Biphenyls in Woods Inlet, Lake Worth, Fort Worth, Texas, 2003}

Table 2. Polychlorinated biphenyl congeners analyzed for this report.

\begin{tabular}{clll}
\hline $\begin{array}{c}\text { Congener } \\
\text { number }\end{array}$ & \multicolumn{1}{c}{$\begin{array}{c}\text { International Union of Pure and } \\
\text { Applied Chemistry (IUPAC) name }\end{array}$} & $\begin{array}{c}\text { Congener } \\
\text { number }\end{array}$ & $\begin{array}{c}\text { International Union of Pure and } \\
\text { Applied Chemistry (IUPAC) name }\end{array}$ \\
\hline 8 & $2,4^{\prime}$-Dichlorobiphenyl & 118 & $2,3^{\prime}, 4,4^{\prime}, 5$-Pentachlorobiphenyl \\
18 & $2,2^{\prime}, 5$-Trichlorobiphenyl & 138 & $2,2^{\prime}, 3,4,4^{\prime}, 5^{\prime}$-Hexachlorobiphenyl \\
22 & $2,3,4^{\prime}$-Trichlorobiphenyl & 146 & $2,2^{\prime}, 3,4^{\prime}, 5,5^{\prime}$-Hexachlorobiphenyl \\
26 & $2,3^{\prime}, 5$-Trichlorobiphenyl & 149 & $2,2^{\prime}, 3,4^{\prime}, 5^{\prime}, 6$-Hexachlorobiphenyl \\
28 & $2,4,4^{\prime}$-Trichlorobiphenyl & 151 & $2,2^{\prime}, 3,5,5^{\prime}, 6$-Hexachlorobiphenyl \\
31 & $2,4^{\prime}, 5$-Trichlorobiphenyl & 170 & $2,2^{\prime}, 3,3^{\prime}, 4,4^{\prime}, 5$-Heptachlorobiphenyl \\
33 & $2,3^{\prime}, 4^{\prime}$-Trichlorobiphenyl & 174 & $2,2^{\prime}, 3,3^{\prime}, 4,5,6^{\prime}$-Heptachlorobiphenyl \\
44 & $2,2^{\prime}, 3,5^{\prime}$-Tetrachlorobiphenyl & 177 & $2,2^{\prime}, 3,3^{\prime}, 4,5^{\prime}, 6^{\prime}$-Heptachlorobiphenyl \\
49 & $2,2^{\prime}, 4,5^{\prime}$-Tetrachlorobiphenyl & 180 & $2,2^{\prime}, 3,4,4^{\prime}, 5,5^{\prime}$-Heptachlorobiphenyl \\
52 & $2,2^{\prime}, 5,5^{\prime}$-Tetrachlorobiphenyl & 183 & $2,2^{\prime}, 3,4,4^{\prime}, 5^{\prime}, 6$-Heptachlorobiphenyl \\
70 & $2,3^{\prime}, 4^{\prime}, 5$-Tetrachlorobiphenyl & 187 & $2,2^{\prime}, 3,4^{\prime}, 5,5^{\prime}, 6$-Heptachlorobiphenyl \\
95 & $2,2^{\prime}, 3,5^{\prime}, 6$-Pentachlorobiphenyl & 194 & $2,2^{\prime}, 3,3^{\prime}, 4,4^{\prime}, 5,5^{\prime}$-Octachlorobiphenyl \\
101 & $2,2^{\prime}, 4,5,5^{\prime}$-Pentachlorobiphenyl & 206 & $2,2^{\prime}, 3,3^{\prime}, 4,4^{\prime}, 5,5^{\prime}, 6$-Nonochlorobiphenyl \\
110 & $2,3,3^{\prime}, 4^{\prime}, 6$-Pentachlorobiphenyl & & \\
\hline
\end{tabular}

aliquots of the sample extract were quantitatively injected into a polystyrene-divinylbenzene gel permeation column (GPC) and eluted with dichloromethane to remove sulfur and partially isolate the target analytes from coextracted high-molecularweight interferents such as humic substances. The first aliquot was passed through a silica column cleanup step and then analyzed for PAHs and alkyl-PAHs by capillary-column gas chromatography (GC) with detection by mass spectrometry (MS). Parent PAHs were identified and quantified by comparison to authentic standards. Individual alkyl-PAHs were quantified when authentic alkyl-substituted standards were available. When authentic alkyl-substituted standards were unavailable, a parent PAH was used as the standard for quantitation. The multiple isomeric alkyl-PAHs were quantified from mass chromatograms as the sum of all isomers at each alkylation level (C1-naphthalenes, C2-naphthalenes, and so forth). Nineteen parent PAHs, 10 specific alkyl-PAHs, and the homologous series of alkyl-PAHs were determined. The second aliquot was further split into two fractions by combined alumina/silica adsorption chromatography followed by a micro Florisil column cleanup step prior to determination of the organochlorine pesticides and PCBs by dual capillary-column gas chromatography with electron capture detection (GC-ECD) (Olson and others, 2004). The organochlorine pesticides were reported as individual compounds. Technical chlordane was estimated from trans-nonachlor, cis-chlordane, and trans-chlordane concentrations. PCBs were reported as individual Aroclor (1016/1242, 1254, or 1260) equivalents (Noriega and others, 2003).

For this study, Fraction 1 (PCB fraction) of the organiccompound analysis was analyzed for 27 (of 209 possible) selected PCB congeners (table 2) along with the other Fraction 1 analytes during GC-ECD analysis. The congeners chosen for this analysis were some of the more dominant congeners in the most widely used Aroclors (1016, 1242, 1254, and 1260). In addition to the dominance of these congeners, potential coelution issues and signal response for this analytical method were considered. A series of dilutions of a custom mixture containing the 27 selected PCB congeners was used to make the calibration standards. Calibration standards were prepared at four levels, and a minimum of three points were used for the calibration curves. An additional congener solution, prepared at a concentration that was mid-range on the curve, was used as a check standard to verify the calibration curve.

The laboratory reporting level for PCB Aroclors was 5 micrograms per kilogram $(\mu \mathrm{g} / \mathrm{kg})$; however, variations in sample mass, sample matrix, and analytical interferences raised reporting levels for some environmental samples to $20 \mu \mathrm{g} / \mathrm{kg}$ or more. A laboratory reporting level has not been established for individual congeners because the method is relatively new (W.T. Foreman, U.S. Geological Survey, written commun., 2001); however, it is believed to be conservatively about 1 $\mu \mathrm{g} / \mathrm{kg}$ (M.C. Noriega, U.S. Geological Survey, oral commun., 2003). Concentrations well below that level were reported when the analyst was confident in the detection; those values were identified in the data tables in appendix 1.2 as estimated (E). Because the quantification of individual congeners is believed to be more precise than the Aroclor equivalents, the sum of the congeners was used as a measure of total PCB rather than the sum of the Aroclors. A comparison of all suspended, streambed, and bottom sediment samples indicated that the sum of the congeners accounted for 57 percent (mean, \pm 6 percent [one standard deviation]) of the sum of the Aroclors.

\section{Quality Control}

Quality control for organic compound (PCB, PAH, organochlorine pesticide) analyses consisted of analyzing an 
Table 3. Summary of median relative percent differences (RPDs) of duplicate samples from this study and other coring and suspended sediment studies done by the U.S. Geological Survey (USGS) in Texas.

[Number of samples in parentheses; PCBs, polychlorinated biphenyls; PAHs, polycyclic aromatic hydrocarbons]

\begin{tabular}{|c|c|c|c|c|}
\hline Constituent & $\begin{array}{l}\text { Core sediment } \\
\text { samples }\end{array}$ & $\begin{array}{c}\text { Surficial bottom } \\
\text { sediment samples }\end{array}$ & $\begin{array}{c}\text { Suspended sediment } \\
\text { samples }\end{array}$ & $\begin{array}{c}\text { Streambed sediment } \\
\text { samples }\end{array}$ \\
\hline \multicolumn{5}{|c|}{ Median RPDs from this study } \\
\hline Aroclors & $12.2(4)$ & $27.5(1)$ & $74.8(1)$ & $13.0(6)$ \\
\hline Congeners & $12.0(4)$ & $21.2(1)$ & $35.5(1)$ & $25.0(6)$ \\
\hline Organochlorine pesticides & No duplicate & $16.3(1)$ & No detections (1) & $40.3(6)$ \\
\hline \multicolumn{5}{|c|}{ Median RPDs from other USGS studies using the same methods (Van Metre and others, 2004) } \\
\hline \multicolumn{5}{|l|}{ PCBs } \\
\hline Aroclors & $11.2(57)$ & $8.3(5)$ & $24.7(5)$ & No duplicate \\
\hline
\end{tabular}

analytical blank sample, a spiked sample, a certified reference material (CRM), and a duplicate, and monitoring recovery of surrogate compounds with each set of 12 environmental samples (Noriega and others, 2003; Olson and others, 2004). PCB and organochlorine pesticide blank samples had no detections. PAH blank samples had detections for eight of the $11 \mathrm{com}-$ pounds, with concentrations ranging from an estimated 0.18 to $1.4 \mu \mathrm{g} / \mathrm{kg}$. The typical minimum reporting level for PAH compounds is $5 \mu \mathrm{g} / \mathrm{kg}$. Median spike recoveries were 68 percent for PCBs and organochlorine pesticides and 69 percent for PAHs. PCB and organochlorine pesticide spike recoveries were within control limits for 93 percent of the spike results. No spike recovery control limits for the PAHs were established by the NWQL. CRM concentrations were within acceptable concentration ranges for 94 percent of the PCB and organochlorine pesticide CRM results and 88 percent of the PAH CRM results. All CRM concentrations that were outside an acceptable range were lower than the minimum value of the range. Recovery corrections were not applied. Quality control for major and trace element analyses consisted of analyzing several standard reference materials (SRMs) and one or more duplicates with each batch of as many as 20 samples. Median relative percent difference (RPD) for all elements for all SRMs was 4.2 percent.

Analytical results from two types of duplicate samples are included in this report-environmental duplicates and laboratory duplicates (appendixes 1 and 2). An environmental duplicate is a sample that is split into two jars at the time of collection; both jars are submitted to the laboratory for analysis. A laboratory duplicate is a single sample that is split by the laboratory during preparation and analyzed in duplicate. Although the analytical methods of PCB analysis were the same for core, surficial, suspended, and streambed sediment, sample mass was small enough for suspended sediment samples that reporting levels and precision were affected, and the number of duplicates analyzed was limited. Twelve duplicate samples were analyzed for PCBs (table 3). The median RPD of the duplicate PCB analyses ranged from 12.0 to 74.8 percent. Fifteen duplicate samples were analyzed for major and trace elements. The median RPD of the duplicate major and trace element analyses ranged from 1.6 to 2.1. Eight duplicate samples were analyzed for PAHs. The median RPD of the duplicate PAH analyses ranged from 19.3 to 30.4 percent. Eight duplicate samples were analyzed for organochlorine pesticides. The median RPD of the duplicate organochlorine pesticide analyses ranged from 16.3 to 40.3 percent. Generally, the median RPDs for PCBs were greater for the suspended and streambed sediment samples than for the core and surficial sediment samples.

In addition to the median RPDs of duplicate samples for this report, table 3 shows the median RPDs of duplicate samples from other USGS sediment coring studies using the same collection and analytical methods. Generally, the median RPDs of organic compounds for the suspended and streambed sediment samples in this report are greater than the median RPDs for the suspended and streambed sediment samples in other sediment coring studies. Few duplicate samples have been analyzed for PCB congeners in other sediment coring studies because the analytical method used by the NWQL is relatively new (W.T. Foreman, U.S. Geological Survey, written commun., 2001). Median RPDs for core sediment samples analyzed for PCBs and for all types of sediment samples analyzed for major and trace elements for this report are similar in magnitude to median RPDs for those constituents from other sediment coring studies. 

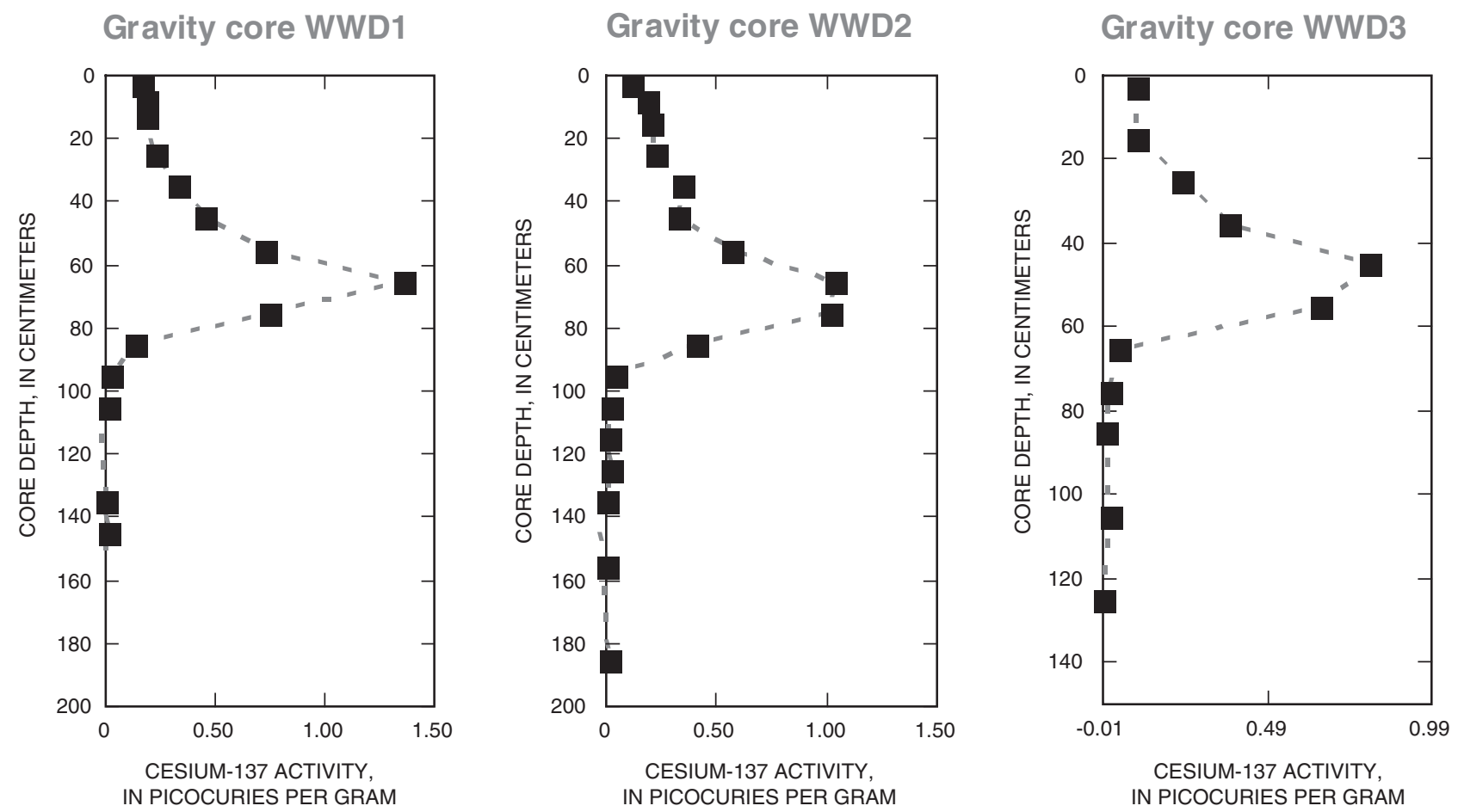

Figure 5. Cesium-137 profiles in gravity cores used for age-dating, Woods Inlet, Lake Worth, Texas, 2003.

\section{Age-Dating Cores}

The methods for age-dating reservoir and inlet cores used in this study are described in Harwell and others (2003) and Van Metre and others (2004). Briefly, a sediment core from an undisturbed depositional zone in a reservoir penetrates through layers of sediment deposited over the history of the reservoir. Several date markers are recorded in the core that allow for estimation of deposition dates for the core, usually assuming a constant sediment mass accumulation rate (MAR, in grams per centimeter squared per year) between the markers. Three date markers were used in cores from Lake Worth: the pre-reservoir land surface (the boundary between soil and lacustrine bottom sediment in the core) dated as 1914, the year construction of the dam was completed; the peak in ${ }^{137} \mathrm{Cs}$, dated as 1964 , when

${ }^{137} \mathrm{Cs}$ fallout from atmospheric testing of nuclear weapons peaked; and the top of the core matched with the sampling date (fig. 5). Between each of these depth-date markers, MARs were used to assign dates on the basis of the mass of each sample and of the cumulative mass between the mid-point of the sample and a date marker. Mass was estimated by accurately weighing measured volumes of wet and dry sediment to determine bulk density and density of solids, each in grams per cubic centimeter.

Sedimentation rates in reservoirs commonly decrease over time as the shoreline gradually stabilizes. Callender and Robbins (1993) found that an exponentially decreasing model of MAR fit the pattern of decreasing sedimentation rates in 48 of 83 reservoirs they studied. Sedimentation rates in all three Woods Inlet gravity cores decreased over time as indi- cated by comparison of MAR before and after the ${ }^{137}$ Cs peak in 1964. An exponential model was applied to these three cores to assign deposition dates to samples following the approach of Van Metre and others (2004). Porosity, activity of ${ }^{137} \mathrm{Cs}$, MAR, and deposition dates are listed in appendix 1.1.

\section{Distribution and Sources of Polychlorinated Biphenyls in Woods Inlet}

Detection frequencies for the 27 PCB congeners varied by the degree of chlorination and by sample type. In general, detection frequency increased with increasing degree of chlorination and was higher in surficial bottom sediment than in suspended and streambed sediment (fig. 6). Detection frequencies for PCB 8 , for example, with two chlorine atoms, were 20 and 8 percent for inlet and stream sediments, respectively. Average detection frequency for the heptachlorobiphenyls (seven chlorine atoms) were 100 and 78 percent for surficial bottom sediments and suspended and streambed sediments, respectively.

\section{Polychlorinated Biphenyls in Bottom Sediment}

Total PCB concentrations in 20 samples of surficial bottom sediment from Woods Inlet ranged from 4.75 to $73.8 \mu \mathrm{g} / \mathrm{kg}$ (fig. 7; appendix 1.2). Total PCB concentrations were highest near the mouth of Meandering Road Creek and decreased 


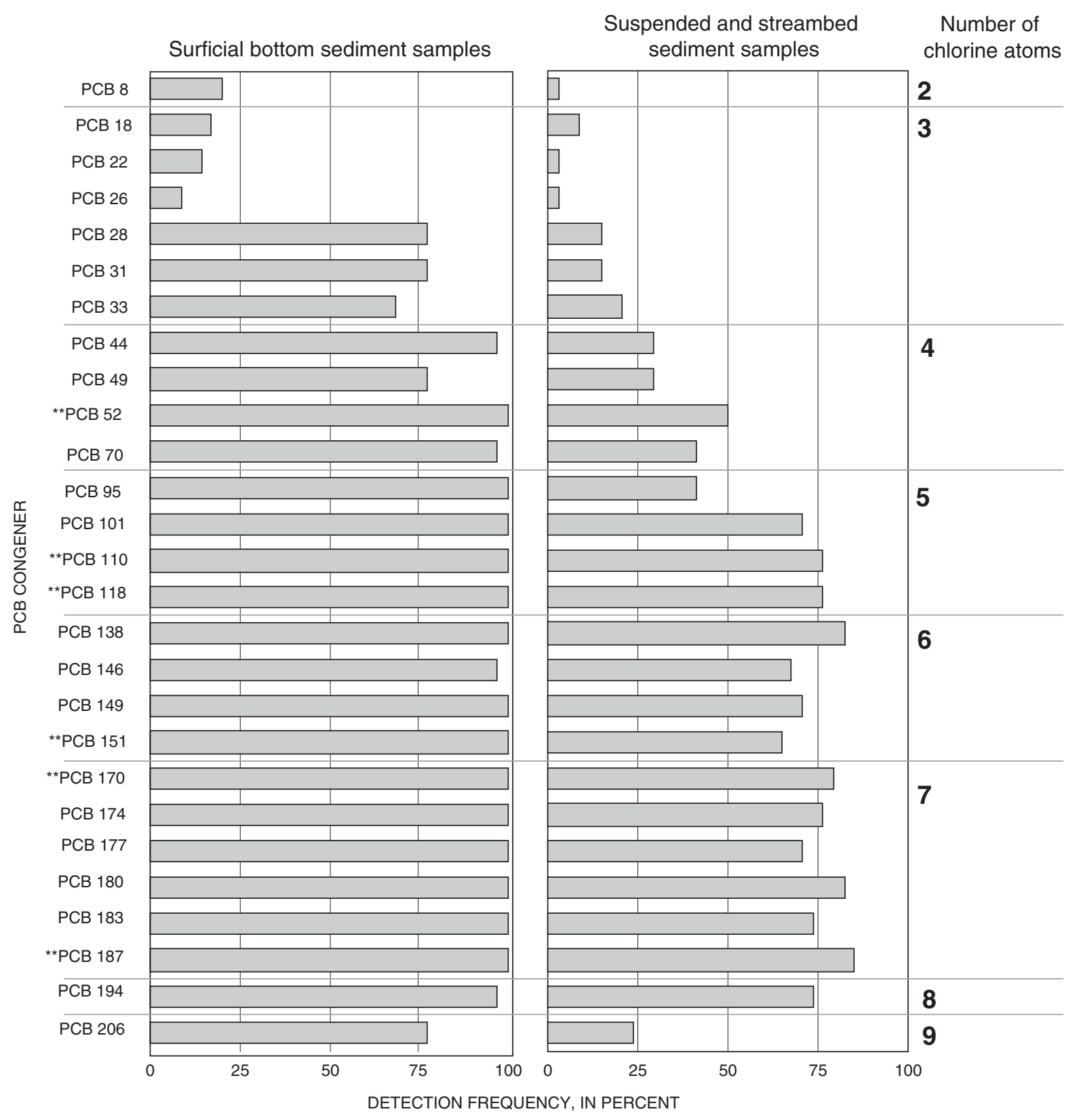

Figure 6. Detection frequency by polychlorinated biphenyl (PCB) congener and sample type, Woods Inlet, Lake Worth, Fort Worth, Texas, 2003 ( ${ }^{* *}$ PCB used in graphical and cluster analysis).

consistently toward the main lake. Total PCB concentrations at the mouth of the other two tributary streams, Gruggs Park Creek and TNG Creek, were lower than at the mouth of Meandering Road Creek and were similar to the surficial bottom sediment concentrations in the middle of Woods Inlet. The spatial distribution of surficial total PCB concentrations indicates that PCBs are originating in the Meandering Road Creek watershed.

Peak total PCB concentrations occurred in the 70-80-cm sample at WWD1, the 30-40-cm sample at WWD2, and the 5060-cm sample at WWD3 (fig. 8; appendix 1.2). These peak total PCB concentration depths correspond to about 1960 for WWD1 and WWD3 and about 1980 for WWD2. PCB concentrations increased greatly from those of the early 1940 s to the peaks in the three gravity cores. The magnitudes of peak total PCB concentrations in the gravity cores followed a spatial distribution generally similar to that of surficial bottom sediment concentrations (fig. 7). The highest concentration at WWD3 $(349 \mu \mathrm{g} / \mathrm{kg})$ was near the mouth of Meandering Road Creek (and at the mouth of TNG Creek), the next highest at WWD1 (128 $\mu \mathrm{g} / \mathrm{kg})$, near the confluence of the three tributary creeks, and the lowest peak concentration at WWD2 $(47.6 \mu \mathrm{g} / \mathrm{kg})$, near the mouth of Gruggs Park Creek. The 1960 peaks at WWD1 and WWD3 are 


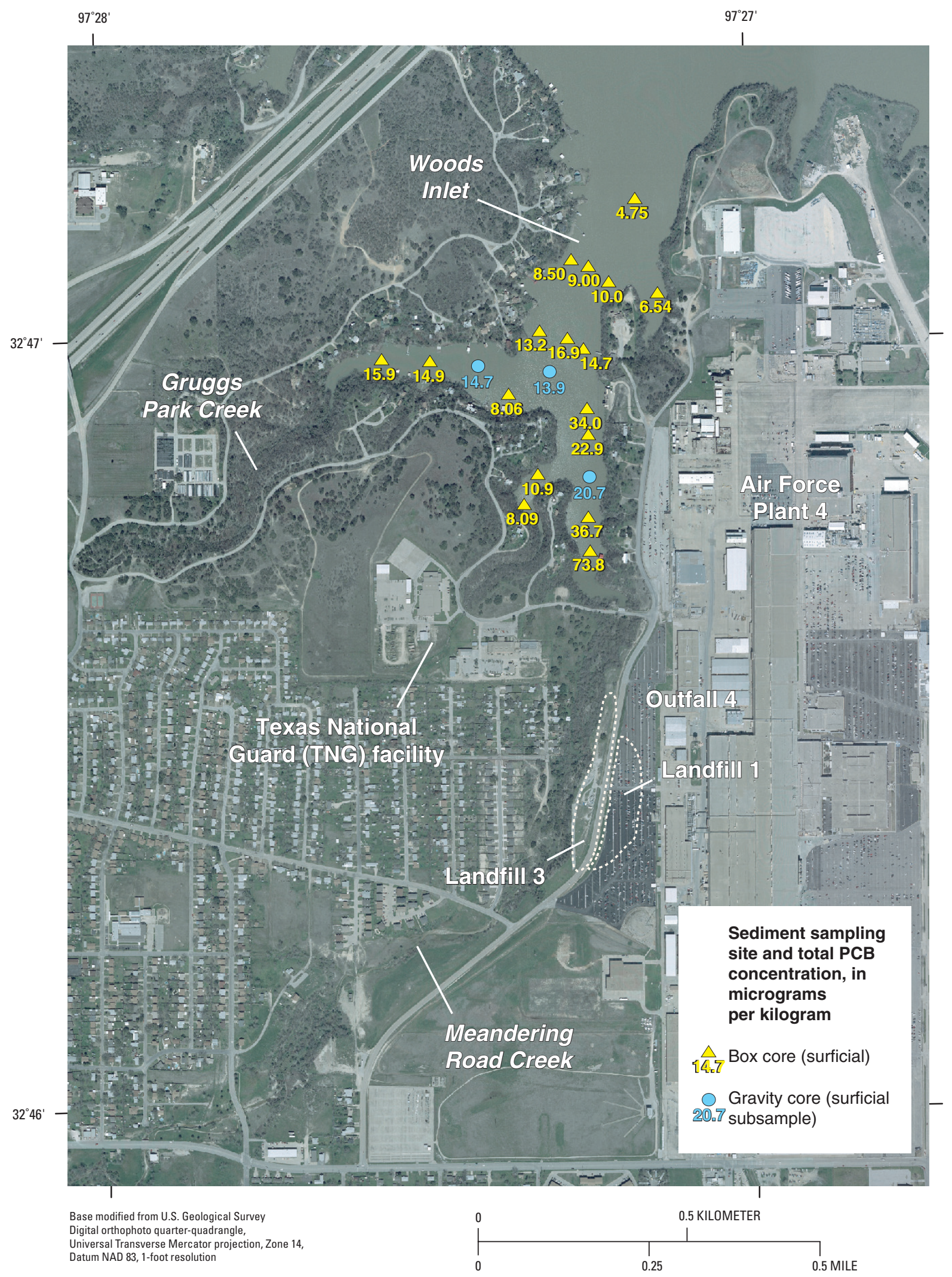

Figure 7. Total polychlorinated biphenyl (PCB) concentrations (sum of PCB congeners) in surficial bottom sediment, Woods Inlet, Fort Worth, Texas, 2003. 
(a)

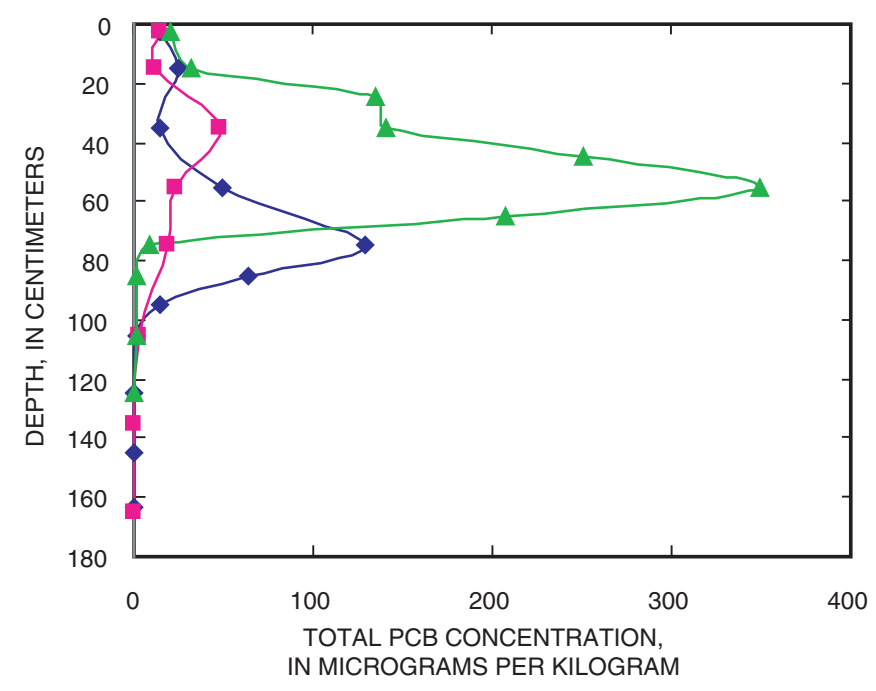

(b)

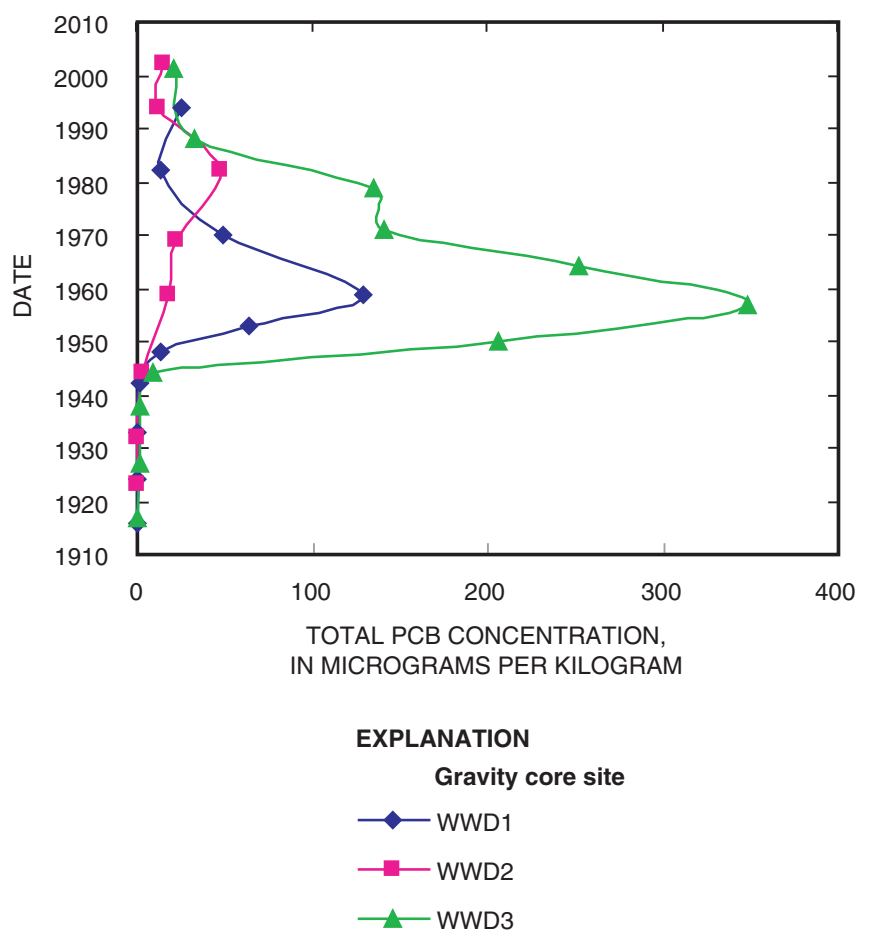

Figure 8. Trends in total polychlorinated biphenyl (PCB) concentrations (sum of PCBcongeners) in sediment cores relative to (a) sediment depth and (b) date of sediment deposition, Woods Inlet, Lake Worth, Fort Worth, Texas, 2003.

consistent in age with the peak in a gravity core from near the mouth of Woods Inlet collected in 2002 (Harwell and others, 2003).

PCB concentrations in surficial bottom sediment were much lower than peak concentrations. The surficial bottom sediment concentration of total PCB at WWD1, for example, is $13.9 \mu \mathrm{g} / \mathrm{kg}$, about one-ninth the peak concentration. Van Metre and others (1998) reported that PCB concentrations in reservoir sediment cores tended to follow an exponential decrease after they were banned, with a half-life of about 10 years. The halflife for total PCB (number of years to degrade to one-half the peak concentration) in the two cores with pronounced 1960 peaks, estimated from a regression line fit to the natural logarithms of total PCB concentrations, was 10.2 years at WWD3 and 14 years at WWD1. These rates were consistent with those in PCB concentrations in sediment cores nationally (Van Metre and others, 1998).

PCBs were not detected in sediment deposited before the 1940s from two of the three Woods Inlet cores (WWD1 and WWD2); however, some PCB congeners were detected at low (estimated) concentrations near the bottom of core WWD3 (appendix 1.2). Commercial manufacturing of PCBs, which have no natural sources, began in 1929, and PCBs usually are not detected in cores of lake sediment deposited before the 1940s (Van Metre and others, 1998). The bottom two samples from core WWD3, dated as 1917 and 1927, predate use of PCBs, which indicates either sample contamination or mixing of sediment containing PCBs in the core. Large, relatively narrow peaks in ${ }^{137} \mathrm{Cs}$ activity and $\mathrm{PCB}$ concentrations and a high sedimentation rate in Lake Worth indicate that mixing extensive enough to move PCBs 30 to $50 \mathrm{~cm}$ down core is unlikely. Cross-contamination of samples is possible during collection and subsampling of a core by smearing of sediment along the inside walls of the core liner. Total PCB concentrations in the bottom three samples from core WWD3 (80-130 cm, 1938 and earlier) ranged from 0.77 to $1.91 \mu \mathrm{g} / \mathrm{kg}$, about 200 times smaller than the peak concentration of $349 \mu \mathrm{g} / \mathrm{kg}$ dated as 1957 (fig. 8; appendix 1.2). Cross-contamination of the samples during subsampling was the likely cause of these low-level detections. This low-level contamination does not affect interpretations of the PCB data in the core.

\section{Polychlorinated Biphenyls in Suspended and Streambed Sediment}

PCBs could reach Woods Inlet from several sources and by several pathways. Potential sources of PCBs include one of the historical landfills or historically contaminated soils on AFP4 and point or nonpoint sources in the surrounding urban area. Because PCBs are very hydrophobic, the primary pathway for them to enter urban creeks and lakes is erosion and fluvial transport attached to sediment. The most likely pathway for them to enter Woods Inlet is attached to suspended sediment transported by runoff during storms.

Total PCB concentrations in suspended and streambed sediment varied greatly among sites and indicated a likely source of $\mathrm{PCB}$ s associated with site $\mathrm{OF} 4$, which receives runoff from AFP4 (fig. 9; appendix 1.2). The three sites not influenced by AFP4 (GRUGGS, TNG, and UMRC) had five samples in which no PCB congeners were detected and 13 samples in which one or more congeners were detected; total PCB for those 13 samples ranged from 0.54 to $14.8 \mu \mathrm{g} / \mathrm{kg}$. In contrast, the 


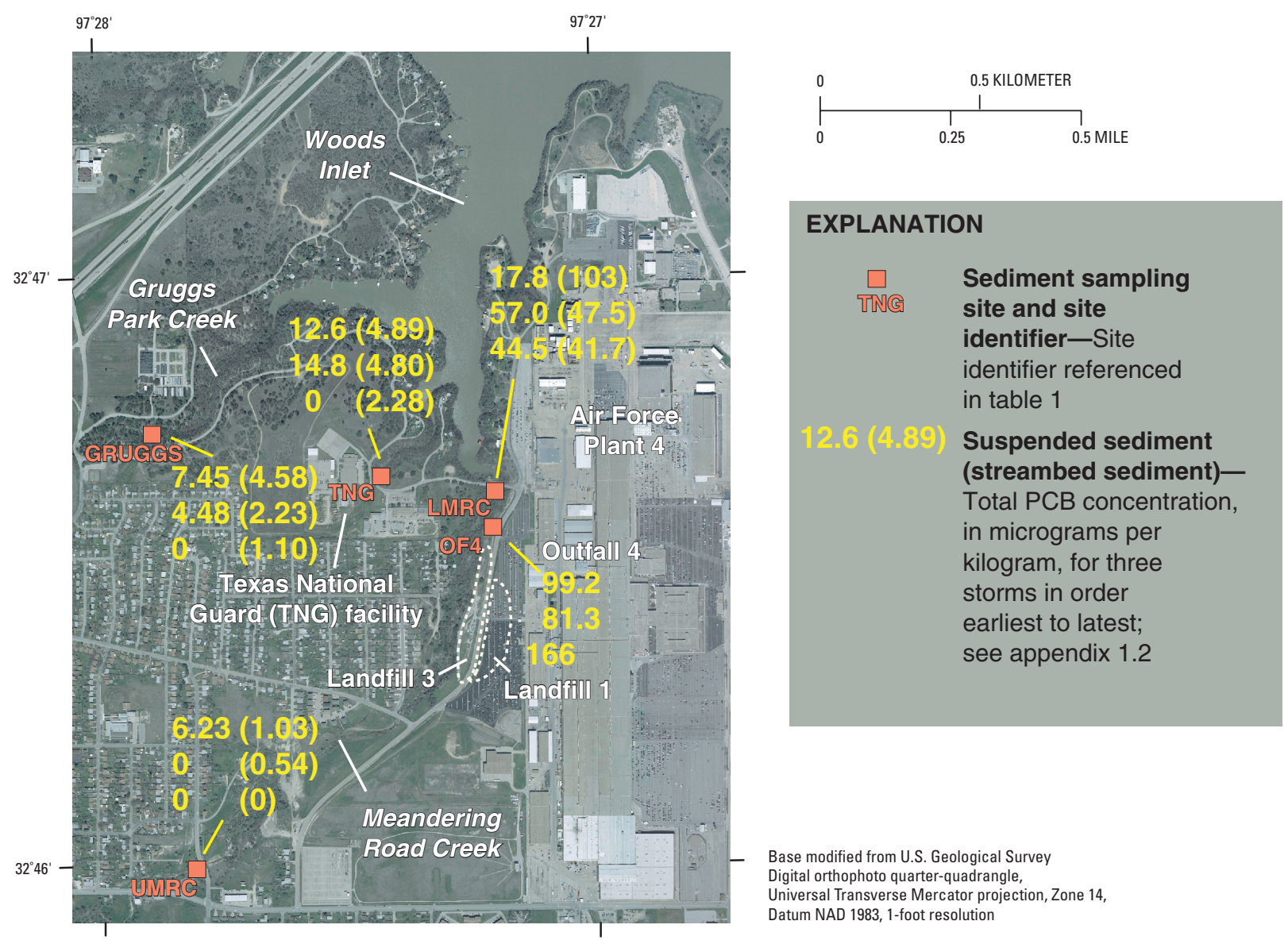

Figure 9. Total polychlorinated biphenyl (PCB) concentrations (sum of PCB congeners) in suspended and streambed sediment from tributary streams to Woods Inlet, Lake Worth, Fort Worth, Texas, 2003.

three suspended sediment samples from OF4 contained total PCB concentrations of $81.3,99.2$, and $166 \mu \mathrm{g} / \mathrm{kg}$, with a mean of $116 \mu \mathrm{g} / \mathrm{kg}$. The six samples from LMRC, influenced by flow at UMRC (no AFP4 runoff) and OF4 (AFP4 runoff), reflected intermediate concentrations that ranged from 17.8 to $103 \mu \mathrm{g} / \mathrm{kg}$.

One or more PCB congeners were detected in both media in eight of the 12 paired suspended and streambed sediment samples (fig. 9). Total PCB was greater for suspended sediment in seven of the eight pairs and the ratio of suspended to streambed sediment concentration ranged from 1.1 to 6.0 , with a median of 2.0. Large concentrations in suspended sediment compared to those in streambed sediments could reflect finer grain size or higher organic carbon concentrations, or both.

The one sample where streambed sediment concentration was greater than suspended sediment concentration was the LMRC sample from August 30, 2003. Total PCB concentration was much less in the August 30 suspended sediment sample than in the two subsequent suspended sediment samples from this site. Differences in major element concentrations between this sample and the two subsequent samples, including higher calcium, lower organic carbon, and slightly lower aluminum and iron, indicate a different source of sediment for the August 30 sample than the two subsequent samples. Grain size was not analyzed for the August 30 sample, but the differences in major element and contaminant concentrations could indicate a coarser, sandier material, possibly material mobilized from the bed of Meandering Road Creek.

\section{Source Identification Using Polychlorinated Biphenyl Congener Assemblages}

Three approaches were applied to identify sources of PCBs in surficial bottom sediment using congener assemblages: (1) graphical comparisons, (2) a simple measure of differences among congener patterns, and (3) cluster analysis. All samples deeper than $5 \mathrm{~cm}$ in the gravity cores, and suspended and streambed sediment samples with frequent nondetections were excluded from these analyses. Concentrations were first normalized by dividing by total PCB to convert each congener 
concentration to a fraction of total PCBs. The assumption in these analyses is that the relative concentrations of congeners in a sediment sample in the inlet are not changed appreciably during transport and deposition from distinct sources, except by mixing, This assumption implies that processes such as degradation and desorption of selected congeners do not greatly alter relative concentrations. Source areas of PCBs that potentially could be identified through interpretation of data collected in this study are urban areas west of AFP4, the Texas National Guard facility, the part of AFP4 that contributes runoff to OF4, and AFP4 (by comparison of UMRC and LMRC results).

The first approach to identify sources of PCBs to Woods Inlet involved graphical analysis of normalized concentrations of six selected congeners. Six congeners were selected that were detected frequently, covered a range in the level of chlorination, were at relatively high concentrations, and varied between samples from different sites. The lines representing normalized sample concentrations of the six congeners from areas of Woods Inlet and from tributary stream sites (fig. 10) generally form similar patterns within sample groups (within graphs). Some patterns on suspended and streambed sediment graphs (column 2 in fig. 10), which represent potential sources, are similar to patterns on surficial bottom sediment graphs (column 1 in fig. 10). Normalized congener concentration patterns for suspended and streambed sediment samples from LMRC are similar to patterns for surficial sediment in the Meandering Road Creek arm of Woods Inlet and the middle of Woods Inlet. Patterns for two of the three samples from OF4 also are similar to those for samples from the Meandering Road Creek arm and middle of Woods Inlet. The TNG sample patterns are variable and distinctly different from any of the patterns of the surficial sediment samples in the inlet, with roughly increasing proportions of congeners with increasing chlorination. The GRUGGS and UMRC (urban reference) sample patterns also are variable and show some similarity to sample patterns of the Gruggs arm of Woods Inlet and to some sample patterns from the middle of Woods Inlet. The clearest visual match between a potential source, as indicated by suspended and streambed sediment graphs, and PCBs in Woods Inlet, as indicated by surficial bottom sediment graphs, is that between site LMRC and the Meandering Road Creek arm of Woods Inlet. A close second in terms of visual match is that between LMRC and the middle of Woods Inlet and that between OF4 (two of four samples) and the Meandering Road Creek arm and middle of Woods Inlet.

The second approach to identify sources using congener assemblages, the measure of differences among congener patterns, was the root mean squared difference (RMSD) between normalized concentrations of the 17 most frequently detected congeners. Normalized concentrations of each of the suspended and streambed sediment samples (representing potential sources) were compared to the mean of all surficial bottom sediment sample concentrations (representing the end-point of interest). The RMSD is computed as the square root of the sum of squared differences between the normalized concentrations; the smaller it is, the more similar the data are. The LMRC sus- pended and streambed sediment samples, and two of the three OF4 samples, are more similar to the Woods Inlet surficial bottom sediment samples than samples from the other tributary sites (table 4), possibly indicating a common source.

The third approach to source identification, cluster analysis (Davis, 2002), was carried out using the six congeners that were used for the graphical analysis. Cluster analysis involves grouping samples on the basis of similarity of a response variable or variables, which, as in the graphical analysis (fig. 10), was the ratio of individual PCB congeners to total PCB. Six clusters were indicated on the basis of interpretation of the data, the distribution of which is shown in figure 11 . Cluster 1 contains middle of Woods Inlet and Meandering Road Creek arm samples (most surficial bottom sediment), three of four samples from LMRC, and two of three samples from OF4. None of the other tributary samples were grouped in this cluster. Cluster 2 comprises three samples from Woods Inlet that were not in the probable path of discharge from Meandering Road Creek and two samples from the urban reference sites GRUGGS and UMRC. Cluster 3 accounts for the Gruggs arm of Woods Inlet samples, along with one sample each from the urban reference

Table 4. Root mean squared difference (RMSD), from smallest to largest, between normalized concentrations of 17 polychlorinated biphenyl congeners in suspended and streambed sediment samples in tributaries and mean of all surficial bottom sediment sample concentrations of those congeners in Woods Inlet, Lake Worth, Fort Worth, Texas, 2003.

\begin{tabular}{lccc}
\hline $\begin{array}{c}\text { Suspended or } \\
\text { streambed } \\
\text { sediment site } \\
\text { (fig. 2) }\end{array}$ & $\begin{array}{c}\text { Sample } \\
\text { date }\end{array}$ & $\begin{array}{c}\text { Sample } \\
\text { type }\end{array}$ & RMSD \\
\hline LMRC & $8 / 30 / 2003$ & Suspended & 0.046 \\
LMRC & $8 / 31 / 2003$ & Streambed & .065 \\
OF4 & $9 / 11 / 2003$ & Suspended & .073 \\
OF4 & $8 / 30 / 2003$ & Suspended & .076 \\
LMRC & $9 / 16 / 2003$ & Streambed & .095 \\
LMRC & $10 / 6 / 2003$ & Streambed & .098 \\
GRUGGS & $8 / 31 / 2003$ & Streambed & .110 \\
UMRC & $8 / 30 / 2003$ & Suspended & .125 \\
OF4 & $10 / 5 / 2003$ & Suspended & .131 \\
UMRC & $8 / 31 / 2003$ & Streambed & .140 \\
TNG & $8 / 31 / 2003$ & Streambed & .141 \\
GRUGGS & $8 / 30 / 2003$ & Suspended & .145 \\
TNG & $9 / 11 / 2003$ & Suspended & .170 \\
TNG & $8 / 30 / 2003$ & Suspended & .200 \\
TNG & $9 / 16 / 2003$ & Streambed & .236 \\
\hline
\end{tabular}




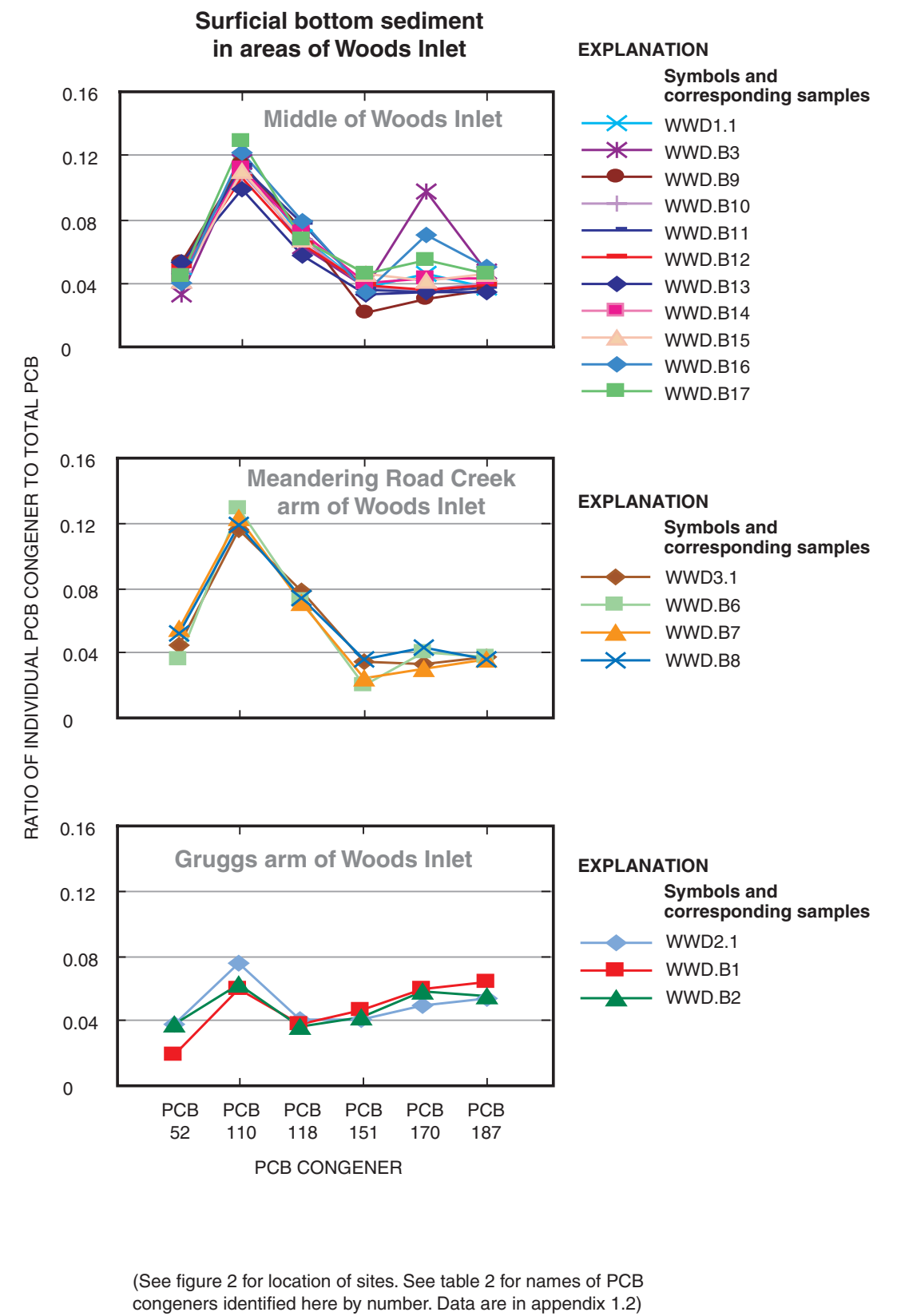

Suspended and streambed sediment in tributary stream sites

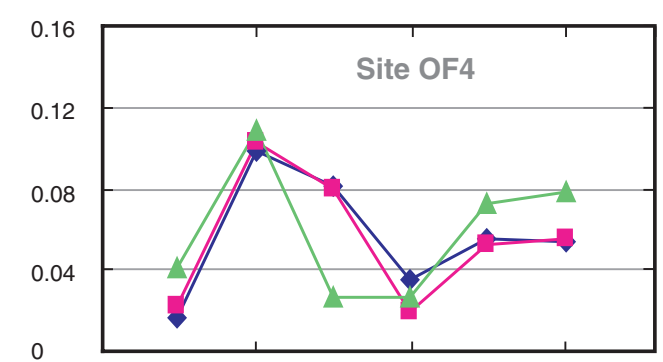

EXPLANATION

Symbols and

corresponding samples

—— Suspended sediment 8/30/2003

- Suspended sediment 9/11/2003

- - Suspended sediment 10/5/2003

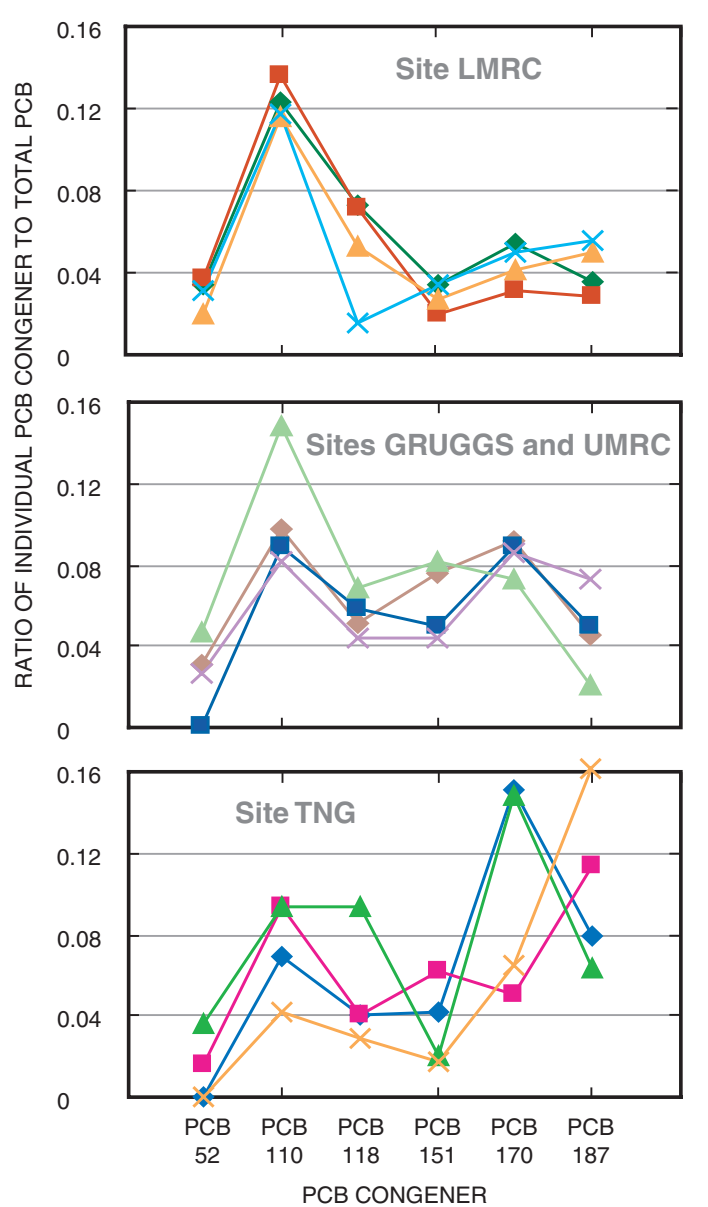

EXPLANATION

Symbols and

corresponding samples

_ Suspended sediment 8/30/2003

- - Streambed sediment 8/31/2003

- - Suspended sediment $9 / 11 / 2003$

$\leftarrow$ Streambed sediment 9/16/2003

EXPLANATION

Symbols and

UMRC

—— Suspended sediment 8/30/2003

- - Streambed sediment 8/31/2003 GRUGGS

- Suspended sediment 8/30/2003

$\longrightarrow$ Streambed sediment $8 / 31 / 2003$

EXPLANATION

Symbols and

corresponding samples

— S Suspended sediment 8/30/2003

- Streambed sediment 8/31/2003

- - Suspended sediment 9/11/2003

$\leftarrow$ Streambed sediment 9/16/2003

Figure 10. Selected polychlorinated biphenyl (PCB) congener assemblages normalized (divided) by total PCB (sum of PCB congeners) for surficial bottom sediment in areas of Woods inlet and suspended and streambed sediment in tributary streams to Woods Inlet, Lake Worth, Texas, 2003. 


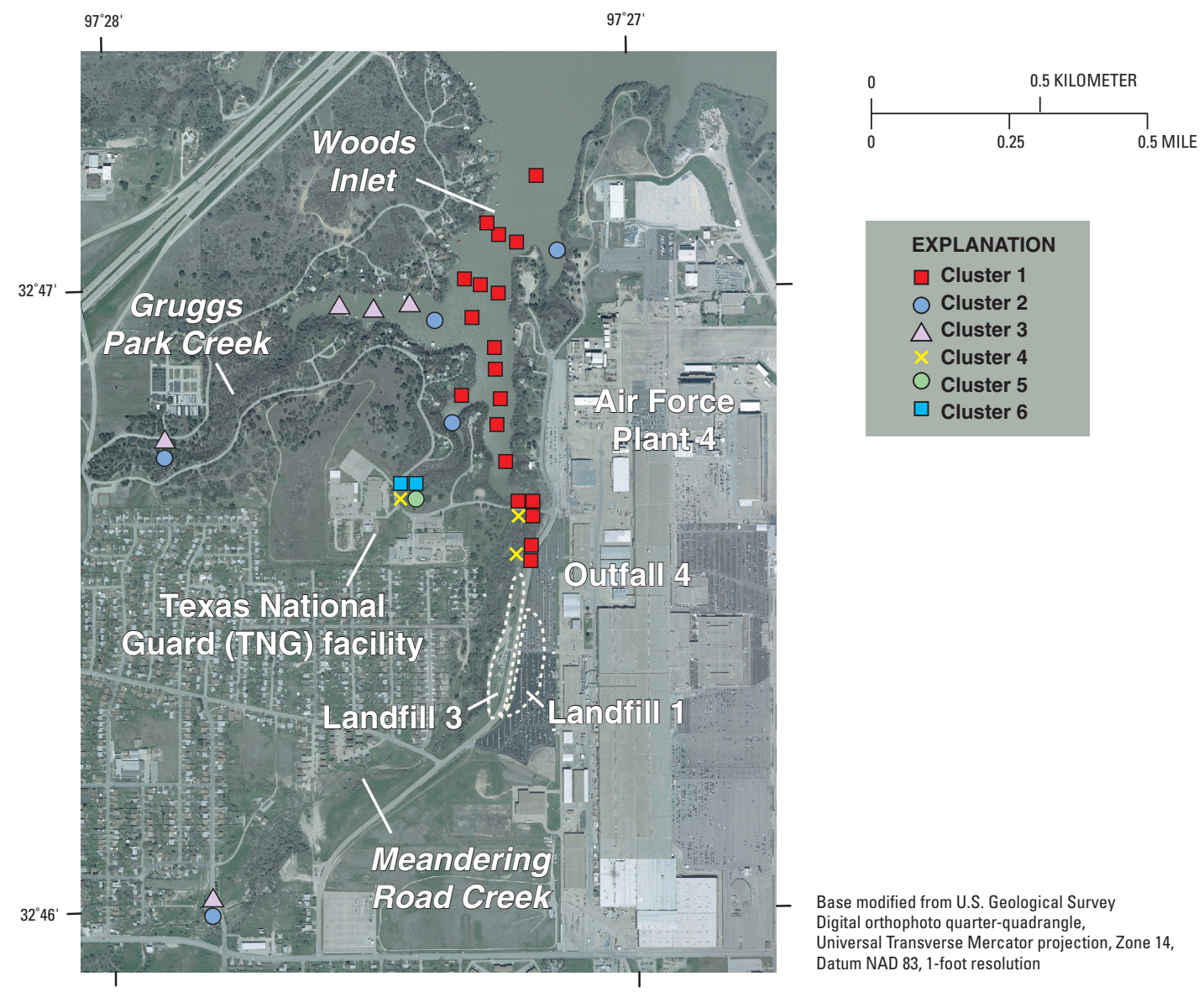

Figure 11. Results of cluster analysis using selected polychlorinated biphenyl (PCB) congeners, Woods Inlet and tributaries, Lake Worth, Fort Worth, Texas, 2003.

sites GRUGGS and UMRC. Cluster 4 contains no inlet samples, only one sample each from OF4, LMRC, and TNG. Cluster 5 consists of a single TNG sample, and cluster 6 comprises two TNG samples. The four samples from site TNG are in three different clusters, which indicates the most variability among tributary sites and inlet areas.

The three approaches to the analyses of congener assemblages indicate that PCBs in surficial bottom sediment of Woods Inlet primarily enter Lake Worth from Meandering Road Creek and that runoff from AFP4 is a source of the PCBs in Meandering Road Creek. Although current (2003) transport of PCBs from AFP4 to the creek is occurring, as OF4 sample analyses indicate, the large decreases in PCB concentrations with decreasing depth in cores WWD1 and WWD3 (fig. 8) are evidence that PCB loading to the inlet has decreased greatly since the 1960s. Because runoff entering Meandering Road Creek from some parts of AFP4 was not measured or sampled in this study, it cannot be said with certainty that site OF4 is the only source of PCBs to Meandering Road Creek.

\section{Summary}

In response to the finding in a previous study of elevated polychlorinated biphenyl (PCB) concentrations in sediment in Woods Inlet, a feature on the southern shore of Lake Worth along the western boundary of Air Force Plant 4 (AFP4) in Fort Worth, Tex., the U.S. Geological Survey, in cooperation with the U.S. Air Force, conducted a study in 2003 to map the distribution of elevated PCB concentrations in Woods Inlet and to identify possible sources (or more specifically, source areas) of PCBs in the watershed of Woods Inlet. Gravity cores (penetration to pre-reservoir sediment at three sites) and surficial bottom sediment samples (top $5 \mathrm{~cm}$ at 20 sites) were collected and analyzed to map the distribution of PCB concentrations in Woods Inlet. Suspended sediment in stormwater runoff and streambed sediment were sampled in tributaries to Woods Inlet following storms to identify possible current (2003) sources of PCBs. In addition, assemblages of PCB congeners in surficial bottom sediments and suspended and streambed sediments were analyzed to indicate sources of PCBs in the surficial bottom 
sediments on the basis of chemical signatures of PCBs. Sediment samples also were analyzed for major and trace elements, selected PAHs, and selected organochlorine pesticides.

Woods Inlet receives runoff primarily from three tributaries: (1) Gruggs Park Creek, (2) the small unnamed creek that drains a Texas National Guard maintenance facility, called TNG Creek for this report, and (3) Meandering Road Creek. Three stormwater sampling sites were established near the mouths of each of these three creeks (GRUGGS, TNG, LMRC, respectively). GRUGGS and TNG receive urban runoff but not runoff from AFP4; LMRC receives urban runoff from AFP4 and other areas. A fourth site (OF4) along Meandering Road Creek upstream from LMRC receives runoff exclusively from AFP4. A fifth site (UMRC) is on Meandering Road Creek upstream from AFP4 but downstream from urban areas; thus it receives urban runoff but none from AFP4. Suspended sediment samples were collected during three storms at each of the five sites. Streambed sediment samples were collected at all of the sites except OF4 following each of the three storms in which suspended sediment samples were collected.

Twenty-seven of 209 possible PCB congeners were analyzed. The sum of the congeners was used as a measure of total PCB. Total PCB concentrations in 20 samples of surficial sediment from Woods Inlet ranged from 4.75 to $73.8 \mu \mathrm{g} / \mathrm{kg}$. Total PCB concentrations were highest near the mouth of Meandering Road Creek and decreased consistently toward Lake Worth. Total PCB concentrations at the mouth of the other two tributary streams, Gruggs Park Creek and TNG Creek, were lower than at the mouth of Meandering Road Creek and were similar to the surficial bottom sediment concentrations in the middle of Woods Inlet. The spatial distribution of surficial total PCB concentrations indicates that PCBs are originating in the Meandering Road Creek watershed.

Peak total PCB concentrations in the three gravity cores occurred at depths corresponding to sediment deposition dates of about 1960 for two of the cores and about 1980 for the third core. The magnitudes of peak total PCB concentrations in the gravity cores followed a spatial distribution generally similar to that of surficial sediment concentrations. The highest concentration at WWD3 $(349 \mu \mathrm{g} / \mathrm{kg})$ was near the mouth of Meandering Road Creek (and at the mouth of TNG Creek), the next highest at WWD1 $(128 \mu \mathrm{g} / \mathrm{kg})$, near the confluence of the three tributary creeks, and the lowest peak concentration at WWD2 $(47.6 \mu \mathrm{g} / \mathrm{kg})$, near the mouth of Gruggs Park Creek.

Total PCB concentrations in suspended and streambed sediment varied greatly among sites and indicated a likely source of PCBs associated with site OF4, which receives runoff from AFP4. The three sites not influenced by AFP4 (GRUGGS, TNG, and UMRC) had five samples in which no PCB congeners were detected and 13 samples in which one or more congeners were detected; total PCB concentration for those 13 samples ranged from 0.54 to $14.8 \mu \mathrm{g} / \mathrm{kg}$. In contrast, the three suspended sediment samples from OF4 contained total PCB concentrations of $81.3,99.2$, and $166 \mu \mathrm{g} / \mathrm{kg}$, with a mean of $116 \mu \mathrm{g} / \mathrm{kg}$. The six samples from LMRC, influenced by flow at UMRC (no AFP4 runoff) and OF4 and other stormwater out- falls from AFP4 (AFP4 runoff), reflected intermediate concentrations that ranged from 17.8 to $103 \mu \mathrm{g} / \mathrm{kg}$.

Three approaches to the analyses of congener assemblages-graphical comparisons of normalized congener concentrations for pattern similarity, a simple measure of difference among congener patterns (root mean squared difference between normalized congener concentrations), and cluster analysis - indicate that PCBs in surficial sediment of Woods Inlet primarily enter Lake Worth from Meandering Road Creek and that runoff from AFP4 is a source of the PCBs in Meandering Road Creek. Although current (2003) transport of PCBs from AFP4 to the creek is occurring as OF4 sample analyses indicate, large decreases in PCB concentrations with decreasing depth in cores WWD3 and WWD1 are evidence that PCB loading to the inlet has decreased greatly since the 1960s. Because runoff entering Meandering Road Creek from some parts of AFP4 was not measured or sampled in this study, it cannot be said with certainty that site OF4 is the only source of PCBs to Meandering Road Creek.

Trace element, PAH, and organochlorine pesticide concentration data from this study are included in the report. However, the data are insufficient to describe the distribution and sources of those constituents in Woods Inlet sediment.

\section{References}

Arbogast, B.F., ed., 1996, Analytical methods manual for the Mineral Resources Surveys Program: U.S. Geological Survey Open-File Report 96-525, 248 p.

Briggs, P.H., and Meier, A.L., 2003, The determination of forty-two elements in geological materials by inductively coupled plasma-mass spectrometry, in Taggart, J.E., Jr., ed., Analytical methods for chemical analysis of geologic and other materials: U.S. Geological Survey Open-File Report 02-223, chap. I, 14 p.

Cacela, Dave, Beltman, D.J., and Lipton, Joshua, 2002, Polychlorinated biphenyl source attribution in Green Bay, Wisconsin, USA, using multivariate similarity among congener profiles in sediment samples: Environmental Toxicology and Chemistry, v. 21, no. 8, p. 1,591-1,599.

Callender, Edward, and Robbins, J.A., 1993, Transport and accumulation of radionuclides and stable elements in a Missouri River reservoir: Water Resources Research, v. 29, no. 6, p. 1,787-1,804.

Colman, J.A., 2000, Source identification and fish exposure for polychlorinated biphenyls using congener analysis from passive water samplers in the Millers River Basin, Massachusetts: U.S. Geological Survey Water-Resources Investigations Report 00-4250, 44 p.

Davis, J.C., 2002, Statistics and data analysis in geology (3d ed.): Wiley, New York, 638 p. 
Harwell, G.R., Van Metre, P.C., Wilson, J.T., and Mahler, B.J., 2003, Spatial distribution and trends in trace elements, polycyclic aromatic hydrocarbons, organochlorine pesticides, and polychlorinated biphenyls in Lake Worth sediment, Fort Worth, Texas: U.S. Geological Survey WaterResources Investigations Report 03-4269, 56 p.

Johnson, G.W., Jarman, W.M., Bacon, C.E., Davis, J.A., Ehrlich, Robert, and Risebrough, R.W., 2000, Resolving polychlorinated biphenyl source fingerprints in suspended particulate matter of San Francisco Bay: Environmental Science and Technology, v. 34, no. 4, p. 552-559.

Mahler, B.J., and Van Metre, P.C., 2003, A simplified approach for monitoring hydrophobic organic contaminants associated with suspended sediments-Methodology and applications: Archives of Environmental Contamination and Toxicology, v. 44, no. 3, p. 288-297.

Moring, J.B., 2002, Data on occurrence of selected trace metals, organochlorines, and semivolatile organic compounds in edible fish tissues from Lake Worth, Fort Worth, Texas, 1999: U.S. Geological Survey Open-File Report 02-016, $23 \mathrm{p}$.

Noriega, M.C., Wydoski, D.S., and Foreman, W.T., 2003, Methods of analysis by the U.S. Geological Survey National Water Quality Laboratory-Determination of organochlorine pesticides and polychlorinated biphenyls in bottom and suspended sediment by gas chromatography with electroncapture detection: U.S. Geological Survey Water-Resources Investigations Report 03-4293, 46 p.
Olson, M.C., Iverson, J.L., Furlong, E.T., and Schroeder, M.P., 2004, Methods of analysis by the U.S. Geological Survey National Water Quality Laboratory-Determination of polycyclic aromatic hydrocarbon compounds in sediment by gas chromatography/mass spectrometry: U.S. Geological Survey Water-Resources Investigations Report 03-4318, 45 p.

Robbins, J.A., and Edgington, D.N., 1976, Determination of recent sedimentation rates in Lake Michigan using ${ }^{210} \mathrm{~Pb}$ and ${ }^{137}$ Cs: Geochimica et Cosmochimica Acta, v. 39, p. 285-304.

Shelton, L.R., and Capel, P.D., 1994, Guidelines for collecting and processing samples of stream bed sediment for analysis of trace element and organic contaminants for the National Water-Quality Assessment Program: U.S. Geological Survey Open-File Report 94-0458, 20 p.

Texas Department of Health, 2004, Fish consumption advisories and bans: accessed March 9, 2004, at http://www.tdh.state.tx.us/bfds/ssd

Van Metre, P.C., Wilson, J.T., Callender, Edward, and Fuller, C.C., 1998, Similar rates of decrease of persistent, hydrophobic and particle-reactive contaminants in riverine systems: Environmental Science and Technology, v. 32, no. 21, p. 3,312-3,317.

Van Metre, P.C., Wilson, J.T., Fuller, C.C., Callender, Edward, and Mahler, B.J., 2004, Collection, analysis, and age-dating of sediment cores from 56 U.S. lakes and reservoirs sampled by the U.S. Geological Survey, 1992-2001: U.S. Geological Survey Scientific Investigations Report 2004-5184, 180 p. 
20 Distribution and Sources of Polychlorinated Biphenyls in Woods Inlet, Lake Worth, Fort Worth, Texas, 2003

Blank Page 
Appendix 1-Core-Specific and Analytical Polychlorinated Biphenyl Data From Core, Surficial Bottom, Suspended, and Streambed Sediment Samples, Woods Inlet and Tributaries, Lake Worth, Fort Worth, Texas 
Blank Page 
Appendix 1.1. Porosity, cesium-137 (137 Cs) activity, mass accumulation rate (MAR), and deposition dates for gravity core samples, Woods Inlet, Lake Worth, Fort Worth, Texas, 2003.

[cm, centimeter; $\mathrm{pCi} / \mathrm{g}$, picocurries per gram; --, not analyzed]

\begin{tabular}{|c|c|c|c|c|c|c|c|}
\hline $\begin{array}{l}\text { Core site and } \\
\text { depth interval } \\
\text { (cm) }\end{array}$ & $\begin{array}{l}\text { Mid- } \\
\text { depth } \\
(\mathrm{cm})\end{array}$ & $\begin{array}{l}\text { Thickness } \\
(\mathrm{cm})\end{array}$ & Porosity & $\begin{array}{l}{ }^{137} \mathrm{Cs} \\
\text { activity } \\
\text { (pCi/g) }\end{array}$ & MAR & $\begin{array}{c}\text { Deposition } \\
\text { date } \\
\text { (year) }\end{array}$ & Comments \\
\hline WWD1 (0-5) & 2.5 & 5 & 0.87 & 0.16 & 0.62 & 2002 & \multirow[b]{12}{*}{ Pre-reservoir surface at $160 \mathrm{~cm}$ (1914) } \\
\hline WWD1 (10-20) & 12.5 & 10 & .81 & .19 & .68 & 1994 & \\
\hline WWD1 (20-30) & 25 & 10 & .80 & .22 & .72 & 1988 & \\
\hline WWD1 (30-40) & 35 & 10 & .79 & .33 & .76 & 1982 & \\
\hline WWD1 (50-60) & 55 & 10 & .77 & .73 & .86 & 1970 & \\
\hline WWD1 (60-70) & 65 & 10 & .78 & 1.36 & .92 & 1964 & \\
\hline WWD1 (70-80) & 75 & 10 & .76 & .74 & .97 & 1959 & \\
\hline WWD1 (80-90) & 85 & 10 & .75 & .13 & 1.03 & 1953 & \\
\hline WWD1 (90-100) & 95 & 10 & .75 & .02 & 1.08 & 1948 & \\
\hline WWD1 (100-110) & 105 & 10 & .73 & .01 & 1.15 & 1942 & \\
\hline WWD1 (150-160) & 155 & 10 & .75 & -.01 & 1.44 & 1920 & \\
\hline WWD1 (160-166) & 163 & 6 & .63 & -- & 1.50 & 1916 & \\
\hline WWD2 (0-5) & 2.5 & 5 & .79 & .12 & .74 & 2002 & \multirow[b]{13}{*}{ Did not penetrate to pre-reservoir surface (1914) } \\
\hline WWD2 (5-10) & 7.5 & 5 & .80 & .18 & .77 & 1999 & \\
\hline WWD2 (10-20) & 15 & 10 & .80 & .20 & .82 & 1994 & \\
\hline WWD2 (20-30) & 25 & 10 & .75 & .23 & .88 & 1988 & \\
\hline WWD2 (30-40) & 35 & 10 & .75 & .34 & .95 & 1982 & \\
\hline WWD2 (40-50) & 45 & 10 & .71 & .32 & 1.03 & 1976 & \\
\hline WWD2 (50-60) & 55 & 10 & .73 & .57 & 1.12 & 1969 & \\
\hline WWD2 (60-70) & 65 & 10 & .74 & 1.04 & 1.19 & 1964 & \\
\hline WWD2 (70-80) & 75 & 10 & .73 & 1.01 & 1.27 & 1959 & \\
\hline WWD2 (150-160) & 155 & 10 & .75 & 0 & 1.91 & 1926 & \\
\hline WWD2 (160-170) & 165 & 10 & .74 & -.01 & 1.98 & 1923 & \\
\hline WWD2 170-180) & 175 & 10 & .76 & -- & 2.08 & 1919 & \\
\hline WWD2 (180-190) & 185 & 10 & .70 & .01 & 2.13 & 1917 & \\
\hline WWD3 (0-5) & 2.5 & 5 & .76 & .09 & .67 & 2001 & \multirow{13}{*}{${ }^{137}$ Cs peak } \\
\hline WWD3 (5-10) & 7.5 & 5 & .65 & -- & .71 & 1996 & \\
\hline WWD3 (10-20) & 15 & 10 & .70 & .09 & .76 & 1988 & \\
\hline WWD3 (20-30) & 25 & 10 & .71 & .23 & .83 & 1979 & \\
\hline WWD3 (30-40) & 35 & 10 & .71 & .37 & .90 & 1971 & \\
\hline WWD3 (40-50) & 45 & 10 & .69 & .80 & .97 & 1964 & \\
\hline WWD3 (50-60) & 55 & 10 & .68 & .65 & 1.03 & 1957 & \\
\hline WWD3 (60-70) & 65 & 10 & .73 & .04 & 1.11 & 1950 & \\
\hline WWD3 (70-80) & 75 & 10 & .69 & .01 & 1.17 & 1944 & \\
\hline WWD3 (80-90) & 85 & 10 & .68 & -.01 & 1.25 & 1938 & \\
\hline WWD3 (90-100) & 95 & 10 & .70 & -- & 1.32 & 1932 & \\
\hline WWD3 (100-110) & 105 & 10 & .69 & .01 & 1.39 & 1927 & \\
\hline WWD3 (110-120) & 115 & 10 & .75 & -- & 1.46 & 1922 & \\
\hline WWD3 (120-130) & 125 & 10 & .61 & -.01 & 1.53 & 1917 & Possible pre-reservoir surface at $124 \mathrm{~cm}$ \\
\hline
\end{tabular}


Appendix 1.2. Selected polychlorinated biphenyl (PCB) Aroclor and PCB congener concentrations in core, surficial bottom, suspended, and streambed sediment samples, Woods Inlet and tributaries, Lake Worth, Fort Worth, Texas, 2003.

[Concentrations in micrograms per kilogram; cm, centimeters; <, nondetection at indicated concentration; E, estimated; dup, duplicate; na, not applicable; env dup, environmental duplicate; lab dup, laboratory duplicate]

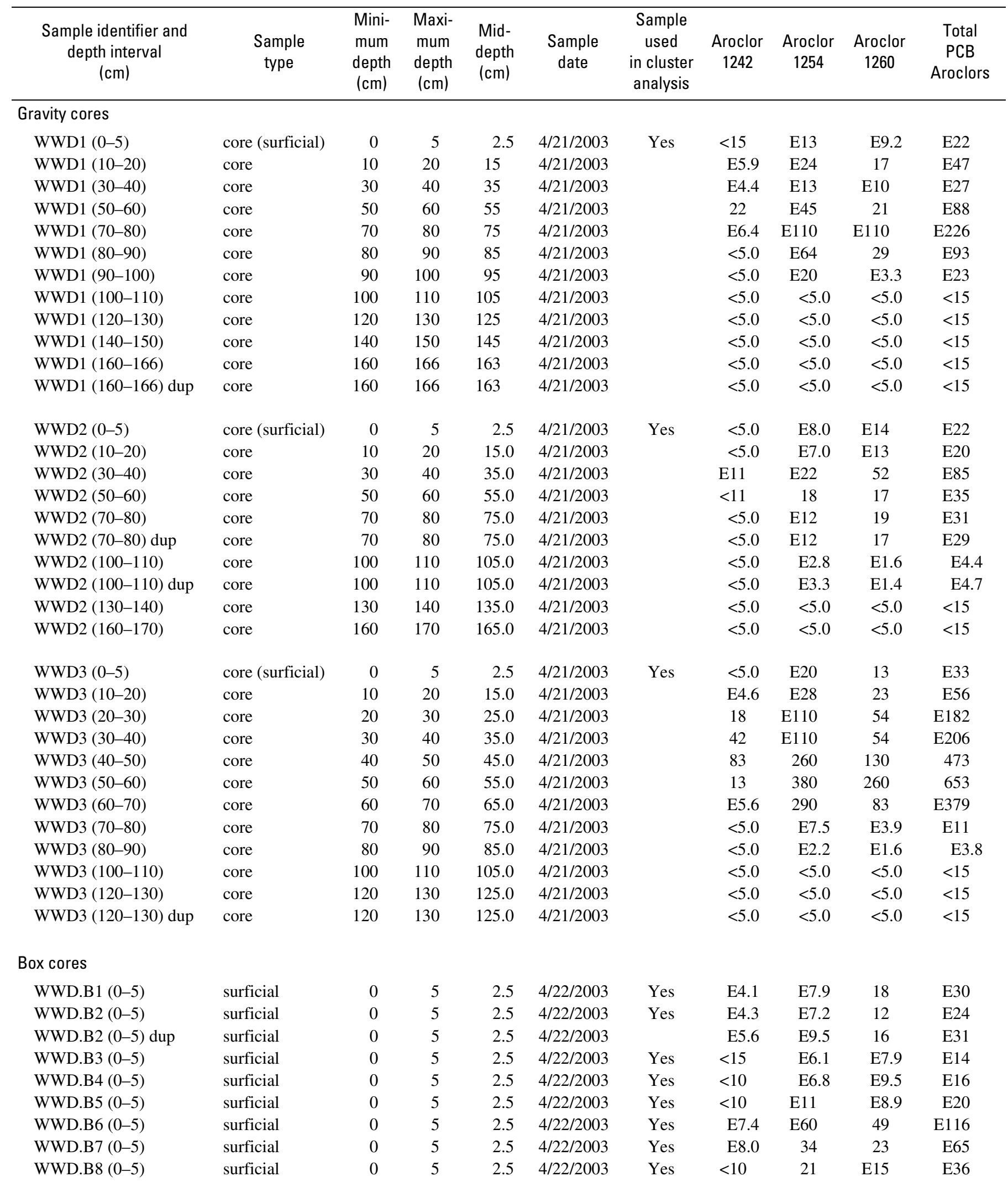


Appendix 1.2. Selected polychlorinated biphenyl (PCB) Aroclor and PCB congener concentrations in core, surficial bottom, suspended, and streambed sediment samples, Woods Inlet and tributaries, Lake Worth, Fort Worth, Texas, 2003—Continued.

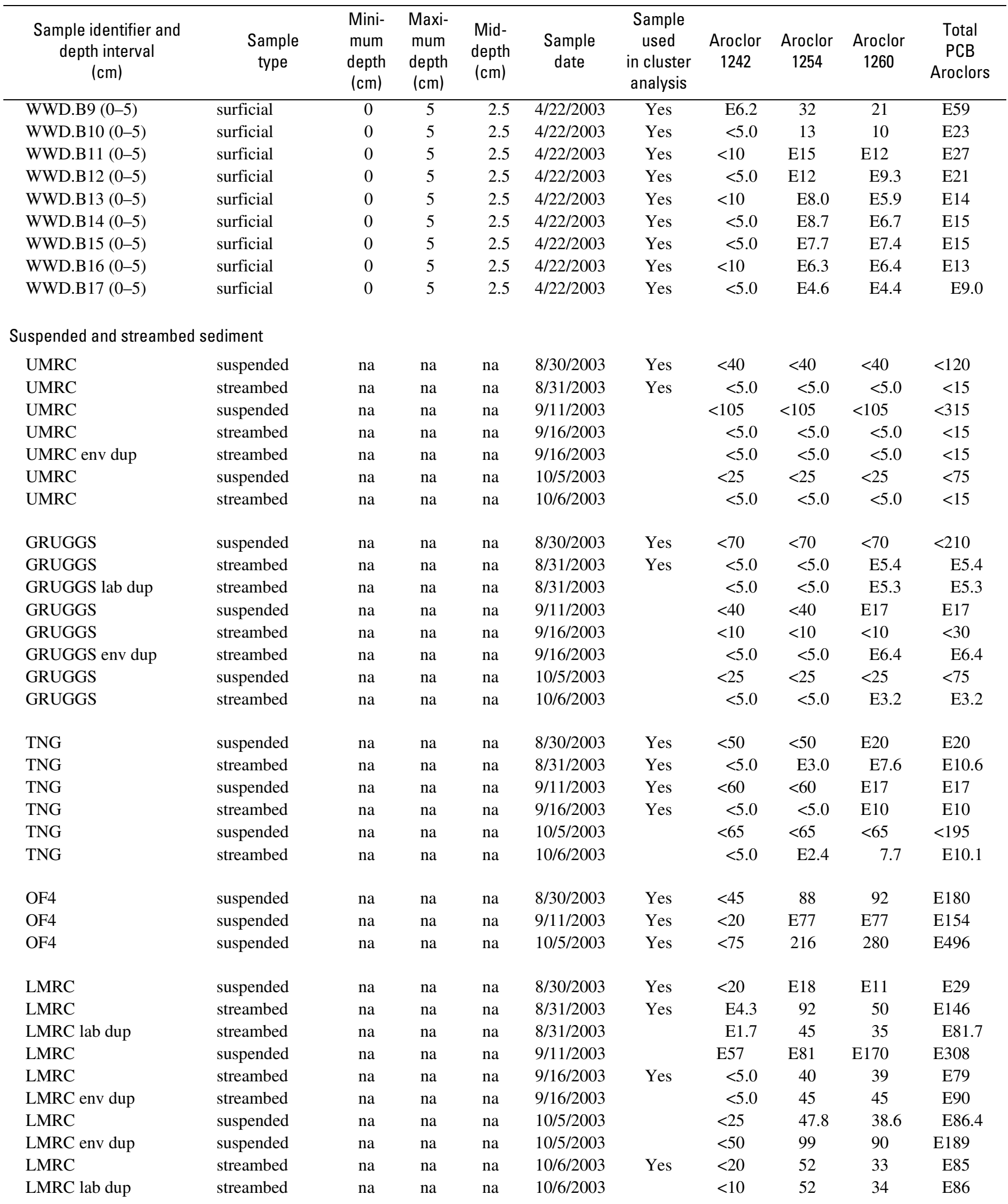


Appendix 1.2. Selected polychlorinated biphenyl (PCB) Aroclor and PCB congener concentrations in core, surficial bottom, suspended, and streambed sediment samples, Woods Inlet and tributaries, Lake Worth, Fort Worth, Texas, 2003—Continued.

\begin{tabular}{|c|c|c|c|c|c|c|c|c|c|c|}
\hline $\begin{array}{l}\text { Sample identifier and } \\
\text { depth interval } \\
\text { (cm) }\end{array}$ & Date & $\begin{array}{l}\text { Sample used } \\
\text { in cluster } \\
\text { analysis }\end{array}$ & PCB 8 & РCB 18 & РCB 22 & PCB 26 & РCB 28 & РСB 31 & РСВ 33 & РCB 44 \\
\hline \multicolumn{11}{|l|}{ Gravity cores } \\
\hline WWD1 (0-5) & $4 / 21 / 2003$ & Yes & $<3.0$ & $<3.0$ & $<3.0$ & $<3.0$ & E0.18 & E0.23 & E0.21 & E0.19 \\
\hline WWD1 (10-20) & $4 / 21 / 2003$ & & E.075 & E.19 & E.090 & E.078 & E.46 & E.36 & E.33 & E.43 \\
\hline WWD1 (30-40) & $4 / 21 / 2003$ & & $<1.0$ & $<1.0$ & $<1.0$ & $<1.0$ & E. 20 & E.15 & E.39 & E. 20 \\
\hline WWD1 (50-60) & $4 / 21 / 2003$ & & E.47 & E.91 & E.11 & $<1.0$ & 1.4 & 1.3 & 1.5 & 1.5 \\
\hline WWD1 (70-80) & $4 / 21 / 2003$ & & $<1.0$ & $<1.0$ & $<1.0$ & $<1.0$ & E.23 & E.47 & E.61 & 1.2 \\
\hline WWD1 (80-90) & $4 / 21 / 2003$ & & $<1.0$ & $<1.0$ & $<1.0$ & $<1.0$ & $<1.0$ & $<1.0$ & E. 55 & E.94 \\
\hline WWD1 (90-100) & $4 / 21 / 2003$ & & $<1.0$ & $<1.0$ & $<1.0$ & $<1.0$ & $<1.0$ & $<1.0$ & E. 25 & E. 30 \\
\hline WWD1 (100-110) & $4 / 21 / 2003$ & & $<1.0$ & $<1.0$ & $<1.0$ & $<1.0$ & $<1.0$ & $<1.0$ & $<1.0$ & $<1.0$ \\
\hline WWD1 (120-130) & $4 / 21 / 2003$ & & $<1.0$ & $<1.0$ & $<1.0$ & $<1.0$ & $<1.0$ & $<1.0$ & $<1.0$ & $<1.0$ \\
\hline WWD1 (140-150) & $4 / 21 / 2003$ & & $<1.0$ & $<1.0$ & $<1.0$ & $<1.0$ & $<1.0$ & $<1.0$ & $<1.0$ & $<1.0$ \\
\hline WWD1 (160-166) & $4 / 21 / 2003$ & & $<1.0$ & $<1.0$ & $<1.0$ & $<1.0$ & $<1.0$ & $<1.0$ & $<1.0$ & $<1.0$ \\
\hline WWD1 (160-166) dup & $4 / 21 / 2003$ & & $<1.0$ & $<1.0$ & $<1.0$ & $<1.0$ & $<1.0$ & $<1.0$ & $<1.0$ & $<1.0$ \\
\hline WWD2 (0-5) & $4 / 21 / 2003$ & Yes & $<1.0$ & $<1.0$ & $<1.0$ & $<1.0$ & E. 31 & E.32 & E.14 & E.26 \\
\hline WWD2 (10-20) & $4 / 21 / 2003$ & & $<1.0$ & $<1.0$ & $<1.0$ & $<1.0$ & $<1.0$ & $<1.0$ & $<1.0$ & E.14 \\
\hline WWD2 (30-40) & $4 / 21 / 2003$ & & $<1.0$ & $<1.0$ & $<1.0$ & $<1.0$ & E.34 & E.17 & $<1.0$ & E.40 \\
\hline WWD2 (50-60) & $4 / 21 / 2003$ & & $<1.0$ & $<1.0$ & $<1.0$ & $<1.0$ & E. 40 & E. 33 & E.62 & E.46 \\
\hline WWD2 (70-80) & $4 / 21 / 2003$ & & $<1.0$ & $<1.0$ & $<1.0$ & $<1.0$ & E.11 & E.10 & E.021 & E.16 \\
\hline WWD2 (70-80) dup & $4 / 21 / 2003$ & & $<1.0$ & $<1.0$ & $<1.0$ & $<1.0$ & E.90 & E.11 & E.0068 & E.14 \\
\hline WWD2 (100-110) & $4 / 21 / 2003$ & & $<1.0$ & $<1.0$ & $<1.0$ & $<1.0$ & $<1.0$ & E.16 & E.015 & E.033 \\
\hline WWD2 (100-110) dup & $4 / 21 / 2003$ & & $<1.0$ & $<1.0$ & $<1.0$ & $<1.0$ & $<1.0$ & E.18 & E.015 & E.039 \\
\hline WWD2 (130-140) & $4 / 21 / 2003$ & & $<1.0$ & $<1.0$ & $<1.0$ & $<1.0$ & $<1.0$ & $<1.0$ & $<1.0$ & $<1.0$ \\
\hline WWD2 (160-170) & $4 / 21 / 2003$ & & $<1.0$ & $<1.0$ & $<1.0$ & $<1.0$ & $<1.0$ & $<1.0$ & $<1.0$ & $<1.0$ \\
\hline WWD3 (0-5) & $4 / 21 / 2003$ & Yes & $<1.0$ & $<1.0$ & $<1.0$ & $<1.0$ & E. 23 & E.18 & $<1.0$ & E. 25 \\
\hline WWD3 (10-20) & $4 / 21 / 2003$ & & $<1.0$ & $<1.0$ & $<1.0$ & $<1.0$ & E. 30 & E. 28 & E.71 & E.44 \\
\hline WWD3 (20-30) & $4 / 21 / 2003$ & & E.74 & E1.4 & E.63 & E. 35 & 1.9 & 2.0 & 1.8 & 2.7 \\
\hline WWD3 (30-40) & $4 / 21 / 2003$ & & E.73 & E1.8 & E. 75 & $<1.0$ & 3.3 & 2.4 & 1.8 & 3.3 \\
\hline WWD3 (40-50) & $4 / 21 / 2003$ & & 1.2 & E5.3 & 2.2 & E.99 & 7.0 & 7.0 & E3.8 & 7.1 \\
\hline WWD3 (50-60) & $4 / 21 / 2003$ & & $<1.0$ & $<1.0$ & $<1.0$ & $<1.0$ & E.68 & 1.3 & E.90 & 3.6 \\
\hline WWD3 (60-70) & $4 / 21 / 2003$ & & $<1.0$ & $<1.0$ & E.92 & $<1.0$ & $<1.0$ & 1.2 & $<1.0$ & 2.8 \\
\hline WWD3 (70-80) & $4 / 21 / 2003$ & & $<1.0$ & $<1.0$ & E.17 & $<1.0$ & $<1.0$ & $\mathrm{E} 2.0$ & $<1.0$ & E.099 \\
\hline WWD3 (80-90) & $4 / 21 / 2003$ & & $<1.0$ & $<1.0$ & $<1.0$ & $<1.0$ & $<1.0$ & $<1.0$ & $<1.0$ & $<1.0$ \\
\hline WWD3 (100-110) & $4 / 21 / 2003$ & & $<1.0$ & $<1.0$ & $<1.0$ & $<1.0$ & $<1.0$ & $<1.0$ & $<1.0$ & $<1.0$ \\
\hline WWD3 (120-130) & $4 / 21 / 2003$ & & $<1.0$ & $<1.0$ & $<1.0$ & $<1.0$ & $<1.0$ & $<1.0$ & $<1.0$ & E.031 \\
\hline WWD3 (120-130) dup & $4 / 21 / 2003$ & & $<1.0$ & $<1.0$ & $<1.0$ & $<1.0$ & $<1.0$ & $<1.0$ & $<1.0$ & E.024 \\
\hline \multicolumn{11}{|l|}{ Box cores } \\
\hline WWD.B1 (0-5) & $4 / 22 / 2003$ & Yes & $<1.0$ & $<1.0$ & $<1.0$ & $<1.0$ & E.33 & E.23 & $<1.0$ & E. 15 \\
\hline WWD.B2 (0-5) & $4 / 22 / 2003$ & Yes & $<1.0$ & $<1.0$ & $<1.0$ & $<1.0$ & E. 34 & E.29 & E.23 & E. 68 \\
\hline WWD.B2 (0-5) dup & $4 / 22 / 2003$ & & $<1.0$ & $<1.0$ & $<1.0$ & $<1.0$ & E.44 & E. 37 & E. 32 & E.33 \\
\hline WWD.B3 (0-5) & $4 / 22 / 2003$ & Yes & $<3.0$ & $<3.0$ & $<3.0$ & $<3.0$ & $<3.0$ & $<3.0$ & $<3.0$ & E. 055 \\
\hline WWD.B4 (0-5) & $4 / 22 / 2003$ & Yes & $<2.0$ & $<2.0$ & $<2.0$ & $<2.0$ & $<2.0$ & $<2.0$ & $<2.0$ & $<2.0$ \\
\hline WWD.B5 (0-5) & $4 / 22 / 2003$ & Yes & $<2.0$ & $<2.0$ & $<2.0$ & $<2.0$ & $<2.0$ & $<2.0$ & $<2.0$ & E.14 \\
\hline WWD.B6 (0-5) & $4 / 22 / 2003$ & Yes & $<1.0$ & $<1.0$ & $<1.0$ & $<1.0$ & E. 55 & E.52 & E.66 & 1.0 \\
\hline WWD.B7 (0-5) & $4 / 22 / 2003$ & Yes & E1.1 & $<2.0$ & $<2.0$ & $<2.0$ & E. 34 & E. 38 & E. 43 & E.64 \\
\hline WWD.B8 (0-5) & $4 / 22 / 2003$ & Yes & $<2.0$ & $<2.0$ & $<2.0$ & $<2.0$ & E.29 & E.36 & E. 23 & E. 43 \\
\hline
\end{tabular}


Appendix 1.2. Selected polychlorinated biphenyl (PCB) Aroclor and PCB congener concentrations in core, surficial bottom, suspended, and streambed sediment samples, Woods Inlet and tributaries, Lake Worth, Fort Worth, Texas, 2003—Continued.

\begin{tabular}{|c|c|c|c|c|c|c|c|c|c|c|}
\hline $\begin{array}{l}\text { Sample identifier and } \\
\text { depth interval } \\
(\mathrm{cm})\end{array}$ & Date & $\begin{array}{l}\text { Sample used } \\
\text { in cluster } \\
\text { analysis }\end{array}$ & PCB 8 & РCB 18 & РСB 22 & РСB 26 & РСB 28 & PCB 31 & РCB 33 & PCB 44 \\
\hline WWD.B9 (0-5) & $4 / 22 / 2003$ & Yes & E0.21 & E0.92 & $<1.0$ & $<1.0$ & E0.59 & E0.61 & E0.30 & E0.69 \\
\hline WWD.B10 (0-5) & $4 / 22 / 2003$ & Yes & $<1.0$ & $<1.0$ & $<1.0$ & $<1.0$ & E.20 & E. 25 & E. 21 & E. 30 \\
\hline WWD.B11 (0-5) & $4 / 22 / 2003$ & Yes & $<2.0$ & $<2.0$ & $<2.0$ & $<2.0$ & E. 25 & E. 30 & E.22 & E.35 \\
\hline WWD.B12 (0-5) & $4 / 22 / 2003$ & Yes & $<1.0$ & $<1.0$ & $<1.0$ & $<1.0$ & E. 28 & E. 28 & Е.077 & E.27 \\
\hline WWD.B13 (0-5) & $4 / 22 / 2003$ & Yes & $<2.0$ & $<2.0$ & $<2.0$ & $<2.0$ & E. 28 & E. 33 & E. 32 & E. 28 \\
\hline WWD.B14 (0-5) & $4 / 22 / 2003$ & Yes & $<1.0$ & $<1.0$ & $<1.0$ & $<1.0$ & $<1.0$ & $<1.0$ & $<1.0$ & E.22 \\
\hline WWD.B15 (0-5) & $4 / 22 / 2003$ & Yes & $<1.0$ & $<1.0$ & $<1.0$ & $<1.0$ & $<1.0$ & $<1.0$ & $<1.0$ & E.13 \\
\hline WWD.B16 (0-5) & $4 / 22 / 2003$ & Yes & $<2.0$ & $<2.0$ & $<2.0$ & $<2.0$ & $<2.0$ & $<2.0$ & $<2.0$ & E.019 \\
\hline WWD.B17 (0-5) & $4 / 22 / 2003$ & Yes & $<1.0$ & $<1.0$ & $<1.0$ & $<1.0$ & $<1.0$ & $<1.0$ & $<1.0$ & E.071 \\
\hline \multicolumn{11}{|c|}{ Suspended and streambed sediment } \\
\hline UMRC & $8 / 30 / 2003$ & Yes & $<8.0$ & $<8.0$ & $<8.0$ & $<8.0$ & $<8.0$ & $<8.0$ & $<8.0$ & $<8.0$ \\
\hline UMRC & $8 / 31 / 2003$ & Yes & $<1.0$ & $<1.0$ & $<1.0$ & $<1.0$ & $<1.0$ & $<1.0$ & $<1.0$ & $<1.0$ \\
\hline UMRC & $9 / 11 / 2003$ & & $<21$ & $<21$ & $<21$ & $<21$ & $<21$ & $<21$ & $<21$ & $<21$ \\
\hline UMRC & $9 / 16 / 2003$ & & $<1.0$ & $<1.0$ & $<1.0$ & $<1.0$ & $<1.0$ & $<1.0$ & $<1.0$ & $<1.0$ \\
\hline UMRC env dup & $9 / 16 / 2003$ & & $<1.0$ & $<1.0$ & $<1.0$ & $<1.0$ & $<1.0$ & $<1.0$ & $<1.0$ & $<1.0$ \\
\hline UMRC & $10 / 5 / 2003$ & & $<5.0$ & $<5.0$ & $<5.0$ & $<5.0$ & $<5.0$ & $<5.0$ & $<5.0$ & $<5.0$ \\
\hline UMRC & $10 / 6 / 2003$ & & $<1.0$ & $<1.0$ & $<1.0$ & $<1.0$ & $<1.0$ & $<1.0$ & $<1.0$ & $<1.0$ \\
\hline GRUGGS & $8 / 30 / 2003$ & Yes & $<14$ & $<14$ & $<14$ & $<14$ & $<14$ & $<14$ & $<14$ & $<14$ \\
\hline GRUGGS & $8 / 31 / 2003$ & Yes & $<1.0$ & $<1.0$ & $<1.0$ & $<1.0$ & $<1.0$ & $<1.0$ & $<1.0$ & $<1.0$ \\
\hline GRUGGS lab dup & $8 / 31 / 2003$ & & $<1.0$ & $<1.0$ & $<1.0$ & $<1.0$ & $<1.0$ & $<1.0$ & $<1.0$ & $<1.0$ \\
\hline GRUGGS & $9 / 11 / 2003$ & & $<8.0$ & $<8.0$ & $<8.0$ & $<8.0$ & $<8.0$ & $<8.0$ & $<8.0$ & $<8.0$ \\
\hline GRUGGS & $9 / 16 / 2003$ & & $<2.0$ & $<2.0$ & $<2.0$ & $<2.0$ & $<2.0$ & $<2.0$ & $<2.0$ & $<2.0$ \\
\hline GRUGGS env dup & $9 / 16 / 2003$ & & $<1.0$ & $<1.0$ & $<1.0$ & $<1.0$ & $<1.0$ & $<1.0$ & $<1.0$ & $<1.0$ \\
\hline GRUGGS & $10 / 5 / 2003$ & & $<5.0$ & $<5.0$ & $<5.0$ & $<5.0$ & $<5.0$ & $<5.0$ & $<5.0$ & $<5.0$ \\
\hline GRUGGS & $10 / 6 / 2003$ & & $<1.0$ & $<1.0$ & $<1.0$ & $<1.0$ & $<1.0$ & $<1.0$ & $<1.0$ & $<1.0$ \\
\hline TNG & $8 / 30 / 2003$ & Yes & $<10$ & $<10$ & $<10$ & $<10$ & $<10$ & $<10$ & $<10$ & $<10$ \\
\hline TNG & $8 / 31 / 2003$ & Yes & $<1.0$ & $<1.0$ & $<1.0$ & $<1.0$ & $<1.0$ & $<1.0$ & $<1.0$ & E.02 \\
\hline TNG & $9 / 11 / 2003$ & Yes & $<12$ & $<12$ & $<12$ & $<12$ & $<12$ & $<12$ & $<12$ & E. 29 \\
\hline TNG & $9 / 16 / 2003$ & Yes & $<1.0$ & $<1.0$ & $<1.0$ & $<1.0$ & $<1.0$ & $<1.0$ & $<1.0$ & $<1.0$ \\
\hline TNG & $10 / 5 / 2003$ & & $<13$ & $<13$ & $<13$ & $<13$ & $<13$ & $<13$ & $<13$ & $<13$ \\
\hline TNG & $10 / 6 / 2003$ & & $<1.0$ & $<1.0$ & $<1.0$ & $<1.0$ & $<1.0$ & $<1.0$ & $<1.0$ & $<1.0$ \\
\hline OF4 & $8 / 30 / 2003$ & Yes & $<9.0$ & $<9.0$ & $<9.0$ & $<9.0$ & $<9.0$ & $<9.0$ & E1.4 & E1.3 \\
\hline $\mathrm{OF} 4$ & $9 / 11 / 2003$ & Yes & $<4.0$ & E. 23 & $<4.0$ & $<4.0$ & E. 58 & E.76 & E.60 & E1.1 \\
\hline OF4 & $10 / 5 / 2003$ & Yes & $<11$ & $<11$ & $<11$ & $<11$ & $<11$ & $<11$ & $<11$ & $<11$ \\
\hline LMRC & $8 / 30 / 2003$ & Yes & $<4.0$ & $<4.0$ & $<4.0$ & $<4.0$ & $<4.0$ & $<4.0$ & $<4.0$ & E.32 \\
\hline LMRC & $8 / 31 / 2003$ & Yes & E. 82 & E.19 & $<1.0$ & $<1.0$ & E. 26 & E. 48 & E.30 & 1.5 \\
\hline LMRC lab dup & $8 / 31 / 2003$ & & $<1.0$ & E.11 & $<1.0$ & $<1.0$ & E.13 & E. 20 & E.10 & E.39 \\
\hline LMRC & $9 / 11 / 2003$ & & $<10$ & $<10$ & E1.3 & E.48 & $<10$ & $<10$ & E.48 & $<10$ \\
\hline LMRC & $9 / 16 / 2003$ & Yes & $<1.0$ & $<1.0$ & $<1.0$ & $<1.0$ & E.12 & E. 20 & E. 10 & E.36 \\
\hline LMRC env dup & $9 / 16 / 2003$ & & $<1.0$ & $<1.0$ & $<1.0$ & $<1.0$ & E.17 & E. 19 & E.13 & E. 40 \\
\hline LMRC & $10 / 5 / 2003$ & & $<10$ & $<10$ & $<10$ & $<10$ & $<10$ & $<10$ & $<10$ & $<10$ \\
\hline LMRC env dup & $10 / 5 / 2003$ & & $<10$ & $<10$ & $<10$ & $<10$ & $<10$ & $<10$ & $<10$ & $<10$ \\
\hline LMRC & $10 / 6 / 2003$ & Yes & $<1.0$ & $<1.0$ & $<1.0$ & $<1.0$ & $<1.0$ & $<1.0$ & $<1.0$ & $<1.0$ \\
\hline LMRC lab dup & $10 / 6 / 2003$ & & $<1.0$ & $<1.0$ & $<1.0$ & $<1.0$ & $<1.0$ & $<1.0$ & $<1.0$ & E.33 \\
\hline
\end{tabular}


Appendix 1.2. Selected polychlorinated biphenyl (PCB) Aroclor and PCB congener concentrations in core, surficial bottom, suspended, and streambed sediment samples, Woods Inlet and tributaries, Lake Worth, Fort Worth, Texas, 2003—Continued.

\begin{tabular}{|c|c|c|c|c|c|c|c|c|c|c|}
\hline $\begin{array}{l}\text { Sample identifier and } \\
\text { depth interval } \\
(\mathrm{cm})\end{array}$ & РСВ 49 & РСВ 52 & РСВ 70 & РСВ 95 & РCВ 101 & РСВ 110 & РСВ 118 & РСВ 138 & PCB 146 & PCB 149 \\
\hline \multicolumn{11}{|l|}{ Gravity cores } \\
\hline WWD1 (0-5) & $<3.0$ & E0.70 & E0.75 & E0.80 & E1.2 & E1.6 & E0.95 & E1.8 & E0.30 & E1.4 \\
\hline WWD1 (10-20) & E.45 & E.90 & 1.1 & 1.0 & 1.4 & 2.5 & 2.7 & 3.2 & E.47 & 1.9 \\
\hline WWD1 (30-40) & E.67 & E.58 & E.54 & E.72 & 1.0 & 1.5 & E. 89 & 1.5 & E.26 & 1.4 \\
\hline WWD1 (70-80) & 2.1 & 3.5 & 3.9 & 5.4 & 9.3 & 14 & E14 & 17 & 2.4 & 12 \\
\hline WWD1 (80-90) & 1.4 & 3.0 & 2.3 & 3.5 & 8.3 & 9.6 & E6.6 & 8.8 & 1.0 & 7.4 \\
\hline WWD1 (90-100) & E.72 & 1.1 & E. 80 & E1.0 & 1.7 & 2.1 & 1.6 & 1.6 & E.15 & 1.2 \\
\hline WWD1 (100-110) & E.036 & E.061 & E.11 & E.064 & E.17 & E. 23 & E.12 & E.14 & E.035 & E.082 \\
\hline WWD1 (120-130) & $<1.0$ & $<1.0$ & $<1.0$ & $<1.0$ & $<1.0$ & $<1.0$ & $<1.0$ & $<1.0$ & $<1.0$ & $<1.0$ \\
\hline WWD2 (0-5) & E. 20 & E.54 & E.71 & E.69 & 1.1 & 1.1 & E.59 & 1.8 & E.16 & 1.4 \\
\hline WWD2 (10-20) & E.14 & E.32 & E. 38 & E.44 & E. 88 & E.89 & E. 55 & 1.6 & E.16 & 1.1 \\
\hline WWD2 (30-40) & E.74 & 1.1 & E. 85 & 1.6 & 2.9 & 2.8 & 1.6 & 7.0 & 1.0 & 7.2 \\
\hline WWD2 (50-60) & E.62 & 1.1 & 1.1 & 1.2 & 1.6 & 2.2 & 1.2 & 2.7 & E.45 & 2.2 \\
\hline WWD2 (70-80) & E.31 & E.51 & E.62 & E.78 & 1.1 & 1.7 & E.74 & 2.3 & E.47 & 2.1 \\
\hline WWD2 (70-80) dup & E.26 & E.49 & E.55 & E.70 & 1.2 & 1.6 & E.64 & 2.1 & E. 42 & 1.9 \\
\hline WWD2 (100-110) & E. 15 & E.16 & E. 23 & E.18 & E. 30 & E. 37 & E.17 & E.37 & E.070 & E. 26 \\
\hline WWD2 (100-110) dup & E.11 & E.17 & E. 21 & E.19 & E. 28 & E.44 & E.18 & E.40 & E.074 & E. 27 \\
\hline WWD2 (130-140) & $<1.0$ & $<1.0$ & $<1.0$ & $<1.0$ & $<1.0$ & $<1.0$ & $<1.0$ & $<1.0$ & $<1.0$ & $<1.0$ \\
\hline WWD3 (50-60) & 3.9 & 16 & E12 & 18 & 32 & 42 & 29 & 50 & 6.6 & 39 \\
\hline WWD3 (60-70) & 3.2 & 13 & E9.4 & 14 & 24 & 32 & E23 & 30 & 3.1 & 22 \\
\hline WWD3 (70-80) & E.21 & E.44 & E. 32 & E. 42 & E.78 & E. 86 & E.61 & E.75 & E.034 & E.60 \\
\hline WWD3 (80-90) & $<1.0$ & E.097 & E.085 & E.065 & E.22 & E.27 & E.17 & E. 31 & $<1.0$ & E.16 \\
\hline WWD3 (100-110) & $<1.0$ & E.048 & $<1.0$ & E. 025 & E.16 & E. 20 & E.10 & E.18 & $<1.0$ & E.12 \\
\hline WWD3 (120-130) & E.030 & E.26 & $<1.0$ & E.080 & E.15 & E.19 & $<1.0$ & $<1.0$ & $<1.0$ & E.025 \\
\hline WWD3 (120-130) dup & E.029 & E. 21 & $<1.0$ & E.060 & E.12 & E.16 & $<1.0$ & $<1.0$ & $<1.0$ & E.021 \\
\hline \multicolumn{11}{|l|}{ Box cores } \\
\hline WWD.B1 (0-5) & E.43 & E.30 & E.58 & E.61 & E.73 & E.94 & E.60 & 2.4 & E.24 & 1.6 \\
\hline WWD.B2 (0-5) & E. 48 & E.56 & E. 58 & E.89 & E.89 & E.92 & E.54 & 1.8 & E.072 & 1.2 \\
\hline WWD.B2 (0-5) dup & E1.0 & E.75 & E.72 & E.82 & E.90 & 1.3 & E.69 & 2.2 & E.14 & 1.5 \\
\hline WWD.B3 (0-5) & $<3.0$ & E.26 & E.42 & E. 21 & E.64 & E.93 & E.51 & E1.2 & E.23 & E1.0 \\
\hline WWD.B4 (0-5) & $<2.0$ & E.24 & $<2.0$ & E.2 & E.55 & E1.1 & E. 48 & E1.2 & $<2.0$ & E.95 \\
\hline WWD.B5 (0-5) & $<2.0$ & E.48 & E.55 & E.62 & E.90 & E1.3 & E.71 & E1.6 & E.087 & E1.0 \\
\hline WWD.B6 (0-5) & 1.1 & 2.7 & 2.0 & 3.3 & 5.6 & 9.5 & 5.3 & 12 & 1.3 & 7.4 \\
\hline WWD.B7 (0-5) & E.97 & 2.0 & E1.4 & E1.4 & 2.6 & 4.5 & 2.6 & E5.6 & E.63 & 3.3 \\
\hline WWD.B8 (0-5) & E. 30 & E1.2 & E1.0 & E1.3 & E1.9 & 2.7 & E1.7 & 3.2 & E. 25 & 2.2 \\
\hline
\end{tabular}


Appendix 1.2. Selected polychlorinated biphenyl (PCB) Aroclor and PCB congener concentrations in core, surficial bottom, suspended, and streambed sediment samples, Woods Inlet and tributaries, Lake Worth, Fort Worth, Texas, 2003—Continued.

\begin{tabular}{|c|c|c|c|c|c|c|c|c|c|c|}
\hline $\begin{array}{l}\text { Sample identifier and } \\
\text { depth interval } \\
(\mathrm{cm})\end{array}$ & РСВ 49 & РСВ 52 & РСВ 70 & РСВ 95 & РСB 101 & РCB 110 & РСB 118 & РСB 138 & РCB 146 & РСВ 149 \\
\hline WWD.B9 $(0-5)$ & E0.72 & 1.8 & 1.4 & 1.9 & 2.7 & 3.9 & 2.5 & E4.5 & E0.59 & 2.9 \\
\hline WWD.B10 (0-5) & E.26 & E.69 & E.60 & E.69 & 1.1 & 1.6 & E.99 & 2.0 & E. 25 & 1.5 \\
\hline WWD.B11 (0-5) & E.33 & E. 85 & E.74 & E. 80 & E1.2 & E1.9 & E1.3 & 2.2 & E.30 & E1.6 \\
\hline WWD.B12 (0-5) & E.23 & E.66 & E.62 & E.71 & 1.0 & 1.4 & E. 86 & 1.7 & E. 24 & 1.3 \\
\hline WWD.B13 (0-5) & E. 20 & E.53 & E.63 & E.50 & E.79 & E.99 & E. 58 & E1.1 & E.14 & E.79 \\
\hline WWD.B14 (0-5) & $<1.0$ & E.40 & E.44 & E.45 & E.92 & 1.0 & E.64 & 1.2 & E.16 & E.96 \\
\hline WWD.B15 (0-5) & $<1.0$ & E.35 & E.36 & E.34 & E.79 & E.94 & E.57 & 1.2 & E.16 & E.91 \\
\hline WWD.B16 (0-5) & $<2.0$ & E.26 & E.41 & E.27 & E.49 & E.79 & E.51 & E.75 & E.032 & E.66 \\
\hline WWD.B17 (0-5) & $<1.0$ & E. 21 & E. 24 & E.16 & E. 47 & E.61 & E. 32 & .72 & E.062 & E.55 \\
\hline \multicolumn{11}{|c|}{ Suspended and streambed sediment } \\
\hline UMRC & $<8.0$ & E.19 & E.73 & E. 31 & E.14 & E. 60 & E. 31 & E. 82 & $<8.0$ & E.62 \\
\hline UMRC & $<1.0$ & $<1.0$ & E.13 & E.04 & E.01 & E.09 & E.06 & E.16 & $<1.0$ & E.08 \\
\hline UMRC & $<21$ & $<21$ & $<21$ & $<21$ & $<21$ & $<21$ & $<21$ & $<21$ & $<21$ & $<21$ \\
\hline UMRC & $<1.0$ & $<1.0$ & $<1.0$ & $<1.0$ & E.09 & E.07 & E. 23 & $<1.0$ & E. 10 & $<1.0$ \\
\hline UMRC env dup & $<1.0$ & $<1.0$ & $<1.0$ & $<1.0$ & $<1.0$ & E.07 & E.06 & E.10 & $<1.0$ & E.06 \\
\hline UMRC & $<5.0$ & $<5.0$ & $<5.0$ & $<5.0$ & $<5.0$ & $<5.0$ & $<5.0$ & $<5.0$ & $<5.0$ & $<5.0$ \\
\hline UMRC & $<1.0$ & $<1.0$ & $<1.0$ & $<1.0$ & $<1.0$ & $<1.0$ & $<1.0$ & $<1.0$ & $<1.0$ & $<1.0$ \\
\hline GRUGGS & $<14$ & E.34 & E.92 & E.47 & E.10 & E1.1 & E.50 & E.91 & $<14$ & E.60 \\
\hline GRUGGS & $<1.0$ & E. 12 & $<1.0$ & E.20 & E. 21 & E. 37 & E. 20 & E.66 & E.06 & E.44 \\
\hline GRUGGS lab dup & $<1.0$ & E.10 & $<1.0$ & E. 20 & E.14 & E.33 & E.17 & E.63 & E.08 & E.42 \\
\hline GRUGGS & $<8.0$ & $<8.0$ & $<8.0$ & $<8.0$ & $<8.0$ & $<8.0$ & $<8.0$ & E.78 & E. 53 & E.70 \\
\hline GRUGGS & $<2.0$ & $<2.0$ & $<2.0$ & $<2.0$ & E.02 & E.16 & E.12 & E.63 & E.05 & E.17 \\
\hline GRUGGS env dup & $<1.0$ & $<1.0$ & $<1.0$ & $<1.0$ & E.07 & E. 33 & E. 22 & E.91 & E. 12 & E.43 \\
\hline GRUGGS & $<5.0$ & $<5.0$ & $<5.0$ & $<5.0$ & $<5.0$ & $<5.0$ & $<5.0$ & $<5.0$ & $<5.0$ & $<5.0$ \\
\hline GRUGGS & $<1.0$ & $<1.0$ & $<1.0$ & $<1.0$ & $<1.0$ & $<1.0$ & $<1.0$ & E. 24 & E.16 & $<1.0$ \\
\hline TNG & $<10$ & $<10$ & E.69 & E.34 & E. 15 & E. 86 & E. 50 & E1.1 & E.14 & E.78 \\
\hline TNG & $<1.0$ & E.08 & $<1.0$ & E.20 & E. 30 & E.46 & E. 20 & E.46 & E.08 & E.34 \\
\hline TNG & $<12$ & E.53 & $<12$ & $<12$ & E.30 & E1.4 & E1.4 & E1.6 & E.08 & E1.5 \\
\hline TNG & $<1.0$ & $<1.0$ & $<1.0$ & $<1.0$ & E.04 & E.20 & E.14 & E.59 & E. 10 & E.38 \\
\hline TNG & $<13$ & $<13$ & $<13$ & $<13$ & $<13$ & $<13$ & $<13$ & $<13$ & $<13$ & $<13$ \\
\hline TNG & $<1.0$ & $<1.0$ & $<1.0$ & $<1.0$ & $<1.0$ & $<1.0$ & $<1.0$ & E. 34 & $<1.0$ & $<1.0$ \\
\hline OF4 & E.75 & E1.6 & E2.6 & E3.8 & E5.1 & 9.7 & E8.0 & 17 & E2.4 & E8.4 \\
\hline OF4 & E.60 & E1.8 & E2.3 & E3.5 & E4.5 & E8.3 & E6.4 & E13 & E2.1 & E7.1 \\
\hline OF4 & $<11$ & E6.6 & $<11$ & $<11$ & 14 & 18 & E4.4 & 28 & E3.4 & 14 \\
\hline LMRC & E. 16 & E. 60 & E. 76 & E1.2 & E1.2 & E2.2 & E1.3 & E2.8 & E. 36 & E1.6 \\
\hline LMRC & 1.0 & 3.8 & 2.8 & E7.9 & E9.6 & E14 & E7.3 & E16 & 2.2 & E12 \\
\hline LMRC lab dup & E. 33 & 1.1 & E. 70 & 2.4 & 3.2 & 6.0 & 3.0 & E10 & 1.1 & 4.9 \\
\hline LMRC & E.21 & E1.8 & E1.8 & $<10$ & $<10$ & E3.6 & E. 38 & E12 & $<10$ & E.16 \\
\hline LMRC & E.30 & E.97 & E.62 & 2.2 & 2.6 & 5.5 & 2.5 & E10 & 1.3 & 5.0 \\
\hline LMRC env dup & E.34 & 1.1 & E.77 & 2.4 & 2.9 & 6.4 & 2.9 & E12 & 1.4 & 6.0 \\
\hline LMRC & $<10$ & $<10$ & $<10$ & $<10$ & E3.9 & E9.2 & E1.9 & E14 & E.26 & $<10$ \\
\hline LMRC env dup & $<10$ & $<10$ & $<10$ & $<10$ & E3.9 & E9.2 & E1.9 & E14 & E. 26 & $<10$ \\
\hline LMRC & E.18 & 1.3 & 2.8 & $<1.0$ & 3.2 & 4.9 & E.67 & E7.9 & 1.2 & 4.4 \\
\hline LMRC lab dup & E.19 & E.48 & 1.0 & $<1.0$ & 1.1 & 5.0 & 1.0 & E8.2 & 1.2 & 4.9 \\
\hline
\end{tabular}


Appendix 1.2. Selected polychlorinated biphenyl (PCB) Aroclor and PCB congener concentrations in core, surficial bottom, suspended, and streambed sediment samples, Woods Inlet and tributaries, Lake Worth, Fort Worth, Texas, 2003—Continued.

\begin{tabular}{|c|c|c|c|c|c|c|c|c|c|c|}
\hline $\begin{array}{l}\text { Sample identifier and } \\
\text { depth interval } \\
(\mathrm{cm})\end{array}$ & $\begin{array}{c}\text { PCB } \\
151\end{array}$ & $\begin{array}{c}\text { PCB } \\
170\end{array}$ & $\begin{array}{c}\text { PCB } \\
174\end{array}$ & $\begin{array}{c}\text { PCB } \\
177\end{array}$ & $\begin{array}{c}\text { PCB } \\
180\end{array}$ & $\begin{array}{c}\text { PCB } \\
183\end{array}$ & $\begin{array}{c}\text { PCB } \\
187\end{array}$ & $\begin{array}{c}\text { PCB } \\
194\end{array}$ & $\begin{array}{l}\text { PCB } \\
206\end{array}$ & $\begin{array}{l}\text { Total PCB } \\
\text { congeners }\end{array}$ \\
\hline \multicolumn{11}{|l|}{ Gravity cores } \\
\hline WWD1 (0-5) & E0.51 & E0.63 & E0.59 & E0.13 & E0.67 & E0.22 & E0.52 & E0.31 & $<0.12$ & 13.9 \\
\hline WWD1 (10-20) & E.40 & 1.3 & E.63 & E. 37 & 1.5 & E.47 & E.79 & E.97 & E.51 & 24.6 \\
\hline WWD1 (30-40) & E.43 & E.73 & E. 44 & E.22 & E.73 & E.22 & E.69 & E. 33 & $<.19$ & 13.8 \\
\hline WWD1 (50-60) & E.68 & E.95 & 1.0 & E.55 & 1.6 & E.66 & 1.3 & E.62 & E.38 & 49.2 \\
\hline WWD1 (70-80) & 2.5 & E7.2 & 4.5 & 2.4 & E9.5 & 2.4 & 5.4 & E6.5 & E1.9 & 128 \\
\hline WWD1 (80-90) & 1.3 & 1.4 & 1.5 & E. 85 & 2.3 & E.96 & 1.7 & E.64 & E.32 & 64.4 \\
\hline WWD1 (90-100) & E.40 & E.25 & E.16 & E.048 & E.24 & E.10 & E. 24 & E.084 & $<.11$ & 14.0 \\
\hline WWD1 (100-110) & E.087 & E.16 & E.028 & $<1.0$ & E.092 & $<1.0$ & E.088 & $<1.0$ & $<.12$ & 1.50 \\
\hline WWD1 (120-130) & $<1.0$ & $<1.0$ & $<1.0$ & $<1.0$ & $<1.0$ & $<1.0$ & $<1.0$ & $<1.0$ & $<1.0$ & 0 \\
\hline WWD1 (140-150) & $<1.0$ & $<1.0$ & $<1.0$ & $<1.0$ & $<1.0$ & $<1.0$ & $<1.0$ & $<1.0$ & $<.21$ & 0 \\
\hline WWD1 (160-166) & $<1.0$ & $<1.0$ & $<1.0$ & $<1.0$ & $<1.0$ & $<1.0$ & $<1.0$ & $<1.0$ & $<.18$ & 0 \\
\hline WWD1 (160-166) dup & $<1.0$ & $<1.0$ & $<1.0$ & $<1.0$ & $<1.0$ & $<1.0$ & $<1.0$ & $<1.0$ & $<.12$ & 0 \\
\hline WWD2 (0-5) & E.60 & E.72 & E.79 & E. 31 & 1.1 & E. 35 & E.79 & E.48 & E.23 & 14.7 \\
\hline WWD2 (10-20) & E.51 & E.65 & E.67 & E.39 & E.97 & E.38 & E.81 & E.37 & $<.19$ & 11.4 \\
\hline WWD2 (30-40) & 1.8 & 3.0 & 2.9 & E.78 & 4.8 & 1.6 & 3.3 & 1.4 & E. 34 & 47.6 \\
\hline WWD2 (50-60) & E.95 & E.76 & E. 83 & E.47 & 1.2 & E.53 & 1.1 & E.56 & E. 32 & 22.9 \\
\hline WWD2 (70-80) & E.74 & E. 82 & E.98 & E.56 & 1.5 & E.49 & 1.3 & E.63 & E.39 & 18.4 \\
\hline WWD2 (70-80) dup & E.64 & E.69 & E. 82 & E.36 & 1.3 & E.51 & 1.1 & E.64 & E. 33 & 17.4 \\
\hline WWD2 (100-110) & E.12 & E.095 & E.078 & E.026 & E.078 & E.024 & E.017 & E.053 & $<.14$ & 2.96 \\
\hline WWD2 (100-110) dup & E.15 & E.085 & E.076 & Е.0058 & E.069 & E.024 & E.033 & E.050 & $<.12$ & 3.05 \\
\hline WWD2 (130-140) & $<1.0$ & $<1.0$ & $<1.0$ & $<1.0$ & $<1.0$ & $<1.0$ & $<1.0$ & $<1.0$ & $<.047$ & 0 \\
\hline WWD2 (160-170) & $<1.0$ & $<1.0$ & $<1.0$ & $<1.0$ & $<1.0$ & $<1.0$ & $<1.0$ & $<1.0$ & $<.0021$ & 0 \\
\hline WWD3 (0-5) & E.71 & E.68 & E.68 & E. 34 & 1.1 & E.42 & E.78 & E.53 & E.26 & 20.7 \\
\hline WWD3 (10-20) & E.71 & 1.1 & 1.1 & E.63 & 1.8 & E.75 & 1.4 & E.74 & E1.0 & 32.5 \\
\hline WWD3 (20-30) & 2.1 & 3.0 & 2.9 & 1.5 & 5.5 & 1.7 & 3.3 & 1.5 & E.67 & 135 \\
\hline WWD3 (30-40) & 2.1 & 3.0 & 3.0 & 1.6 & 4.6 & 1.8 & 3.5 & 1.6 & E1.0 & 141 \\
\hline WWD3 (40-50) & 3.7 & 5.7 & 5.9 & 2.8 & 10 & 3.7 & 7.5 & 3.1 & E1.6 & 251 \\
\hline WWD3 (50-60) & 8.9 & 12 & 13 & 6.8 & 21 & 7.6 & 15 & 7.5 & E1.8 & 349 \\
\hline WWD3 (60-70) & 3.4 & 4 & 3.9 & 1.8 & 6.5 & 3.2 & 3.7 & 1.1 & E.44 & 207 \\
\hline WWD3 (70-80) & E. 23 & E.27 & E.17 & E.041 & E. 23 & E.10 & E. 20 & E.17 & E.28 & 8.98 \\
\hline WWD3 (80-90) & E.084 & E.11 & E.053 & E.045 & E.088 & $<1.0$ & E.10 & E.054 & $<.098$ & 1.91 \\
\hline WWD3 (100-110) & E.064 & E.089 & $<1.0$ & $<1.0$ & E.087 & $<1.0$ & $<1.0$ & E.021 & $<.0090$ & 1.09 \\
\hline WWD3 (120-130) & $<1.0$ & $<1.0$ & $<1.0$ & $<1.0$ & $<1.0$ & $<1.0$ & $<1.0$ & $<1.0$ & $<.012$ & .77 \\
\hline WWD3 (120-130) dup & $<1.0$ & $<1.0$ & $<1.0$ & $<1.0$ & $<1.0$ & $<1.0$ & $<1.0$ & $<1.0$ & $<1.0$ & .62 \\
\hline \multicolumn{11}{|l|}{ Box cores } \\
\hline WWD.B1 (0-5) & E.73 & E.93 & E.87 & E.52 & 1.5 & E.47 & 1.0 & E.51 & E.26 & 15.9 \\
\hline WWD.B2 (0-5) & E.62 & E.85 & E.69 & E.39 & 1.0 & E.43 & E.81 & E.36 & E.26 & 14.9 \\
\hline WWD.B2 (0-5) dup & E.73 & E.73 & E.77 & E.47 & 1.2 & E.53 & E.96 & E.36 & $<.15$ & 17.2 \\
\hline WWD.B3 (0-5) & E.30 & E.78 & E. 33 & E.18 & E.46 & E.17 & E.38 & $<3.0$ & $<3.0$ & 8.06 \\
\hline WWD.B4 (0-5) & E.32 & E.62 & E.42 & E.17 & E.67 & E.17 & E.52 & E. 28 & E.20 & 8.09 \\
\hline WWD.B5 (0-5) & E.42 & E.58 & E.41 & E.15 & E. 23 & E.63 & E.49 & E. 30 & E.27 & 10.9 \\
\hline WWD.B6 (0-5) & 1.5 & 3.0 & 2.6 & 1.3 & 5.4 & 1.6 & 2.8 & 1.9 & E.74 & 73.8 \\
\hline WWD.B7 (0-5) & E.91 & E1.1 & E1.2 & E.64 & E1.8 & E.83 & E1.3 & E.63 & E. 31 & 36.7 \\
\hline WWD.B8 (0-5) & E. 82 & E1.0 & E.79 & E. 32 & E1.1 & E.52 & E.82 & E. 48 & $<.20$ & 22.9 \\
\hline
\end{tabular}


Appendix 1.2. Selected polychlorinated biphenyl (PCB) Aroclor and PCB congener concentrations in core, surficial bottom, suspended, and streambed sediment samples, Woods Inlet and tributaries, Lake Worth, Fort Worth, Texas, 2003—Continued.

\begin{tabular}{|c|c|c|c|c|c|c|c|c|c|c|}
\hline $\begin{array}{l}\text { Sample identifier and } \\
\text { depth interval } \\
(\mathrm{cm})\end{array}$ & $\begin{array}{l}\text { PCB } \\
151\end{array}$ & $\begin{array}{l}\text { PCB } \\
170\end{array}$ & $\begin{array}{l}\text { PCB } \\
174\end{array}$ & $\begin{array}{l}\text { PCB } \\
177\end{array}$ & $\begin{array}{c}\text { PCB } \\
180\end{array}$ & $\begin{array}{l}\text { PCB } \\
183\end{array}$ & $\begin{array}{l}\text { PCB } \\
187\end{array}$ & $\begin{array}{l}\text { PCB } \\
194\end{array}$ & $\begin{array}{l}\text { PCB } \\
206\end{array}$ & $\begin{array}{l}\text { Total PCB } \\
\text { congeners }\end{array}$ \\
\hline WWD.B9 (0-5) & E0.71 & 1.0 & 1.0 & E0.53 & 1.6 & E0.67 & 1.2 & E0.73 & E0.32 & 34.0 \\
\hline WWD.B10 (0-5) & E.54 & E.53 & E.53 & E.22 & E.78 & E. 28 & E. 58 & E. 33 & E.22 & 14.7 \\
\hline WWD.B11 (0-5) & E.60 & E.59 & E.65 & E. 25 & E.92 & E.32 & E.64 & E. 38 & E. 24 & 16.9 \\
\hline WWD.B12 (0-5) & E.52 & E.47 & E.46 & E.21 & E.69 & E.26 & E.52 & E.30 & E. 20 & 13.2 \\
\hline WWD.B13 (0-5) & E.33 & E.35 & E. 40 & E.099 & E.42 & E.15 & E.34 & E. 26 & E.23 & 10.0 \\
\hline WWD.B14 (0-5) & E.36 & E. 38 & E.42 & E.12 & E.50 & E.17 & E. 38 & E. 28 & $<.15$ & 9.00 \\
\hline WWD.B15 (0-5) & E.39 & E.35 & E.32 & E.12 & E.61 & E.17 & E.39 & E.18 & E.22 & 8.50 \\
\hline WWD.B16 (0-5) & E.22 & E.46 & E. 25 & E.087 & E.46 & E.12 & E.33 & E.23 & E.19 & 6.54 \\
\hline WWD.B17 (0-5) & E.22 & E. 26 & E. 20 & E.072 & E. 10 & E.097 & E.22 & E.17 & $<.090$ & 4.75 \\
\hline \multicolumn{11}{|c|}{ Suspended and streambed sediment } \\
\hline UMRC & E.47 & E.57 & E.17 & E.34 & E.50 & E.18 & E.28 & $<8.0$ & $<.18$ & 6.23 \\
\hline UMRC & E.05 & E.09 & E.04 & E.05 & E.09 & E.03 & E.05 & E.06 & $<.03$ & 1.03 \\
\hline UMRC & $<21$ & $<21$ & $<21$ & $<21$ & $<21$ & $<21$ & $<21$ & $<21$ & $<21$ & 0 \\
\hline UMRC & $<1.0$ & $<1.0$ & $<1.0$ & $<1.0$ & $<1.0$ & $<1.0$ & E.05 & $<1.0$ & $<1.0$ & .54 \\
\hline UMRC env dup & E.05 & E.07 & E.02 & $<1.0$ & E.08 & E.02 & E.03 & E.04 & $<.03$ & .60 \\
\hline UMRC & $<5.0$ & $<5.0$ & $<5.0$ & $<5.0$ & $<5.0$ & $<5.0$ & $<5.0$ & $<5.0$ & $<5.0$ & 0 \\
\hline UMRC & $<1.0$ & $<1.0$ & $<1.0$ & $<1.0$ & $<1.0$ & $<1.0$ & $<1.0$ & $<1.0$ & $<1.0$ & 0 \\
\hline GRUGGS & E.60 & E.54 & E.03 & E. 50 & E. 52 & E.17 & E.15 & $<14$ & $<.25$ & 7.45 \\
\hline GRUGGS & E. 20 & E.39 & E.24 & E.21 & E.51 & E.16 & E.33 & E. 28 & $<.05$ & 4.58 \\
\hline GRUGGS lab dup & E.19 & E.41 & E.22 & E.23 & E.53 & E.14 & E.31 & E. 20 & $<.05$ & 4.30 \\
\hline GRUGGS & $<8.0$ & E. 55 & $<8.0$ & $<8.0$ & E. 83 & $<8.0$ & E.62 & E.47 & $<8.0$ & 4.48 \\
\hline GRUGGS & E.08 & E. 25 & E.09 & E.04 & E. 33 & E.11 & E.18 & $<2.0$ & $<2.0$ & 2.23 \\
\hline GRUGGS env dup & E.02 & E. 55 & E. 26 & E.19 & E.66 & E.16 & E. 35 & E. 27 & $<.12$ & 4.54 \\
\hline GRUGGS & $<5.0$ & $<5.0$ & $<5.0$ & $<5.0$ & $<5.0$ & $<5.0$ & $<5.0$ & $<5.0$ & $<5.0$ & 0 \\
\hline GRUGGS & $<1.0$ & $<1.0$ & $<1.0$ & $<1.0$ & E. 24 & $<1.0$ & E.13 & E. 33 & $<1.0$ & 1.10 \\
\hline TNG & E.53 & E1.9 & E.50 & E.53 & E1.5 & E.44 & E1.0 & E1.6 & $<1.4$ & 12.6 \\
\hline TNG & E. 30 & E. 25 & E. 33 & E.19 & E.61 & E.19 & E. 56 & E. 32 & $<.44$ & 4.89 \\
\hline TNG & E.30 & E2.2 & E.38 & E.19 & E1.9 & E.62 & E.95 & E1.2 & $<1.6$ & 14.8 \\
\hline TNG & E.08 & E. 31 & E.44 & E. 20 & E. 89 & E.25 & E.78 & E. 40 & $<.56$ & 4.80 \\
\hline TNG & $<13$ & $<13$ & $<13$ & $<13$ & $<13$ & $<13$ & $<13$ & $<13$ & $<13$ & 0 \\
\hline TNG & $<1.0$ & E.17 & E.10 & $<1.0$ & E.54 & $<1.0$ & E.46 & E. 27 & E.40 & 2.28 \\
\hline OF4 & E3.5 & E5.4 & E4.5 & E2.4 & 9.9 & E3.4 & E5.3 & E2.8 & $<.16$ & 99.2 \\
\hline OF4 & E1.5 & E4.2 & E3.2 & E2.0 & E8.8 & E2.2 & E4.4 & E2.1 & $<1.0$ & 81.3 \\
\hline OF4 & E4.4 & 12 & E10 & E5.4 & 24 & E5.0 & 13 & E3.4 & $<11$ & 166 \\
\hline LMRC & E.62 & E.96 & E.44 & E.42 & E1.2 & E.38 & E.63 & E.66 & $<.21$ & 17.8 \\
\hline LMRC & 2.1 & 3.2 & 2.7 & 1.6 & E6.2 & 1.8 & 3.0 & 1.2 & E.68 & 103 \\
\hline LMRC lab dup & 1.2 & 1.9 & 1.7 & 1.0 & 4.0 & 1.1 & 2.2 & E. 85 & E.48 & 48.1 \\
\hline LMRC & $<10$ & E8.7 & E5.5 & E2.8 & E1.8 & E1.6 & E8.8 & E4.9 & E.69 & 57.0 \\
\hline LMRC & 1.3 & 2.0 & 1.8 & 1.1 & 4.3 & 1.2 & 2.4 & E.94 & E.69 & 47.5 \\
\hline LMRC env dup & 1.5 & 2.4 & 2.2 & 1.3 & 4.9 & 1.4 & 2.8 & 1.0 & E.64 & 55.2 \\
\hline LMRC & $<10$ & E2.8 & E1.9 & E.53 & E5.5 & E. 51 & E3.2 & E.78 & $<10$ & 44.5 \\
\hline LMRC env dup & $<10$ & E2.8 & E1.9 & E.53 & E5.5 & E.51 & E3.2 & E.78 & $<10$ & 44.5 \\
\hline LMRC & 1.4 & 2.1 & 1.7 & 1.1 & 3.8 & 1.2 & 2.3 & 1.0 & E.50 & 41.7 \\
\hline LMRC lab dup & 1.8 & 2.2 & 1.9 & 1.1 & 3.9 & 1.2 & 2.4 & 1.2 & E.53 & 39.6 \\
\hline
\end{tabular}


Blank Page 
Appendix 2-Analytical Data for Major and Trace Elements, Selected Polycyclic Aromatic Hydrocarbons, and Selected Organochlorine Pesticides From Core, Surficial Bottom, Suspended, and Streambed Sediment Samples, Woods Inlet and Tributaries, Lake Worth, Fort Worth, Texas 
Blank Page 
The trace element, polycyclic aromatic hydrocarbon $(\mathrm{PAH})$, and organochlorine pesticide data reported here expand and complement the data of Harwell and others (2003).

However, the combined data (this study and Harwell and others
[2003]) are insufficient to describe the distribution and sources of trace elements, PAHs, and organochlorine pesticides in Woods Inlet. 
Appendix 2.1. Selected major and trace element concentrations in surficial bottom, suspended, and streambed sediment samples, Woods Inlet and tributaries, Lake Worth, Fort Worth, Texas, 2003.

[Concentrations in micrograms per gram except organic carbon, which is in weight percent; cm, centimeters; dup, duplicate; --, not analyzed; na, not applicable; env dup, environmental duplicate; lab dup, laboratory duplicate]

\begin{tabular}{|c|c|c|c|c|c|c|c|c|c|c|c|c|c|c|c|c|}
\hline $\begin{array}{l}\text { Sample identifier and } \\
\text { depth interval } \\
(\mathrm{cm})\end{array}$ & $\begin{array}{l}\text { Sample } \\
\text { type }\end{array}$ & $\begin{array}{l}\text { Mini- } \\
\text { mum } \\
\text { depth } \\
\text { (cm) }\end{array}$ & $\begin{array}{l}\text { Maxi- } \\
\text { mum } \\
\text { depth } \\
\text { (cm) }\end{array}$ & $\begin{array}{l}\text { Mid- } \\
\text { depth } \\
\text { (cm) }\end{array}$ & $\begin{array}{c}\text { Sample } \\
\text { date }\end{array}$ & $\begin{array}{l}\text { Or- } \\
\text { ganic } \\
\text { car- } \\
\text { bon }\end{array}$ & $\begin{array}{l}\text { Alumi- } \\
\text { num }\end{array}$ & Calcium & Iron & $\begin{array}{l}\text { Potas- } \\
\text { sium }\end{array}$ & $\begin{array}{c}\text { Mag- } \\
\text { nesium }\end{array}$ & Sodium & $\begin{array}{l}\text { Phos- } \\
\text { phorus }\end{array}$ & $\begin{array}{l}\text { Tita- } \\
\text { nium }\end{array}$ & Arsenic & Barium \\
\hline \multicolumn{17}{|l|}{ Gravity cores } \\
\hline WWD1 (0-5) & $\begin{array}{l}\text { core } \\
\text { (surficial) }\end{array}$ & 0 & 5 & 2.5 & $04 / 21 / 03$ & 2.44 & 48,200 & 99,400 & 21,000 & 7,700 & 5,770 & 521 & 517 & 4,460 & 7.53 & 246 \\
\hline WWD.B3 (0-5) & surficial & 0 & 5 & 2.5 & $04 / 22 / 03$ & 2.76 & 55,100 & 97,600 & 24,200 & 8,970 & 6,120 & 702 & 615 & 4,380 & 8.72 & 288 \\
\hline WWD.B3 (0-5) dup & surficial & 0 & 5 & 2.5 & $04 / 22 / 03$ & -- & 56,500 & 98,500 & 24,700 & 9,050 & 6,170 & 698 & 631 & 4,320 & 8.32 & 294 \\
\hline WWD.B5 (0-5) & surficial & 0 & 5 & 2.5 & $04 / 22 / 03$ & 2.32 & 32,200 & 79,200 & 14,400 & 5,940 & 3,710 & 912 & 384 & 4,590 & 6.08 & 241 \\
\hline WWD.B7 (0-5) & surficial & 0 & 5 & 2.5 & $04 / 22 / 03$ & 2.88 & 37,700 & 130,000 & 17,000 & 6,040 & 4,360 & 746 & 464 & 4,560 & 6.20 & 232 \\
\hline WWD.B8 (0-5) & surficial & 0 & 5 & 2.5 & $04 / 22 / 03$ & 2.25 & 44,600 & 109,000 & 20,100 & 6,840 & 4,970 & 582 & 488 & 4,520 & 6.63 & 245 \\
\hline
\end{tabular}

Suspended and streambed sediment

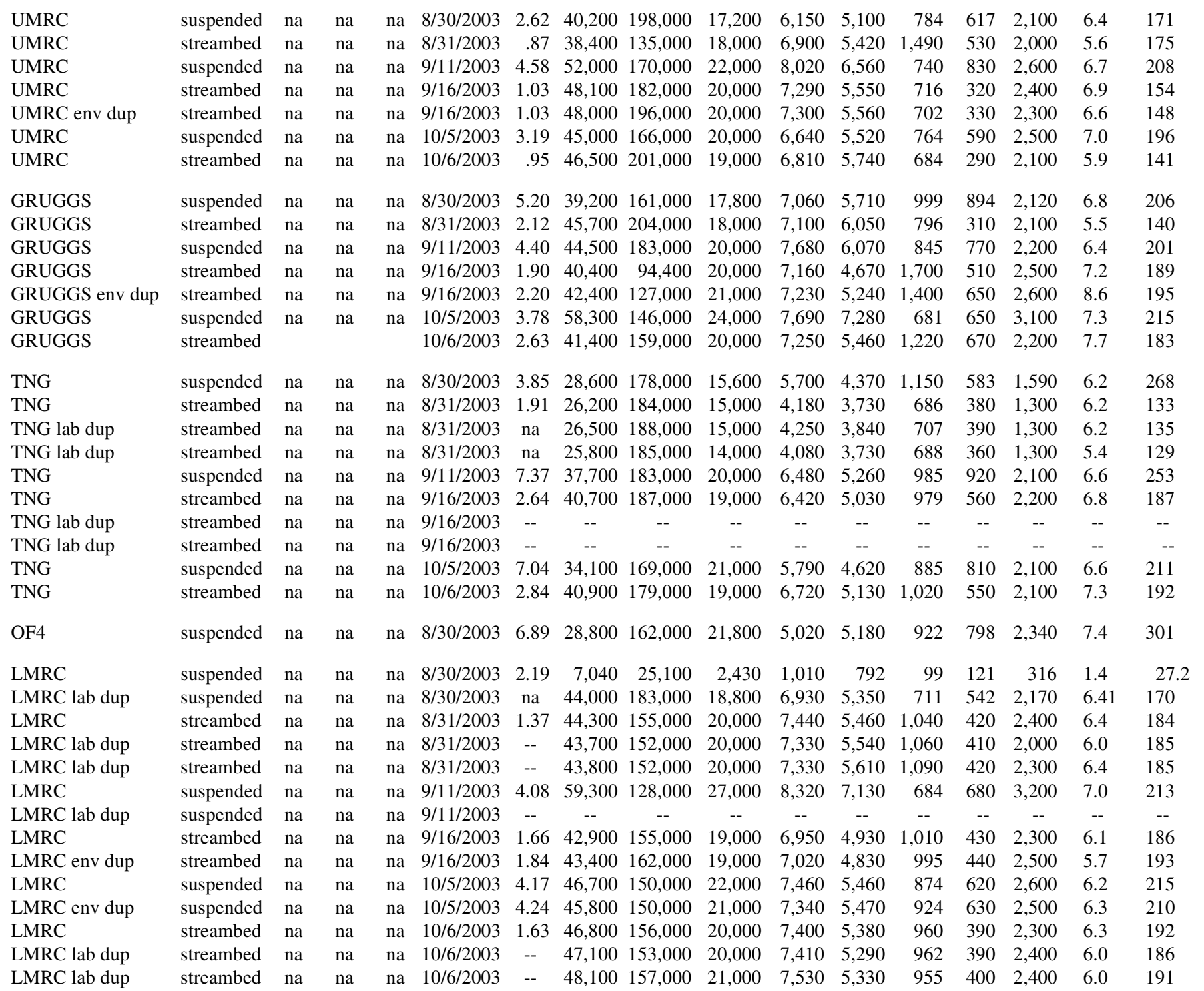


Appendix 2.1. Selected major and trace element concentrations in surficial bottom, suspended, and streambed sediment samples, Woods Inlet and tributaries, Lake Worth, Fort Worth, Texas, 2003—Continued.

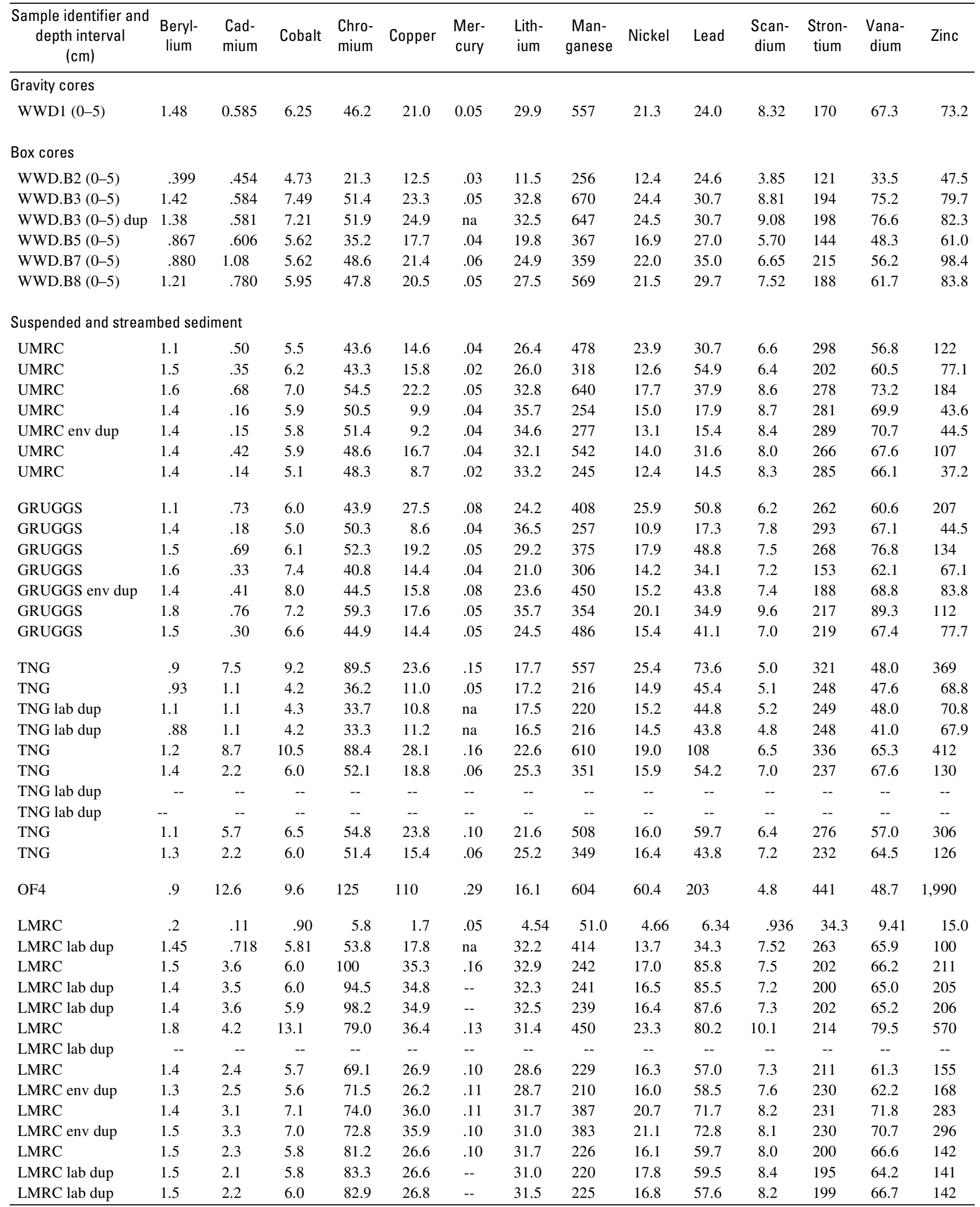


Appendix 2.2. Selected polycyclic aromatic hydrocarbon concentrations in surficial bottom, suspended, and streambed sediment samples, Woods Inlet and tributaries, Lake Worth, Fort Worth, Texas, 2003.

[Concentrations in micrograms per kilogram; cm, centimeter; E, estimated; lab dup, laboratory duplicate; na, not applicable; env dup, environmental duplicate; <, nondetection at indicated concentration]

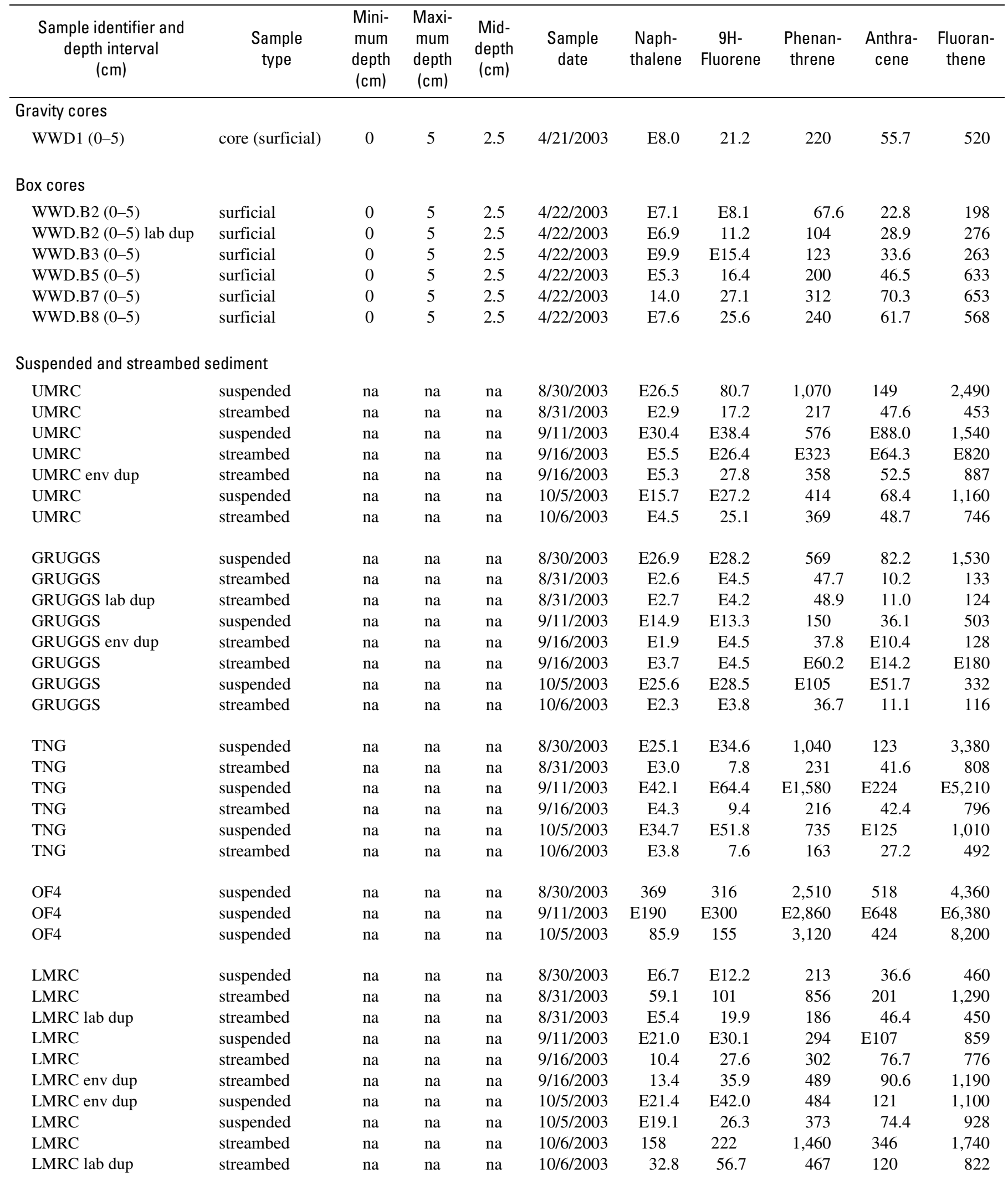


Appendix 2.2. Selected polycyclic aromatic hydrocarbon concentrations in surficial bottom, suspended, and streambed sediment samples, Woods Inlet and tributaries, Lake Worth, Fort Worth, Texas, 2003—Continued.

\begin{tabular}{|c|c|c|c|c|c|c|c|c|c|}
\hline $\begin{array}{l}\text { Sample identifier and } \\
\text { depth interval } \\
\text { (cm) }\end{array}$ & Pyrene & $\begin{array}{l}\text { Benz(a) } \\
\text { anthra- } \\
\text { cene }\end{array}$ & Chrysene & $\begin{array}{l}\text { Benzo(a) } \\
\text { pyrene }\end{array}$ & $\begin{array}{c}\text { Dibenzo } \\
(\mathrm{a}, \mathrm{h}) \\
\text { anthra- } \\
\text { cene }\end{array}$ & Coronene & $\begin{array}{l}\text { Total } \\
\text { PAH }\end{array}$ & $\begin{array}{l}\text { Combus- } \\
\text { tion } \\
\text { PAH }\end{array}$ & $\begin{array}{c}(2+3) / \\
\text { Combus- } \\
\text { tion } \\
\text { PAH }\end{array}$ \\
\hline \multicolumn{10}{|l|}{ Gravity cores } \\
\hline WWD1 (0-5) & 409 & 225 & 227 & 209 & 41.4 & E14.7 & 4,270 & 2,518 & 0.37 \\
\hline \multicolumn{10}{|l|}{ Box cores } \\
\hline WWD.B2 (0-5) & 153 & 80.9 & 104 & 97 & $<10$ & E10.7 & 1,990 & 1,042 & .54 \\
\hline WWD.B2 (0-5) lab dup & 207 & 109 & 125 & 110 & $<10$ & E10.7 & 2,474 & 1,295 & .52 \\
\hline WWD.B3 (0-5) & 211 & 116 & 131 & 118 & 25.9 & E11.6 & 2,494 & 1,389 & .50 \\
\hline WWD.B5 (0-5) & 502 & 267 & 286 & 281 & 57.5 & E23.1 & 4,931 & 3,232 & .25 \\
\hline WWD.B7 (0-5) & 492 & 265 & 290 & 259 & 67.0 & E30.6 & 5,032 & 3,117 & .33 \\
\hline WWD.B8 (0-5) & 431 & 240 & 254 & 230 & 54.3 & E28.5 & 4,725 & 2,726 & .34 \\
\hline \multicolumn{10}{|c|}{ Suspended and streambed sediment } \\
\hline UMRC & 1,840 & 555 & 1,090 & 687 & 138 & E120 & 16,101 & 10,631 & .27 \\
\hline UMRC & 360 & 143 & 191 & 155 & 30.9 & E18.6 & 3,019 & 2,002 & .24 \\
\hline UMRC & 1,180 & 431 & 876 & 631 & 114 & E96.9 & 11,875 & 8,071 & .25 \\
\hline UMRC & E650 & E296 & E310 & E328 & E57.7 & na & 5,672 & 3,715 & .23 \\
\hline UMRC env dup & 698 & 312 & 332 & 348 & 54.9 & na & 5,870 & 3,937 & .23 \\
\hline UMRC & 907 & 413 & 584 & 730 & 73.2 & E39.8 & 9,938 & 6,963 & .22 \\
\hline UMRC & 588 & 261 & 317 & 451 & 36.9 & E18.8 & 5,803 & 4,223 & .19 \\
\hline GRUGGS & 1,080 & 497 & 931 & 563 & 131 & E116 & 11,818 & 7,907 & .22 \\
\hline GRUGGS & 103 & 51.7 & 78.7 & 53.4 & 11.6 & E8.5 & 1,204 & 712 & .37 \\
\hline GRUGGS lab dup & 97.0 & 53.1 & 83.6 & 60.1 & 13.5 & E9.2 & 1,269 & 736 & .37 \\
\hline GRUGGS & 397 & 169 & 273 & 237 & 45.3 & E39.4 & 4,264 & 2,819 & .32 \\
\hline GRUGGS env dup & 99.4 & 43.7 & 59.9 & 55.9 & E12.7 & na & 1,102 & 674 & .29 \\
\hline GRUGGS & E143 & E67.8 & E102 & E86.1 & E17.4 & E21.2 & 1,429 & 1,035 & .22 \\
\hline GRUGGS & 266 & E120 & 206 & 166 & E56.6 & E40.9 & 3,546 & 2,021 & .55 \\
\hline GRUGGS & 91.4 & 40.6 & 62.0 & 51.5 & 8.4 & E5.9 & 896 & 622 & .28 \\
\hline TNG & 2,590 & 816 & 1,690 & 1,210 & 261 & E198 & 22,740 & 16,536 & .15 \\
\hline TNG & 602 & 336 & 351 & 340 & 66.7 & na & 5,360 & 3,886 & .14 \\
\hline TNG & $\mathrm{E} 3,960$ & $\mathrm{E} 1,420$ & $\mathrm{E} 2,380$ & $\mathrm{E} 1,950$ & E512 & E368 & 33,634 & 24,170 & .15 \\
\hline TNG & 618 & 316 & 354 & 351 & 64 & na & 5,593 & 3,698 & .18 \\
\hline TNG & 1,750 & 671 & 983 & 901 & E180 & E101 & 13,408 & 9,459 & .26 \\
\hline TNG & 373 & 192 & 245 & 329 & 37.0 & E16.1 & 4,404 & 3,203 & .13 \\
\hline OF4 & 3,330 & 1,570 & 2,630 & 1,720 & 408 & E509 & 38,177 & 23,060 & .37 \\
\hline OF4 & $\mathrm{E} 5,460$ & E2,580 & $\mathrm{E} 3,250$ & $\mathrm{E} 2,760$ & E443 & E279 & 49,723 & 31,850 & .27 \\
\hline OF4 & 6,600 & 3,210 & 4,720 & 5,650 & 493 & E203 & 79,622 & 56,660 & .14 \\
\hline LMRC & 324 & 153 & 252 & 157 & 33.1 & E38.9 & 3,580 & 2,213 & .33 \\
\hline LMRC & 991 & 613 & 540 & 509 & 96.7 & na & 9,912 & 5,904 & .37 \\
\hline LMRC lab dup & 345 & 191 & 188 & 192 & 41.8 & na & 3,391 & 2,146 & .25 \\
\hline LMRC & 684 & 338 & 536 & 424 & E88.8 & E69.1 & 8,156 & 4,999 & .39 \\
\hline LMRC & 604 & 342 & 342 & 314 & 66.5 & na & 5,838 & 3,718 & .25 \\
\hline LMRC env dup & 914 & 456 & 466 & 467 & 88.6 & na & 8,394 & 5,521 & .24 \\
\hline LMRC env dup & 869 & 437 & 588 & 496 & 83.4 & E46.4 & 9,229 & 5,934 & .28 \\
\hline LMRC & 732 & 518 & 752 & 556 & 62.2 & E31.6 & 8,389 & 5,722 & .23 \\
\hline LMRC & 1,240 & 892 & 858 & 1,130 & 168 & E34.5 & 16,379 & 10,094 & .37 \\
\hline LMRC lab dup & 642 & 389 & 396 & 560 & 50.4 & E15.7 & 7,166 & 5,202 & .21 \\
\hline
\end{tabular}


Appendix 2.3. Selected organochlorine pesticide concentrations in surficial bottom, suspended, and streambed sediment samples, Woods Inlet and tributaries, Lake Worth, Fort Worth, Texas, 2003.

[Concentrations in micrograms per kilogram; cm, centimeter; g, grams; --, not analyzed; E, estimated; <, nondetection at indicated value; dup, duplicate; env dup, environmental duplicate; lab dup, laboratory duplicate]

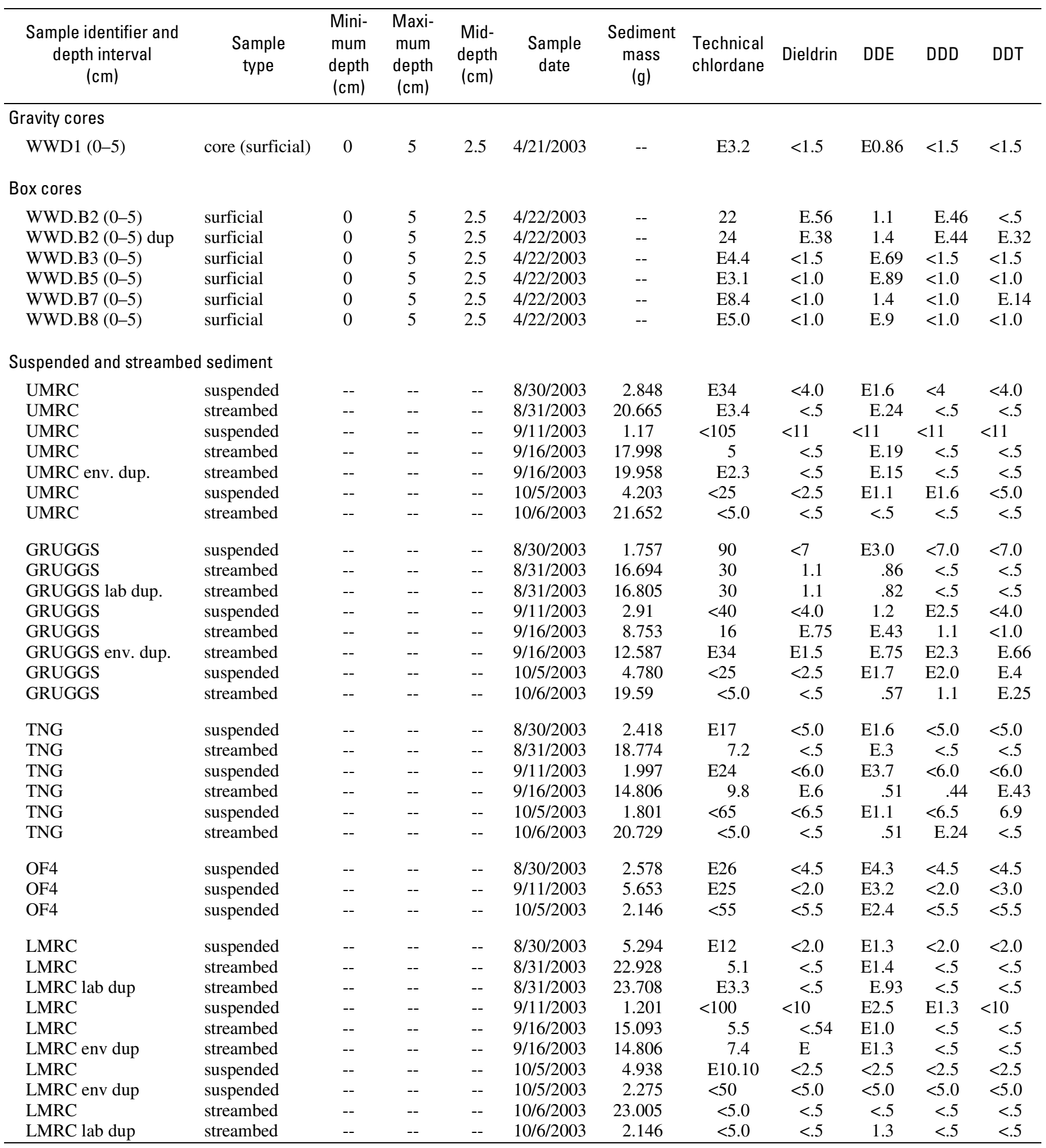


Prepared by the USGS Texas Water Science Center:

8027 Exchange Drive

Austin, TX 78754-4733

Information regarding water resources in Texas is available at http: //tx.usgs.gov/ 